\title{
AN EXAMINATION OF ENVIRONMENTAL INSTRUMENTS TO PROMOTE SUSTAINABLE TOURISM DEVELOPMENT FOR SAVUSAVU, FIJI
}

By

\author{
Logan Elizabeth Van Vliet
}

B.A., Wilfrid Laurier University, Waterloo, 2015

\author{
A thesis \\ presented to Ryerson University \\ in partial fulfillment of the \\ requirements for the degree of \\ Master of Applied Science \\ in the Program of \\ Environmental Applied Science and Management
}

Toronto, Ontario, Canada, 2017

(C) Logan Van Vliet 2017 


\section{Author's Declaration}

I hereby declare that I am the sole author of this thesis. This is a true copy of the thesis, including any required final revisions, as accepted by my examiners.

I authorize Ryerson University to lend this thesis to other institutions or individuals for the purpose of scholarly research.

I further authorize Ryerson University to reproduce this thesis by photocopying or by other means, in total or in part, at the request of other institutions or individuals for the purpose of scholarly research.

I understand that my thesis may be made electronically available to the public. 
An Examination of Environmental Instruments to Promote Sustainable Tourism Development for Savusavu, Fiji

Master of Applied Science, 2017

Logan Elizabeth Van Vliet

Environmental Applied Science and Management, Ryerson University

\section{Abstract}

This study explores the opportunity to implement environmental instruments to promote sustainable tourism development. Environmental instruments are tools, regulations and strategies that can improve the sustainability of a destination. This study was based on ideas from Governing the Commons Theory and Stakeholder Theory, which suggests sustainable development can be achieved by including stakeholders to form collective management and avoid natural resource tragedies. The study uses faceto-face, semi-structured interviews with stakeholders $(n=41)$ to explore environmental instruments to implement in Savusavu, Fiji -- a small island developing state (SIDS). The study identified lack of waste management, education and participation amongst stakeholders and the island's susceptibility to climate change as the key issues the destination faces in developing a sustainable tourism industry. The study recommends implementing a voluntary fund, environmental education and stakeholder participation instruments to promote sustainable development in Savusavu. 


\section{Acknowledgments}

This thesis is dedicated to Tuli.

There are a handful of people I would like to thank who helped and supported me in completing this thesis.

First, I would like to thank my supervisors, Dr. Sonya Graci and Dr. Richard Shaker. Dr. Graci, even while pregnant and with a newborn, you gave me the guidance I needed to complete this thesis. Without your support and enthusiasm I would have never been able to conduct this research and would have missed out on this experience. Through your teachings I have learned a great deal about the research process and am proud of what I accomplished.

Dr. Shaker, thank you for joining our team. Your constant positivity and coaching throughout the writing process of my thesis is truly appreciated. Your feedback and ideas were extremely helpful. Your support gave me the confidence I needed to complete this paper.

I would also like to acknowledge Karl and Francis Smith for allowing me to stay on their farm in Savusavu. Your kindness and hospitality made travelling on my own for the first time a complete joy. I adapted to island time and the Savusavu community with ease with you and your family as my hosts. Vinaka Vinaka!

Many thanks to the Savusavu community and those who participated in my study.

I would also like to thank Ryerson International and the Environmental Applied Science and Management Program for funding my research.

Finally, I would like to acknowledge and thank my friends and family. Thank you for your support and positivity. Also, a special thank you is offered to Taylor for spending hours in the library with me. One person who has truly been behind me throughout it all, and who encouraged me right up until the completion of this thesis is my mom. Thank you for the love and support.

Thank you all! 


\section{Table of Contents}

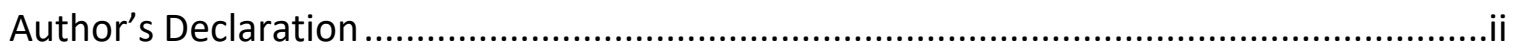

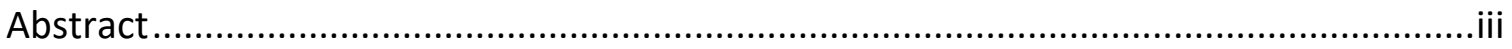

Acknowledgments................................................................................................... iv

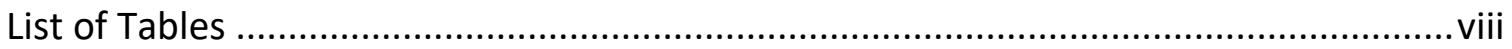

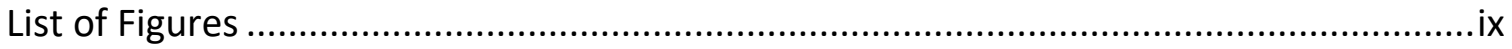

List of Appendices .....................................................................................................

1 Chapter 1: Introduction ................................................................................. 1

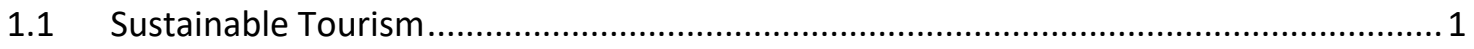

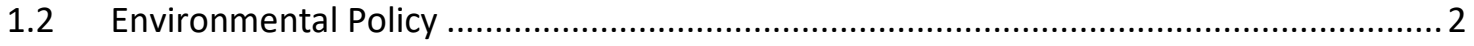

1.3 Research Objectives ...............................................................................

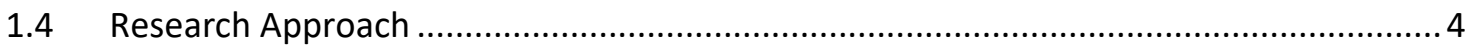

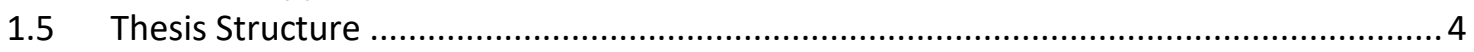

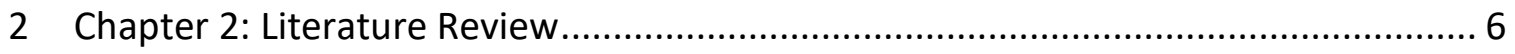

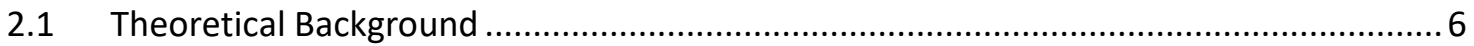

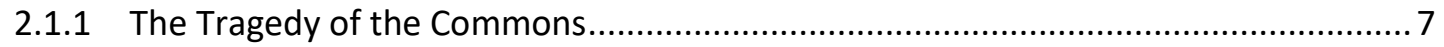

2.1.2 Application of the Tragedy of the Common in Tourism .......................................... 8

2.1.3 Limitations of the Tragedy of the Commons ………………………………….....

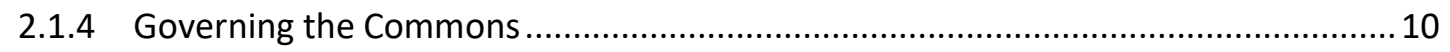

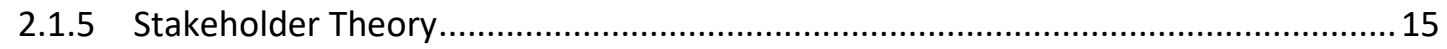

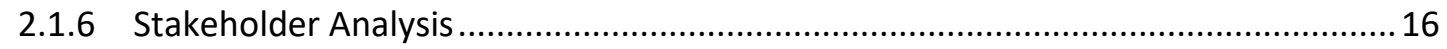

2.1.7 Stakeholder Groups in Tourism and Natural Resource Management.......................19

2.1.8 Limitations of Stakeholder Theory ....................................................................2

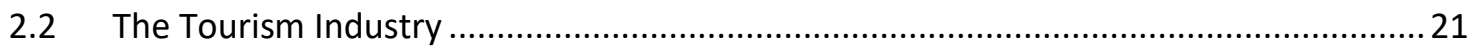

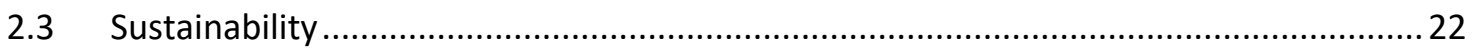

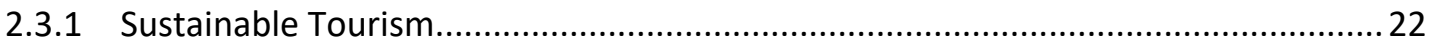

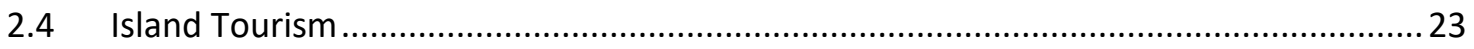

2.4.1 Impacts of Tourism on Small Islands ................................................................2 23

2.4.2 Challenges of Small Island Developing Sates Being Sustainable ……......................2.25

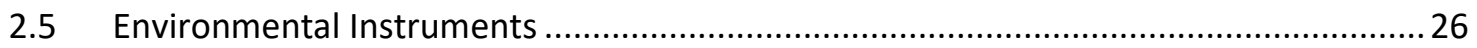

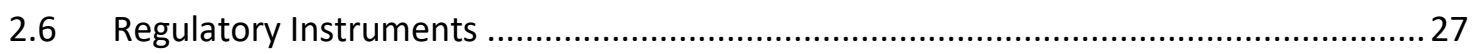

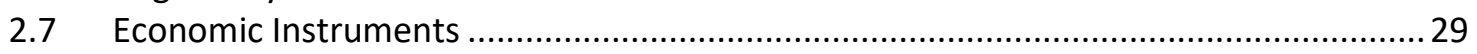

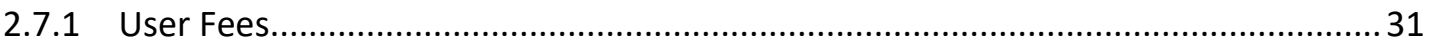

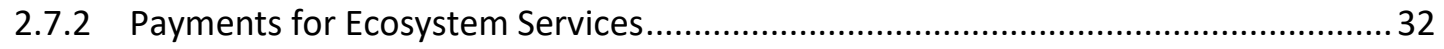

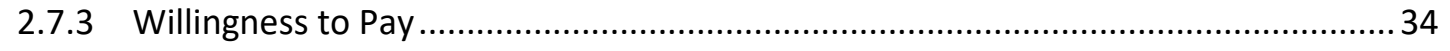

2.8 Education and Public Outreach Instruments .............................................................35

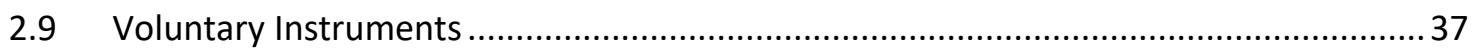

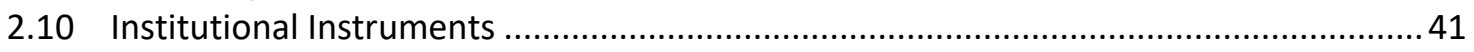

2.11 Environmental Instrument Implementation ..........................................................42

2.11.1 Importance of Public Participation ..................................................................... 43

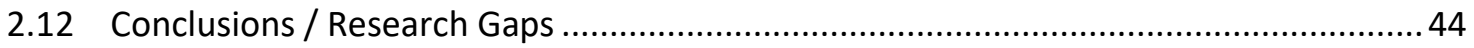

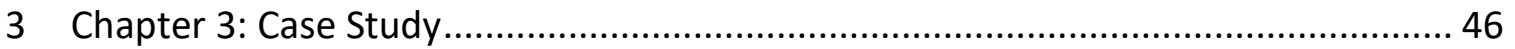

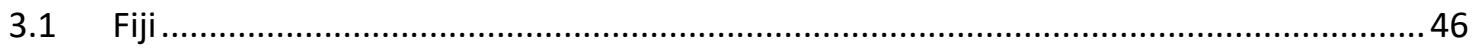

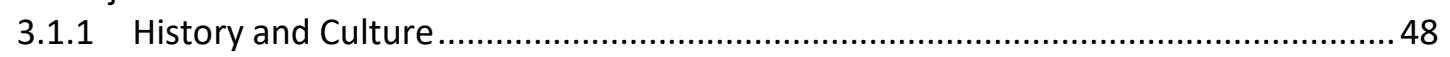

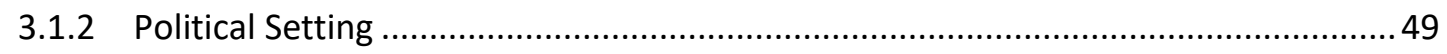




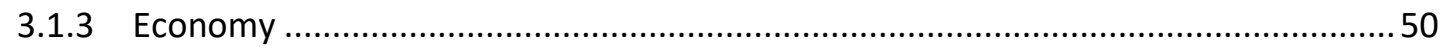

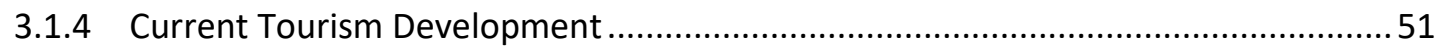

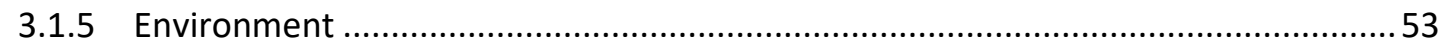

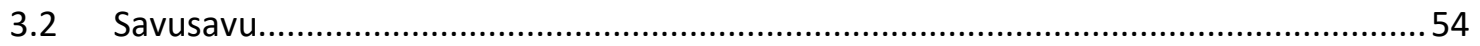

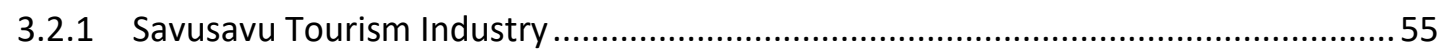

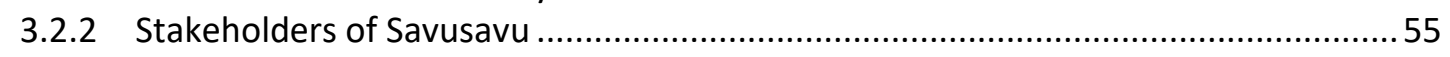

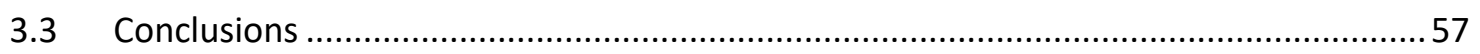

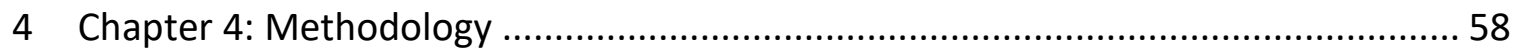

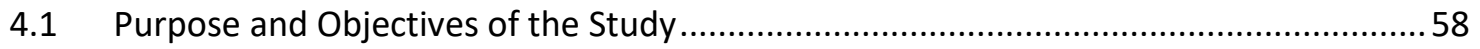

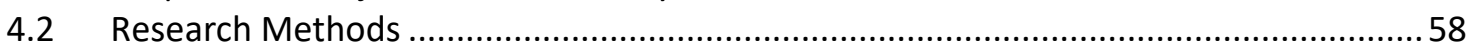

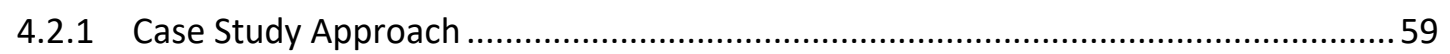

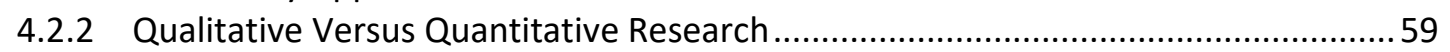

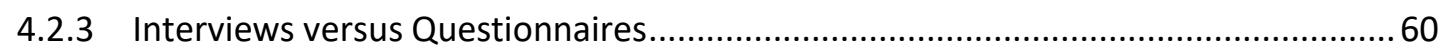

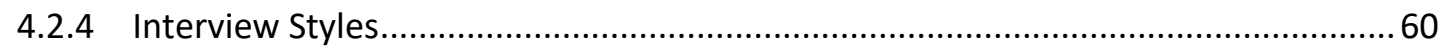

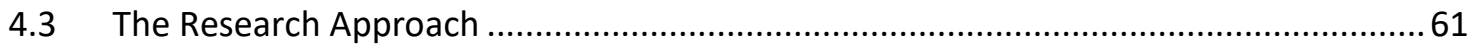

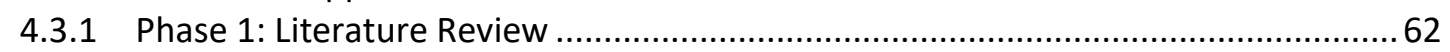

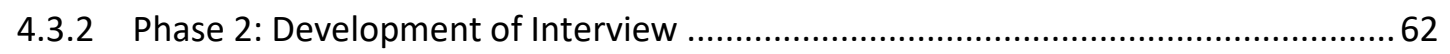

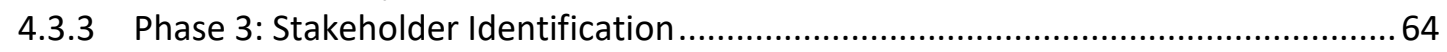

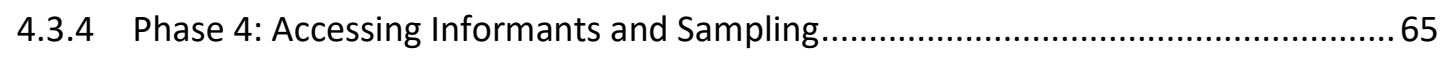

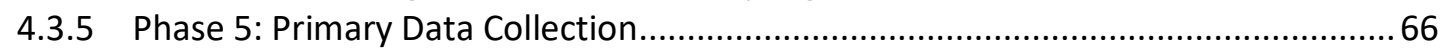

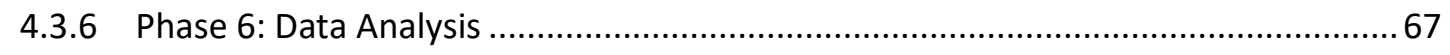

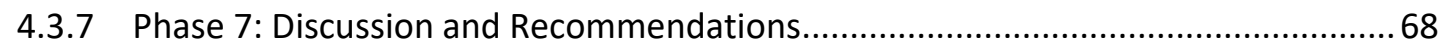

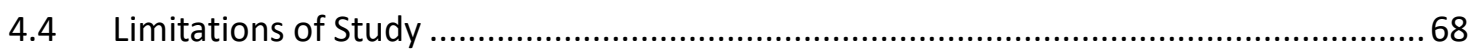

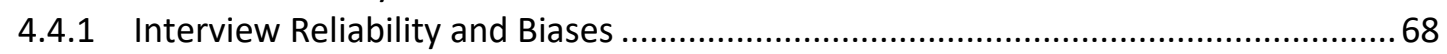

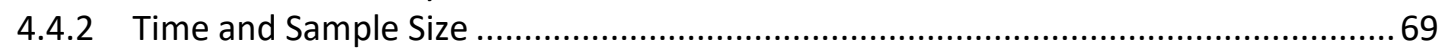

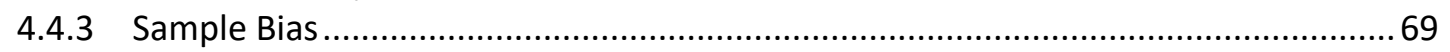

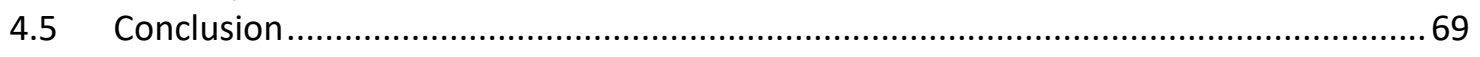

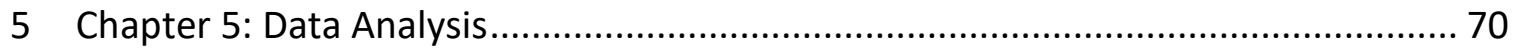

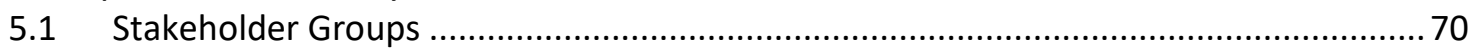

5.1.1 Perceived Influential Stakeholder Groups of Tourism Industry ............................... 71

5.1.2 Respondent's Personal Involvement in the Tourism Related Decisions ................... 72

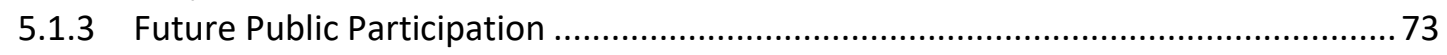

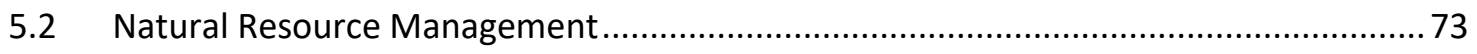

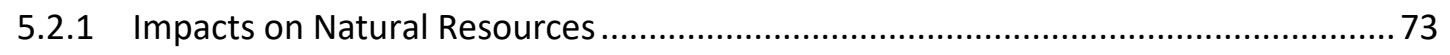

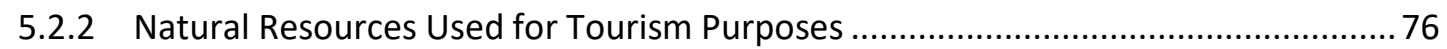

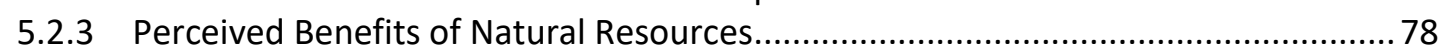

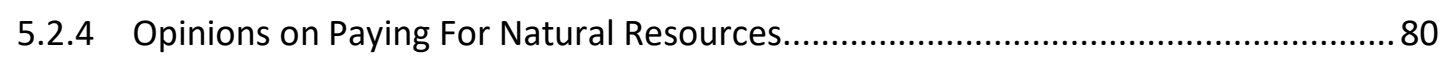

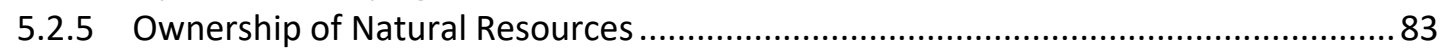

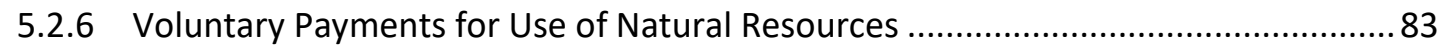

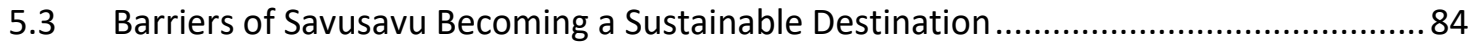

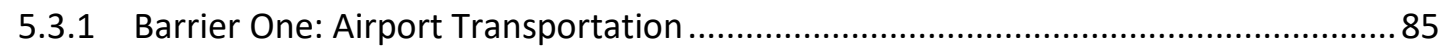

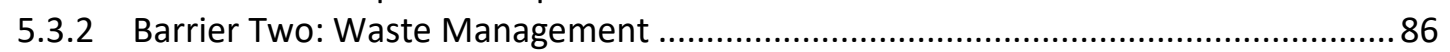

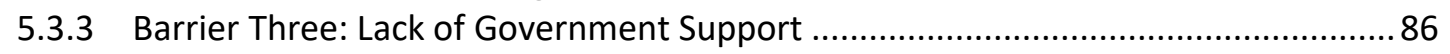

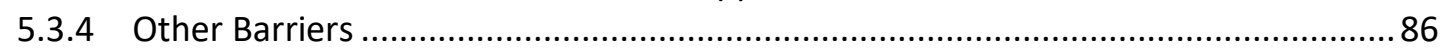

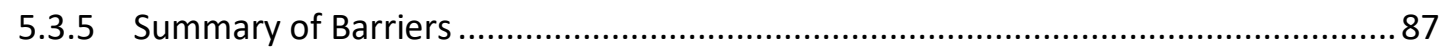

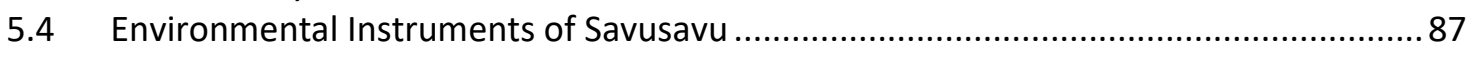

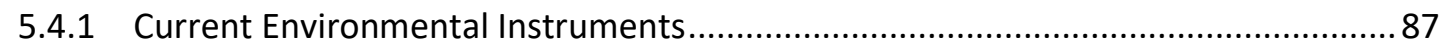




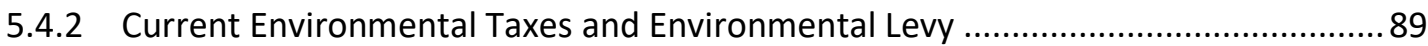

5.4.3 Current Regulatory Instruments and Marine Protected Areas ................................ 90

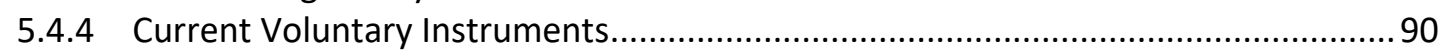

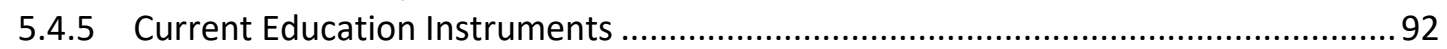

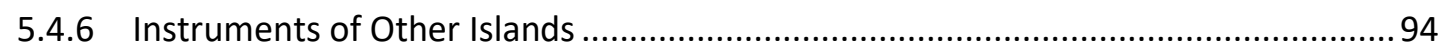

5.5 New Environmental Instruments for Implementation ............................................ 95

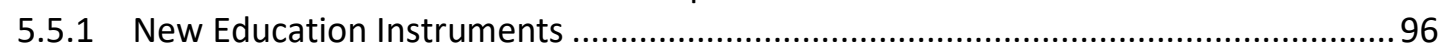

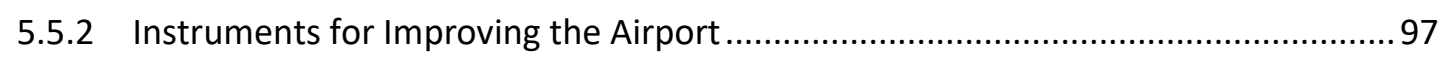

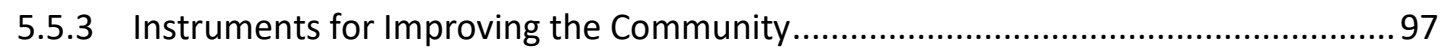

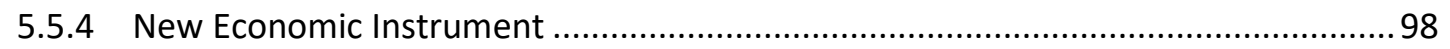

5.5.4.1 Acceptance of an Economic Instrument to Promote Sustainability ..................100

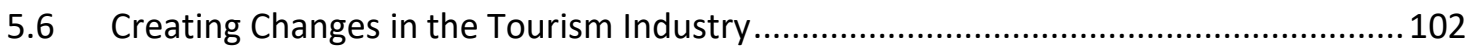

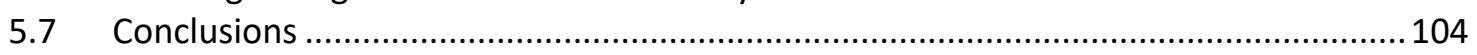

6 Chapter 6: Discussion and Recommendations ............................................... 105

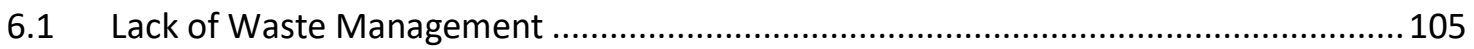

6.2 Lack of Education and Participation amongst Stakeholders in Tourism....................... 107

6.2.1 Lack of Stakeholder Participation in Tourism ......................................................... 108

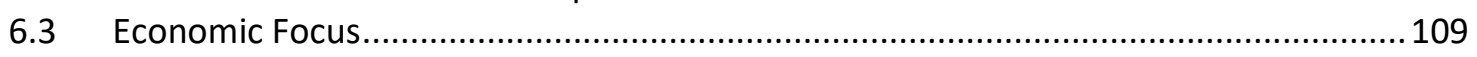

6.4 Susceptibility to Climate Change and Natural Disasters ............................................ 110

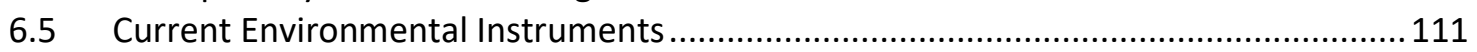

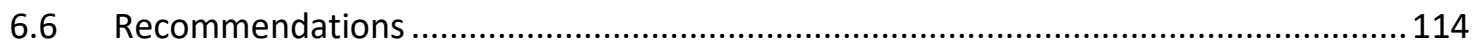

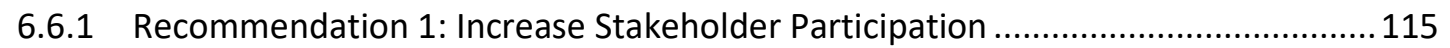

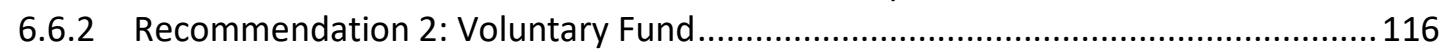

6.6.3 Recommendation 3: Environmental Education Instruments for all Stakeholders .. 118

6.6.4 Justification of Education Instrument Content..................................................... 118

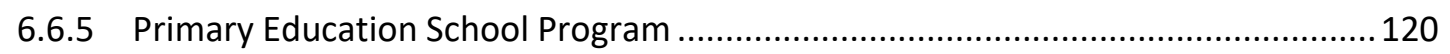

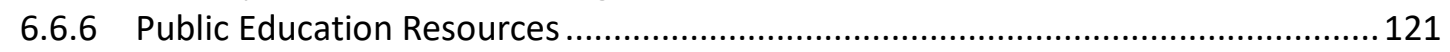

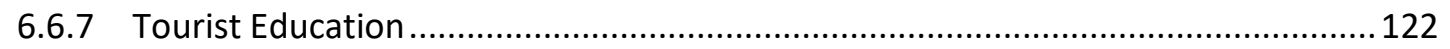

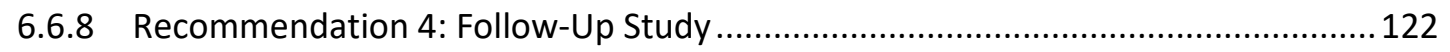

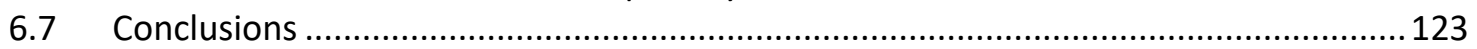

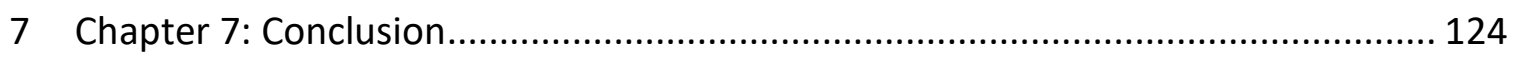

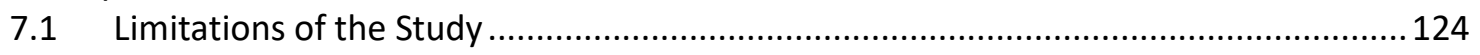

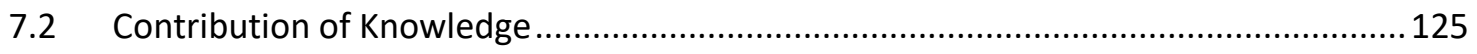

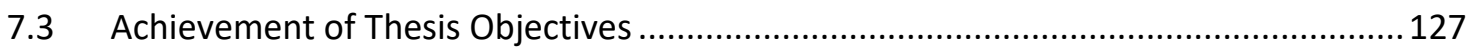

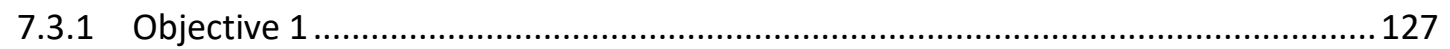

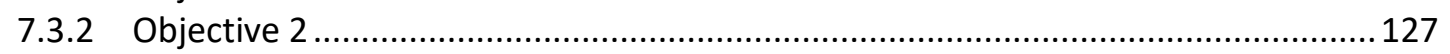

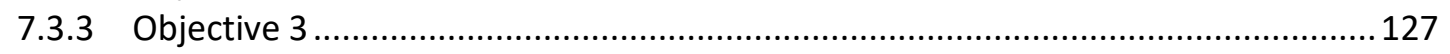

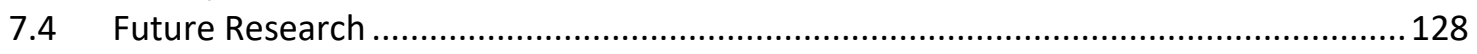

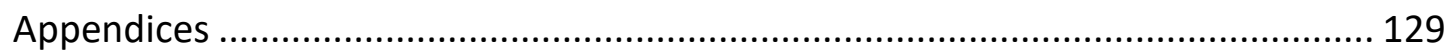

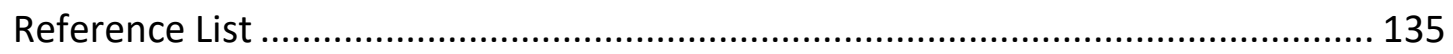




\section{List of Tables}

Table 1 Stakeholder Analysis Techniques (Reed et al., 2009, p. 1937) 17

Table 2 Natural Resource Stakeholder Analysis Techniques from Grimble \& Chan (1995) 19

Table 3 Summary of Environmental Instruments (information adapted from Winfield, 2016) 27

Table 4 Categories of PES as seen from WWF $(2016$, p.1) 33

Table 5 Voluntary instrument as seen in Ayuso $(2007$, p.5) 38

Table 6 Count of Savusavu stakeholders groups $\quad 70$

Table 7 Stakeholder groups who indicated they were not involved in tourism decisions $\quad 72$

$\begin{array}{ll}\text { Table } 8 \text { Natural resource management issues of Savusavu } & 74\end{array}$

Table 9 Natural resources used for tourism purposes by stakeholders 76

Table 10 Examples of respondents who indicated using the marine environment $\quad 77$

Table 11 Stakeholder views on their personal benefit from the use of natural resources 78

Table 12 Respondents perceived benefits of using natural resources $\quad 79$

Table 13 Respondents opinion on paying for the use of natural resources 80

Table 14 Suggested ways to set up an economic instrument for the use of natural resources 81

Table 15 Reasons for opposing payments for the use of natural resources 82

Table 16 Examples of responses that opposed payments for the use of natural resources $\quad 82$

Table 17 Opinions on voluntarily paying for natural resources $\quad 84$

Table 18 Perceived barriers to sustainable development of Savusavu $\quad 85$

Table 19 Current environmental instruments of Savusavu 88

Table 20 Examples of responses related to current environmental instruments in Savusavu $\quad 89$

Table 21 Current voluntary environmental instruments of Savusavu 91

Table 22 Examples of responses indicating using voluntary instruments 91

Table 23 Example of responses to instruments seen on other Islands 94

Table 24 Recommended new environmental instruments for Savusavu 96

Table 25 Suggested methods for funding changes 98

Table 26 Examples of responses indicating sources of funding for new instruments 99

Table 27 Stakeholders' perceptions of the community's acceptance of a new

environmental instrument $\quad 100$

Table 28 Respondents reasoning's for maybe accepting a new economic instrument $\quad 100$

Table 29 Reasonings for rejection of an economic instrument 101

Table 30 Reasonings for acceptance of a new economic instrument 102

Table 31 Respondents' answers to how changes are made to Savusavu's tourism industry 103

Table 32 Quotes indicating the stakeholders involved in tourism decisions 103

Table 33 Code book for question $6 \quad 133$

Table 34 Example of coded responses 133 


\section{List of Figures}

Figure 1 Literature review map $\quad 6$

Figure 2 Ostrom's eight design principles (Ostrom, 2015) 12

Figure 3 Tourism stakeholder map from Freeman (1984, p.55) 19

Figure 4 Flow diagram of important steps in the ElA process (Glasson et al., 2013) 28

Figure 5 Map of Fiji, from http://asiapacific.anu.edu.au/mapsonline/base-maps/fiji 47

Figure 6 Map of Savusavu stakeholder groups 56

Figure 7 Phases of the research process $\quad 62$

Figure 8 The perceived influential stakeholder groups in Savusavu $\quad 71$

Figure 9 Representation of respondents' beliefs on the owners of natural resources 83

Figure 10 Perceived community understanding of the impacts of tourism on the natural

resources 


\section{List of Appendices}

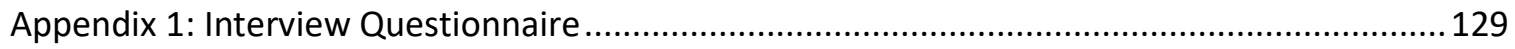

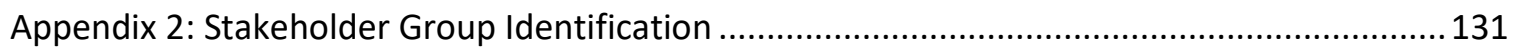

Appendix 3: Example of Qualitative Interview Data Coding................................................... 133 


\section{Chapter 1: Introduction}

Sustainability is a concept describing development that meets the needs of the present without compromising the future generation's ability to meet their own (Brundtland, 1987). The idea of sustainability is first seen in forestry literature under the term, sustainable yield. Early German thinkers Carlowitz (1732) and Hartig (1803) used the term to explain how the sustainable use of wood could save Europe from social and economic disasters during the times of the European Enlightenment (Vehkamaki, 2005). The concept of sustainability was further developed in the 1700s. Francois Quesnay's (1758) ideas of population growth, philosopher Adam Smith's $(1759,1776)$ studies on political ecology and Thomas Malthus's (1798) work on carrying capacity fueled the concept of sustainability used today (Lumley \& Armstrong, 2004). The term sustainability is now widely applied to many areas of academia.

\subsection{Sustainable Tourism}

This research is specifically concerned with the concept of sustainability and what it means for tourism. Tourism is one of the oldest, largest and most influential industries of the world (UNEP, 2003; WTO, 2015). Sustainable tourism can be defined as, "tourism that takes full account of its current and future economic, social and environmental impacts, addressing the needs of visitors, the industry, the environment and host communities" (WTO, 2015,p.1). Sustainable tourism develops and maintains an area at such a scale that it remains viable over an indefinite period of time and does not degrade or alter the environment in which it exists (Butler, 1993). Sustainable forms of tourism have proven to provide many benefits. Tourism can produce a large proportion of a country's gross domestic product (GDP), create employment opportunities, defend environmental protection, improve community healthcare and education, and reduce poverty of a destination (Catibog-Sinha, 2010; Palmer \& Riera, 2003; WTO, 2015; Wilkinson \& Salvat, 2012). However, if forms of sustainable tourism do not exist many negative impacts can occur. These impacts can include habitat destruction, natural resource depletion, erosion, increase in crime and a loss of local identity (Butler, 2008; Dredge \& Jamal, 2015; Dodds \& Graci, 2012).

Sustainable development is important for all forms of tourism, but this researcher's focus is on island tourism. Island destinations are appealing usually for their climate, remote locations and exotic flora and fauna. As such, island destinations receive high numbers of tourists each year (Butler, 2008; Davenport \& Davenport, 2006). For these destinations sustainability is imperative as they are especially vulnerable to the negative impacts of tourism. Islands have limited resources, are susceptible to natural 
disasters and climate change and usually rely heavily on the success of their tourism industry for economic gains (Juvan et al., 2016; Ruckelshaus et al., 2013). Their dependence on the success of tourism tends to put economic success at the forefront of their management styles, leaving environmental and social impacts neglected. With the amount of research illustrating the importance of the impacts of sustainable tourism, planners and managers are expected to strive to develop a form of this tourism (Fodness, 2016; Liu 2003; Saarinen, 2006). However, this is not always the case and islands struggle to development a form sustainable tourism.

The concept of sustainable tourism has been in the literature for the past 40 years (Brundtland, 1987; Davenport \& Davenport, 2006; Dodds, 2013; Hardy \& Benton, 2001). The literature presents ideas, methods, frameworks and theories revolving around the concept. For example, Butler's Tourism Life Cycle is a framework that is widely used and discussed when determining proper planning and management of a destination (Aguilo et al., 2005; Albaladejo et al., 2016; Yang et al., 2014). The model produced by Butler in 1980 helps managers understand the stages of development a destination passes, and to carefully plan, develop and manage the area for sustainability (Garay \& Canoves, 2011). Researchers also use indicators to measure the sustainability of a destination (Castellani \& Sala, 2010). An example of an indicator is a destination's ecological footprint. A footprint analysis can help managers identify key environmental indicators, like waste production, and use these indicators to measure the level of sustainability of an area (Hunter \& Shaw, 2007). However, even though there is a plethora of research on the sustainable development of tourism, unsustainable forms of tourism continue to exist (Choi \& Sirakaya, 2006; Fodness, 2016; Lupu, 2016).

\subsection{Environmental Policy}

Environmental policy reflects an organization's commitment to the environment. This research acknowledges that environmental policy has a significant influence on the way tourism develops (Hall, 2011; Harrington \& Morgenstern, 2007; Rodrigues et al., 2014; Saarinen, 2006). Environmental policy management largely impacts the way in which tourism organizations can maximize the positive impacts of tourism and mitigate the negative impacts. Ultimately, environmental policy influences the development of sustainable tourism.

Environmental policy-making began in the 1960s. In 1972 the United Nation's environment summit in Stockholm supported the concept of environmental policy development. Today it is a widely studied and applied concept (Sterner, 2003).Policy is studied within tourism research, but significant 
knowledge gaps remain concerning the extent to which policy can contribute to more sustainable tourism development (Aall, 2014; Brendehaug et al., 2016; Hall, 2010; Holden, 2009).

The policy-making process is challenging for the case of tourism. The process involves defining a problem, identifying goals to be achieved and then implementing instruments to address the problem and achieve set goals (Goeldener \& Ritchie, 2007). Environmental instruments are what put policy into action (Winfield, 2016; UNEP, 2003). Environmental instruments are strategies, laws, tools and devices used to reach policy goals. Tourism stretches across many domains such as transportation, natural resource management, land use planning and political settings, which add complexity to policy-making. There are also many stakeholders involved, adding another dimension to the policy-making (Bramwell \& Lane, 2011). "A stakeholder is any individual or group who can affect the firm's performance or who is affected by the achievement of the organization's objectives" (Freeman \& Reed, 1983, p.88). If stakeholders do not work toward similar goals, it can be difficult for a destination to become sustainable or move towards some sort of sustainability (Dodds \& Graci, 2012). Policy and environmental instruments must be designed specifically for existing environments to succeed (Sterner, 2003). Since tourism destinations, like islands, differ in their economic, social and environment states it is a challenge to identify environmental instruments that will effectively achieve policy goals. Managers therefore struggle in identifying the best solution to a wide variety of problems, involving multiple stakeholders.

Organizations like the World Tourism Organization (WTO) and the United Nations Environmental Program (UNEP) have created resources for policy makers with the intention of making tourism more sustainable. They provide development guidelines, management techniques and instruments to aid national and local governments, as well as the tourism industry, to incorporate sustainability principles into their decision- making processes (UNEP, 2003). Other policy frameworks like the Local Agenda 21 were developed for local authorities to better use policy to manage tourism (UNEP, 2003). Ecotourism policies, principles and practices have also been researched to attempt to develop sustainable tourism (Wood, 2002). However, even with the available resources unsustainable tourism continues to exist.

With the amount of research and resources available to tourism managers, the effectiveness of the current policy-making process is questioned in this study. This study looks for alternative methods of managing tourism that do not always rely on traditional policy-making and governmental involvement. This research believes that by improving our knowledge on environmental instruments managers can begin to develop sustainable forms of tourism. The research builds on the knowledge of the selection process and implementation of environmental instruments to promote sustainable development. More 
specifically, this research is a case study in Savusavu, Fiji. Savusavu is a coastal town in Vanua Levu Island. This is the second largest island in Fiji and a popular tourism destination. This case study explores whether environmental instruments can be recommended through the use of stakeholder perceptions to promote sustainable tourism development. Savusavu is a growing tourism destination in Fiji. It is known for its diving, tropical rainforest, exotic culture and climate. The destination's main attraction is its natural resources. The natural resources are what draw tourists to the destination. Ultimately, the success of the tourism industry and viability of the destination rely on the management of natural resources to sustain the tourism industry.

\subsection{Research Objectives}

The purpose of this research is to recommend environmental instruments to implement in Savusavu to promote sustainable tourism. The research is intended to build on the knowledge of sustainable tourism development specifically for small island states and the application of environmental instruments as a means to promote sustainability. To do so the following objectives are outlined:

1. Review the current literature on sustainable tourism development and environmental instruments and their implementation;

2. Conduct stakeholder interviews to determine the key issues Savusavu faces in becoming a sustainable tourism destination and the goals of the destination;

3. Use information from the literature review and the stakeholder interviews to identify the environmental instruments that can be recommended for implementation in Savusavu;

\subsection{Research Approach}

This is a traditional thesis that took on a case study approach to reach its objectives. The research used face-to- face, semi-structured interviews with stakeholders in the Savusavu tourism industry to collect their perspectives and justifications on key issues. The research was coded using common themes and ideas. The data was analyzed and discussed so that recommendations and conclusions for the research could be made.

\subsection{Thesis Structure}

This chapter presents the purpose of the research. Chapter 2 is a literature review on current and past research studies related to the major topics of the thesis. The chapter examines Governing the Commons and Stakeholder theory as they shape and justify the study. Literature on sustainable tourism, environmental instruments and their implementation for the case of small island destinations is 
presented to gain an understanding of what is known on these topics and of the gaps still apparent in the literature. Chapter 3 describes the case study of the thesis. Fiji's political setting, environment and history are discussed. Savusavu, its tourism industry and stakeholders are also presented to give context for the discussion of the thesis. Chapter 4 reviews the research methodology and the methods chosen for this study. A detailed description and explanation for each choice is made. Chapter 5 is the data analysis and discussion. The results from the qualitative interviews are presented. There is a focus on identifying the major environmental issues and barriers to Savusavu's sustainable tourism development. As well as, stakeholder perceptions on environmental instruments are included. Chapter 6 presents a discussion on the key findings of this study and recommendations for environmental instruments to implement to promote sustainable outcomes for Savusavu. Finally, Chapter 7 presents a summary of the research, its contribution to knowledge, limitations and recommendations for future studies. 


\section{Chapter 2: Literature Review}

This chapter presents current and past studies relevant to this thesis. First, the literature on the Tragedy of the Commons and Governing the Commons theories is explored to better understand natural resource management, as this is essential for island destinations. Stakeholder theory is also explored to gain a better understanding of how to shape this research. Literature on the existing knowledge of sustainable tourism, small island tourism and its impacts are discussed. Finally, environmental instruments are studied and evaluated to develop a deep understanding of their application in terms of environmental management. Figure 1 below is a map of the topics covered in the literature review. The yellow arrows illustrate how this study fits into the map. The study uses a case study approach to explore whether environmental instruments can support sustainable tourism for island destinations. This literature review's objective is to examine and identify gaps in current research on the implementation of environmental instruments for the case of small island destinations as means of supporting sustainable tourism development.

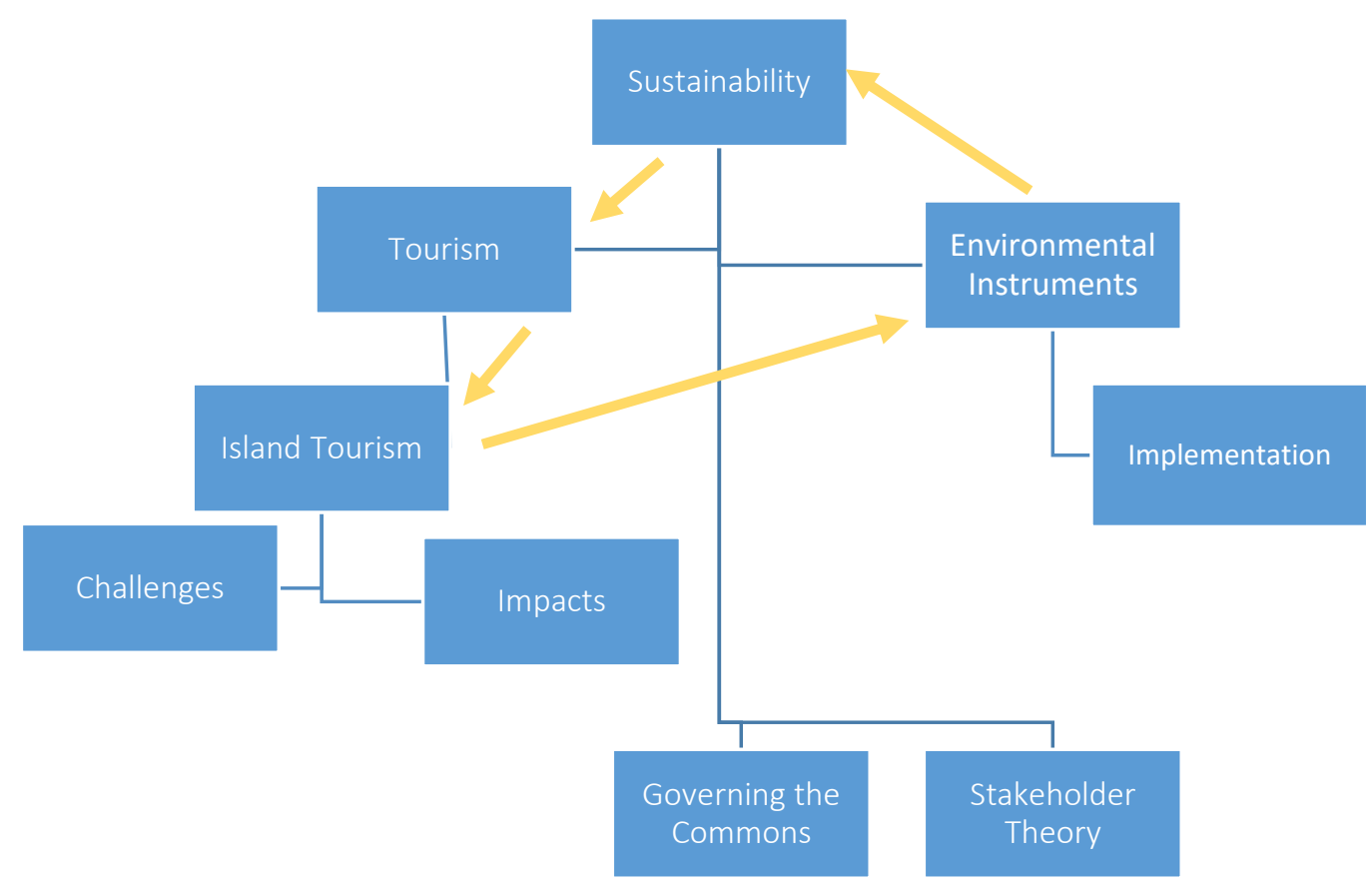

Figure 1 Literature review map

\subsection{Theoretical Background}

To better understand the application of environmental instruments to promote sustainable tourism Ostrom's Governing the Commons and Stakeholder Theory are reviewed. By examining these 
theories the study can better understand how to collectively manage natural resources that are used by multiple individuals. Natural resources of SIDS are limited and are integral to the tourism industry. Improving the knowledge on natural resource management is therefore important for this study.

Ostrom's (1990) Governing the Commons supports that the collective management of resources can avoid natural resource tragedies. The idea that natural resources will eventually see tragedy with continuous uncontrolled use by stakeholders is seen in the Tragedy of the Commons theory, so this is discussed first. Governing the Commons is then presented as a possible solution to the Tragedy of the Commons.

Stakeholder theory can be applied to natural resource and tourism management. The theory supports that by incorporating all stakeholders in the planning process effective management strategies will be created. The theory can be used to identify stakeholder groups and better address distributional and social impacts of environmental policies related to tourism by breaking down the interests of stakeholders (Grimble \& Chan, 1995).

\subsubsection{The Tragedy of the Commons}

The Tragedy of The Commons was presented in an essay written by Garret Hardin (1968) and discusses the dangers of resource overuse by multiple stakeholders. While Hardin is credited with the idea of the commons, the idea of resource overuse was seen earlier. First, from Malthus's (1803) essay on the principles of population as it affects the future improvement of society and in 1833 by Lloyd who presented lectures on over-population. The idea has since been used by many researchers in a variety of disciplines concerned with natural resource management, politics, law and population studies (Feeny et al., 1990; Schmidtz, 2003).

In Hardin's essay (1968) he asks readers to picture a pasture, freely open to everyone. He explains that the herdsmen of the pasture can graze their cows in the pasture and that every herdsman will try to graze as many cows as possible in pursuit of self-interests. The herdsmen will keep adding cows to increase their own wealth, knowing that the pasture is slowly degrading. Though the herdsmen are aware of the impacts they each have the pasture, the herdsman does not believe his action of adding an extra cow will ruin the land. The costs of whatever damage is done to the land will be shared by all the herdsmen, so they do not care about their individual impacts. The issue arises in that if each herdsman shares this idea then the result is that the commons is overgrazed (Hardin, 1968). This is where the tragedy occurs. The essay illustrates that what looks rational from each individual is irrational 
from a collective view point (Williston, 2012). Hardin suggests privatizing the commons to avoid tragedy (Hardin, 1968).

Hardin's essay has many critics but remains an influential theory of the $20^{\text {th }}$ century (Cole et al, 2014; Walker, 2009). His essay referring to the theory has been referenced thousands of times in scientific articles, books and media (Walker, 2009). The theory is flexible in that it can be applied to many management situations. An example of its application is on the issue of climate change. Williston (2012) uses the theory to illustrate who is at fault and who is to blame for climate change. Williston (2012) compares the world's atmosphere to a commons. "It is a sink whose capacity to absorb the carbon we emit is essentially finite" (p.282). Each country can be seen as a herdsman. He argues a country may think if for one more year we promote unrestrained economic growth powered by fossil fuels, it will not bring on the impacts of climate change on the world. Countries might also believe that if they do restrain themselves, other countries likely will not, which will put them at a comparative economic disadvantage. Since every country has these thoughts, the atmosphere will eventually be ruined and end in tragedy (Williston, 2012).

\subsubsection{Application of the Tragedy of the Common in Tourism}

The theory can be applied to tourism as the resources are at a potential for conflict regarding their usage by involved stakeholders (Biomonte, 2008; Briassoulis, 2002; Cole et al., 2014). Resources used for tourism can be considered a commons. A common-property resource can include groundwater, oceans, rivers, forests, beaches and the wildlife occupying these lands. Trying to control access to these resources is usually costly as it would require a lot of monitoring and can be virtually impossible due their size (Feeny et al., 1990; Pirotta \& Lusseau, 2015). The various stakeholders of the tourism industry who use the resources of a destination can all be seen as the herdsman referred to by Hardin (1968). Each stakeholder has their own self-interests and wants to use the commons to reach their own goals, thus reducing its availability to others. As a result tourism resources can experience overuse, degradation, long-term damage and lack incentives for individuals to want to invest to maintain or improve them (Briassoulis, 2002; Pirotta \& Lusseau, 2015).

An example where the theory is applied is seen by Pirotta \& Lusseau (2015) when studying the non-lethal effects of wildlife tourism on the conservation status of targeted animal populations. They comment on the resource depletion involved with wildlife tourism and how the depleted resources compromise the economic viability of the industry. The authors urge the need to manage common 
resources for tourism appropriately. Wilkinson \& Salvat (2012) applied this theory to their study concerned with the decline in the biodiversity of resources and services that coral reefs, mangrove forests, fisheries and sea grass beds provide. Despite the fact that there is an improved understanding of ecosystems and application of conservation management techniques, there is still exploitation and decline of coastal resources by the involved stakeholders. This tragedy is a result of stakeholders not working together to collectively manage the commons (Wilkinson \& Salvat, 2012).

\subsubsection{Limitations of the Tragedy of the Commons}

While the Tragedy of the Commons is widely applied in the literature it does have its limitations. There are substantial amounts of research that criticize the lack of context given to the pasture. Criticisms that the "pasture open to all" is very hypothetical and presented without context. Where is the location of the pasture? What is the size, who are the herdsman, can the herdsman communicate and various other influential aspects are missing from the theory. It is argued that you cannot apply the theory to every location as there are different political, social, and natural circumstances for each "pasture" (Walker, 2009).

Feeny et al., (1990) depict different scenarios illustrating the need for a clear definition of the pasture (commons). They suggest a commons could be considered an open access resource that usually does not have well-defined property rights. The resource management is unregulated and access is free to everyone. It could also be considered a communal property that is owned by a group of interdependent users. Users can exclude outside groups and regulate the property themselves (Feeny et al., 1990; Walker, 2009; Ostrom, 1999). The issue is that each scenario may manage the commons differently and the solution of privatization and government involvement may not be appropriate depending on the common.

It has been said by Cole et al. (2014) that its flaws have made it so successful. "Its sustained influence is a product of both its ability to successfully predict resource collapse and its failure to consider the possibility that groups of resources user might recognize the dangers of overexploitation and successfully develop self-organized systems of common-property governance"(Cole et al., 2014, p. 3). The theory's flaws have led to research in order to prove this theory wrong. Researchers have identified a number of ways in order to manage the commons so it does not end in a tragedy. 


\subsubsection{Governing the Commons}

Elinor Ostrom's Governing the Commons is a theory that has been put forth as a solution to Hardin's Tragedy of the Commons. In Elinor Ostrom's book (1990) “Governing the Commons: The Evolution of Institutions for Collective Action", the researcher theorizes institutional solutions to solving common dilemmas of natural resources discussed by Hardin (1968). Her book argues that selfgovernance by many institutions with shared behaviours and regulations of individuals can be established to manage open natural resources (Ostrom, 2015). The herders described in Hardin's theory can create their own solution, in which they themselves create a contract to commit themselves to a cooperative strategy that they will work out on their own (Ostrom, 2015). Ostrom's solution differs from Hardin's in that she does not believe privatization and government control are the only methods to solving common pool resource situations.

Ostrom describes common pool resource situations as those where different appropriators have interests in common-pool resources, also referred to as resource systems and resource units. Common pool resources (CPRs) are defined as, "resources with no owner, not naturally restricted to and for usage. CPRs are natural or man-made resource systems that are sufficiently large as to make it costly (but not impossible) to exclude potential beneficiaries from obtaining benefits from its use" (Ostrom, 2015, p.10). A resource system is defined as a stock that is available to everybody and it is nearly impossible to exclude individuals for the system. Resources units are what individuals actually use from the resource system. The appropriators are individuals who withdraw resource units from a system and have to make different and difficult decisions to overcome CPR related problems. Those decisions depend on benefits and costs and therefore have many uncertainties (e.g. lack of knowledge) (Ostrom, 2015). Ostrom refers to providers as those who arrange for the provision of a CPR; they create the institution. Producers ensure the long-term sustenance of the resource system itself. Providers and producers usually have incentives to keep the CPR running. The institution "sets out working rules that are used to determine who is eligible to make decisions in some arena, what actions are allowed or constrained, what aggregation rules will be used, what procedures must be followed, what information must or must not be provided, and what payouts will be assigned to individuals dependent on their actions." (Ostrom, 2015, p.11).

By studying CPR situations her theory attempts to better understand the capabilities and limitations of self-governing institutions versus the privatization of resources. To understand situations using CPRs Ostrom asks a set of questions: 
1. How can natural resources best be governed? How is it possible that some individuals organize themselves to govern and manage CPRs and others do not?

2. How do individuals organize and govern themselves to obtain collective benefits when temptations to free-ride exist and to break commitments are substantial?

3. What are the incentives for participants to continue to invest time and effort in self-governance and management of CPRs?

4. What are successful design principles of the institutions?

5. What internal and external factors impede or enhance the capabilities of individuals to use and govern CPRs (Ostrom, 2015, p.7).

To answer her questions and understand CPR situations Ostrom developed a system to code, analyze and synthesize findings in scientific articles dealing with CPRs. Previous to her empirical study there was no attempt in science or policy articles to organize the data dealing with the self-governance of CPRs (Ostrom, 2009). The variables used to code were: the structure of the resource system, the attributes and behaviors of the appropriators, the rules the appropriators were using and the outcomes resulting from the behaviors of the appropriators (Ostrom, 1990; 2015).

Her study found that many adaptive governance systems have effectively managed resources and avoided tragedy without government control or privatization of common resources (Dietz et al., 2003). One example is from Mongolia. Satellite images revealed large differences in grassland degradation under traditional, self-organized group-property regime versus central government management in comparing Northern China's Mongolia and Russia's Southern Siberia. Mongolian pastoralists continue to use their traditional group-property institutions, which involved large-scale movements between seasonal pastures. The Mongolian image shows much less degradation than the Siberian part of the image. The Siberian pastures are state-owned agricultural lands that are permanent settlements (Ostrom et al., 1999). Another example presented was in a Swiss village. Here farmers tend private plots for crops but share communal meadows to graze their cows. Ostrom discovered that overgrazing by the cows was not an issue. "There is an agreement in place among the villagers that they cannot graze more cows on the meadow than they can care for over the winter. This rule is said to date back to 1517 and continues to produce sustainable outcomes today" (Ostrom, 2015, p.15). By presenting multiple examples of self-governance Ostrom proves privatization and government involvement are not the only solutions to common pool resource dilemmas as suggested by Hardin (1968).

Through her analysis Ostrom concluded three major findings: 
1. neither the state nor the market is uniformly successful in enabling individuals to sustain longterm, productive use of natural resource systems;

2. collective action increases the returns from the appropriation efforts;

3. Eight design principles (Figure 1) which illustrate long-enduring CPR institutions (Ostrom, 2015, p. 5).

1. Clearly defined boundaries - individuals or households who have rights to withdraw resource units from the CPR must be clearly defined, as must the boundaries of the CPR itself.

2. Congruence between appropriation and provision rules and local conditions. Appropriation rules restricting time, place, technology and/or quantity of resource units are related to local conditions and to provision rules requiring labor, material and/ or money.

3. Collective-choice arrangements - most individuals affected by the operational rules can participate in modifying the operational rules

4. Monitoring - monitors who actively audit CPR conditions and appropriate behavior are accountable to the appropriators

5. Graduated Sanctions - those who violate operational rules are likely to be assessed graduated sanctions

6. Conflict resolution mechanisms

7. Minimal recognition of rights to organize. The rights of appropriators to devise their own institution are not challenged by external governmental authorities.

8. Nested enterprises ( CPRS that are not part of Larger systems)

Figure 2 Ostrom's eight design principles (Ostrom, 2015)

Studies looking to develop and sustain a collective form of management for natural resources can apply these principles to ensure effective management. These design principles will be considered for this study as the study will attempt to manage natural resources of Savusavu so that natural resource tragedy does not occur. By considering these principles the study does not rely on the sole solution of privatization and government control.

Ostrom also provides additional information in regards to the obstacles involved with setting up self-governance and collective management of common resources. First, developing institutions with rights and rules are difficult, time-consuming and conflict-invoking processes (Ostrom et al., 1999). Many solutions exist for many different problems as each CPR situation is different. Understanding the variables for each situation and then creating the rules that will work for the situation is a trial and error process that can take a long time. Due to this time there are costs that will impact the system and benefits are not being gained (Ostrom et al., 1999). 
In order for a new collective action to come about there must be an incentive for individuals to want to participate. Identifying the benefits and costs of the system is therefore important to form a collective form of self-governance. Trust among the individuals must be created so that they will continue to work together to solve the CPR problems. Economic success of the institutions relies on the individual's ability to solve collective problems (Ostrom, 2015).

Self-governing for long-term sustainability needs constant monitoring and enforcement of rules to determine if some users cheat on the rules outlined by the institution (Ostrom, 2009). In order for new institutional arrangement to form and credible commitment to be made there must be monitoring and knowledge. Establishing trust and a sense of community are ways to have individuals supply their own rules. Individuals will not monitor themselves. The biggest problem seen by Ostrom in this context is that "without monitoring, there can be no credible commitment; without credible commitments, there is no reason to propose new rules" (Ostrom, 1990, p.44).

Ostrom's theory has been applied to other studies related to tourism and natural resource management. Ostrom's theory influenced a study exploring Community-Based Natural Resource Management and its effectiveness in managing open natural resources (CBNRM) (Fabricius \&Collins, 2007). The theory was applied because CBNRM focuses on the collective management of ecosystems to promote human well-being and develop authority for ecosystem management to the local community. The study's goal was to defend that CBNRM can produce good governance of resources even though this form of management can have a high rate of failure (Fabricius \& Collins, 2007). To do so, the authors explored different case studies where successful CBNRM situations exist in Macubeni and Makuele in Eastern Cape and Richterveld in Northern Cape, South Africa. With these cases the authors argued that CBNRM can be successful at establishing communication, monitoring, lasting incentives for participation and developing management capacity. The study suggests 7 design principles on how to promote good governance of CBNRM and overcome challenges of implementation:

1. Develop knowledge networks that draw on the experience and wisdom of a wide range of key individuals.

2. Establish formalized decision-making structures (e.g. multi-level project steering committees) with clear constitutions and codes of conduct.

3. Clearly define and legitimize conflict resolution procedures.

4. Ensure acceptance of the governance structure by community members.

5. Obtain formal commitment to well-defined roles and responsibilities by key individuals.

6. Establish tangible incentives to key individuals for meeting their commitments

7. Develop the capacity for facilitation to promote communication. 
(Fabricius \&Collins, 2007, p. 10)

The study supports that the co-management of stakeholders like local communities, government and scientists play central roles in establishing governance of natural resources. The study provides an example of how Ostrom's theory can be used to overcome challenges which can arise in the implementation of new forms of governance related to natural resource management. It also provides an example of how Ostrom's design principles can be used to influence the management of natural resources.

A study by Haase et al., (2009) uses Ostrom's theory and design principles as a framework to analyze the strengths and weaknesses of a self-regulation system in the Antarctic's tourism sector. They found the case to be a successful example of self-organization driven by a collective interest to maintain environmental quality of the area. Traditional or formal tourism legislation in the Antarctic has been limited and the local International Association of Antarctica Tour Operators (IAATO) group has been successful in self-regulation of the industry. The perceived benefits of being a member to the group is a large determinant for why the group has been successful, as stakeholders are motivated to participate. The benefits being managing wilderness space, and prime wilderness space (Haase et al., 2009). This is important for the destination because the pristine natural environment is the main reason tourists want to visit the area. Internal factors affecting the self-governance were diverging interests among IAATO members, and noncompliance by individual entrepreneurs that may upset the current equilibrium. External factors were new environmental or safety regulations (Haase et al., 2009). As the destination grows in tourists and operators, the paper defends that incentives are crucial for self-governance. This study provides an example of how Ostrom's theory can be used to analyze an already existent case of self-governance and provide insights on how to improve it for the case of tourism. If cases of selfgovernance already exists in Savusavu then the theory could be used to evaluate them.

This framework is useful for this research as it provides additional support on how to manage natural resources used for tourism purposes. Ostrom does believe that resources can see tragedies and tragedies have occurred, however she demonstrates that there are self-organized cases where commonpool resources are self-governed for long-term sustainability. Hardin suggests government ownership and privatization but they are subject to failure and not the only solution available (Ostrom et al., 1999). Her framework gives attention to the governance and management of common resources, the institutions dealing with the resources and their structure. The theory can be applied to this research as it focuses on small scale CPRs, located in one country, with 50 to 15000 people that are related to it and 
that are heavily dependent on the CPR for economic returns (Ostrom, 2015). Applying the theory to tourism calls for all tourism stakeholders to manage the commons in a collective fashion to overcome possible tragedy.

\subsubsection{Stakeholder Theory}

Stakeholder theory defines a project or issue as a stakeholder interest, co-ordinating and optimizing entity (Donaldson \& Preston, 1995). Stakeholder theory defends that including all stakeholders and their perspective interests leads to effective management strategies. By incorporating all stakeholders it is said that managers can better anticipate and deal with stakeholder opposition and conflict. This is crucial in improving policy design and implementation (Grimble \& Chan, 1995; Freeman, 1987; Mason and Mitroff, 1981). Donaldson \& Preston (1995) describe the theory as: descriptive accuracy, instrumental power, and normative validity. It is descriptive in that it describes the issue at hand. It is instrumental in that it establishes a framework of examining the connections between stakeholders to achieve goals. And it is normative in that researchers must accept that stakeholders are persons or groups with legitimate interests. Stakeholders are identified by their interests and these interests are of intrinsic value (Donaldson \& Preston, 1995).

Origins of the theory are from Freemans' landmark book, "Strategic Management: A Stakeholder Approach" (1984). While Freeman is credited with putting forth the theory it can be traced back to Adam Smith and the Theory of Moral Sentiments (1759). Throughout the 1990s multiple studies on the theory came out. Some research studies that are widely cited and helped the theory gain importance are Clarkson (1994, 1995), Donaldson and Preston (1995) and Mitchell et al., (1997). Since this time it has been applied by policy-makers, regulators, governmental and non-governmental organizations, businesses and the media. The theory can be applied at project level, regional or local level, institutional level and even national levels (Reed et al., 2009).

The approach was developed in the response to the failure of conventional economic and social approaches for assessing and designing policies (Grimble \& Chan, 1995). Managers would pay inadequate attention to the interests and characteristics of stakeholders (Grimble \& Wellard, 1997; Prell et al., 2009). As a result policies were seen as adverse to stakeholders and led to non-cooperation. When dealing with natural resources that are sometimes open access the cooperation and collaboration of stakeholders is crucial in proper management (Grimble \& Chan, 1995; Littau et al., 2010). This theory 
recognizes the importance of stakeholder involvement and public participation for proper management and is why it will be applied to the research.

The application of stakeholder theory specifically for natural resources management gained popularity in the 1990s. Collaboration among key players is an essential ingredient in sustainable development efforts and is why this approach is applicable to the realm of natural resource management (Sautter \& Leisen, 1999). Stakeholder theory is a better way of looking at the “implementability” of natural resource management and tourism strategies in real life. Grimble \& Chan (1995) defend the theory can help policy-makers understand conflict of interest and trade-offs that can threaten the success of a tourism industry. Participation by multiple stakeholders with differing interests and perspectives can encourage more consideration of the varied social, cultural, environmental, economic and political issues affecting sustainable development (Bramwell \& Lane, 1993).

Stakeholder theory is used in resource management as environmental problems can cut across social, economic and political units, therefore involve many stakeholders at different levels. Natural resources are used by many people, for many different reasons, making the consideration of trade-offs and benefits especially important (Grimble \& Chan, 1995). It is also applicable to natural resource management as resources are not always owned and rather a commons, but they required cooperation in management (Grimble \& Chan, 1995). Stakeholder theory considers all stakeholders and attempts to identify a cooperative method to manage a resource.

Community participation has long been viewed as an important tenet of tourism planning, and there is general consensus among researchers that engaging all stakeholder groups contributes to tourism sustainability. Stakeholder theory can solve problems of lack of understanding amongst communities and improve community participation by identifying common goals (Waligo et al., 2013). The foundation of stakeholder theory is based on including and having all stakeholders involved in the planning and management of a project. Therefore the theory will be applied to this research and all stakeholders will be included to better manage the resources used for tourism.

\subsubsection{Stakeholder Analysis}

Stakeholder Analysis (SA) is the procedure for gaining an understanding of a project by identifying the key stakeholders (Grimble \& Chan, 1995). SA is also seen in the literature under the terms stakeholder identification and management (Clarkson, 1994; Wagner et al., 2011). It is a process that is used to identify individuals, groups and organizations that are affected by or can affect those 
parts of the issue or project at hand (Reed et al., 2009). SA aims to prioritize the identified individuals and groups in decisions related to the project. Ultimately SA is assessing stakeholder's respective interests to avoid conflicts and ensure marginalization of groups is not reinforced (Grimble \& Chan, 1995; Prell et al., 2009). Researchers (Grimble \& Chan, 1995; Freeman, 1984) define stakeholders as all those who affect and/or are affected by the policies, decisions and actions of the system. They can be "individuals, communities, social groups or institutions of any size, aggregation or level in society" (Grimble \& Chan, 1995, p.114).

Stakeholder identification techniques are seen in literature. Reed et al., (2009) summarized different methods used to identify stakeholders, differentiate between and categorize stakeholders, and how to investigate relationships between stakeholders. Table 1 summarizes each method with details of the resources required, level of stakeholder participation, and their strengths and weaknesses.

Table 1 Stakeholder Analysis Techniques (Reed et al., 2009, p. 1937)

\begin{tabular}{|c|c|c|c|c|}
\hline Method & Description & Resources & Strengths & Weaknesses \\
\hline $\begin{array}{l}\text { Semi Structured } \\
\text { Interviews }\end{array}$ & $\begin{array}{l}\text { Interviews with a } \\
\text { cross-section of } \\
\text { stakeholders to check } \\
\text { groups }\end{array}$ & $\begin{array}{l}\text { Interview time; } \\
\text { transport between } \\
\text { interviews, voice } \\
\text { recorder }\end{array}$ & $\begin{array}{l}\text { Useful for in-depth } \\
\text { insights to } \\
\text { stakeholder } \\
\text { relationships }\end{array}$ & $\begin{array}{l}\text { Time-consuming and } \\
\text { can be costly; difficult } \\
\text { to reach consensus } \\
\text { over stakeholder } \\
\text { categories }\end{array}$ \\
\hline Snow-Ball Sampling & $\begin{array}{l}\text { Individuals from initial } \\
\text { stakeholder } \\
\text { categories are } \\
\text { interviewed, } \\
\text { identifying new } \\
\text { stakeholder } \\
\text { categories and } \\
\text { contacts }\end{array}$ & Interview time & $\begin{array}{l}\text { Easy to secure } \\
\text { interviews without } \\
\text { data protection issues }\end{array}$ & $\begin{array}{l}\text { Sample may be biased } \\
\text { by the social networks } \\
\text { of the first individual } \\
\text { in the snow-ball } \\
\text { sample }\end{array}$ \\
\hline $\begin{array}{l}\text { Interest-Influence } \\
\text { Matrices }\end{array}$ & $\begin{array}{l}\text { Stakeholder are } \\
\text { placed on a matrix } \\
\text { according to their } \\
\text { relative interest and } \\
\text { influence }\end{array}$ & $\begin{array}{l}\text { Can be done with } \\
\text { focus setting or } \\
\text { individually by } \\
\text { stakeholder during } \\
\text { interviews }\end{array}$ & $\begin{array}{l}\text { Possible to prioritize } \\
\text { stakeholders for } \\
\text { inclusion; makes } \\
\text { power dynamics } \\
\text { explicit }\end{array}$ & $\begin{array}{l}\text { Prioritization may } \\
\text { marginalize certain } \\
\text { groups }\end{array}$ \\
\hline $\begin{array}{l}\text { Stakeholder-led } \\
\text { Stakeholder } \\
\text { Categorization }\end{array}$ & $\begin{array}{l}\text { Stakeholders } \\
\text { themselves categorize } \\
\text { stakeholders into } \\
\text { categories which they } \\
\text { have created }\end{array}$ & $\begin{array}{l}\text { Same as semi- } \\
\text { structured interviews }\end{array}$ & $\begin{array}{l}\text { Stakeholder } \\
\text { categories are based } \\
\text { on perceptions of } \\
\text { stakeholders }\end{array}$ & $\begin{array}{l}\text { Different stakeholders } \\
\text { may be placed in the } \\
\text { same categories by } \\
\text { different respondents } \\
\text { Does not identify all } \\
\text { possible discourses } \\
\text { only the ones } \\
\text { exhibited by the }\end{array}$ \\
\hline
\end{tabular}




\begin{tabular}{|c|c|c|c|c|}
\hline & & & & $\begin{array}{l}\text { interviewed } \\
\text { stakeholders }\end{array}$ \\
\hline Q Methodology & $\begin{array}{l}\text { Stakeholders sort } \\
\text { statements drawn } \\
\text { from a concourse } \\
\text { according to how } \\
\text { much they agree with } \\
\text { them, analysis allow } \\
\text { social discourses to be } \\
\text { identified }\end{array}$ & $\begin{array}{l}\text { Materials for } \\
\text { statement sorting; } \\
\text { interview time; } \\
\text { transport between } \\
\text { interviews }\end{array}$ & $\begin{array}{l}\text { Different social } \\
\text { discourses } \\
\text { surrounding an issue } \\
\text { can be identified and } \\
\text { individuals can be } \\
\text { categorized according } \\
\text { to their "fit" within } \\
\text { the discourse }\end{array}$ & $\begin{array}{l}\text { Does not identify all } \\
\text { possible discourses } \\
\text { only the one exhibited } \\
\text { by the interviewed by } \\
\text { stakeholders }\end{array}$ \\
\hline $\begin{array}{l}\text { Actor-Linkage } \\
\text { Matrices }\end{array}$ & $\begin{array}{l}\text { Stakeholders are } \\
\text { tabulated in a two- } \\
\text { dimensional matrix } \\
\text { and their relationships } \\
\text { are described using } \\
\text { codes }\end{array}$ & $\begin{array}{l}\text { Can be done within } \\
\text { focus group setting or } \\
\text { individually by } \\
\text { stakeholders during } \\
\text { interviews }\end{array}$ & $\begin{array}{l}\text { Relatively easy, } \\
\text { requiring few } \\
\text { resources }\end{array}$ & $\begin{array}{l}\text { Can become confusing } \\
\text { and difficult to use if } \\
\text { many linkages are } \\
\text { described }\end{array}$ \\
\hline $\begin{array}{l}\text { Social-Network } \\
\text { Analysis (SNA) }\end{array}$ & $\begin{array}{l}\text { Used to identify the } \\
\text { network of } \\
\text { stakeholders and } \\
\text { measuring relational } \\
\text { ties between } \\
\text { stakeholders through } \\
\text { use of structure } \\
\text { interview/ } \\
\text { questionnaire }\end{array}$ & $\begin{array}{l}\text { Interviewer, } \\
\text { questionnaire and } \\
\text { training in the } \\
\text { approach and } \\
\text { analyses, time, } \\
\text { software }\end{array}$ & $\begin{array}{l}\text { Gain insight into the } \\
\text { boundary of } \\
\text { stakeholder network; } \\
\text { identifies influential } \\
\text { stakeholders and } \\
\text { peripheral } \\
\text { stakeholders }\end{array}$ & $\begin{array}{l}\text { Time-consuming; } \\
\text { questionnaire can be } \\
\text { tedious for } \\
\text { respondents; need } \\
\text { specialist in the } \\
\text { method }\end{array}$ \\
\hline Knowledge Mapping & $\begin{array}{l}\text { Used in conjunction } \\
\text { with SNA; involves } \\
\text { semi-structured } \\
\text { interviews to identify } \\
\text { interactions and } \\
\text { knowledge }\end{array}$ & $\begin{array}{l}\text { Same as semi- } \\
\text { structured interviews }\end{array}$ & $\begin{array}{l}\text { Identifies } \\
\text { stakeholders that } \\
\text { would work well } \\
\text { together as well as } \\
\text { those with power } \\
\text { balances }\end{array}$ & $\begin{array}{l}\text { Knowledge needs may } \\
\text { still not be met due to } \\
\text { difference in the types } \\
\text { of knowledge held } \\
\text { and needed by } \\
\text { different stakeholders }\end{array}$ \\
\hline Radical Transitiveness & $\begin{array}{l}\text { Snow-ball sampling to } \\
\text { identify fringe } \\
\text { stakeholders; } \\
\text { development of } \\
\text { strategies to address } \\
\text { their concerns }\end{array}$ & $\begin{array}{l}\text { Training in the } \\
\text { approach }\end{array}$ & $\begin{array}{l}\text { Identifies stakeholder } \\
\text { and issues that might } \\
\text { otherwise be missed } \\
\text { and minimizes risks to } \\
\text { future project }\end{array}$ & $\begin{array}{l}\text { Time-consuming and } \\
\text { costly }\end{array}$ \\
\hline
\end{tabular}

Researches can use these techniques or combination of techniques to begin to understand a project stakeholders and its groups. This research is specifically concerned with stakeholder groups seen in natural resource management and tourism. Three SA approaches commonly used in natural resources management are displayed in Table 2. 
Table 2 Natural Resource Stakeholder Analysis Techniques from Grimble \& Chan (1995)

\begin{tabular}{|l|l|}
\hline Stakeholder identification Method & Explanation \\
\hline Reputational Approach & $\begin{array}{l}\text { Asking knowledgeable or important individuals to identify those groups they } \\
\text { believe have a stake in the issue in question. i.e. asking head of a village }\end{array}$ \\
\hline Focal Group Approach & $\begin{array}{l}\text { Starts by identifying a stakeholder groups which plays a central role or pivotal } \\
\text { role in the system in question. Other stakeholders are then uncovered by } \\
\text { identifying individuals, groups and institutions who have important } \\
\text { relationships with the focal group with respect to the natural }\end{array}$ \\
\hline Demographic Approach & $\begin{array}{l}\text { Used to complement other approaches. Provides a general, systematic way of } \\
\text { ensuring that all common social groupings are considered. Identifies } \\
\text { stakeholders by a set of standardized characteristics (gender, age, occupation } \\
\text { etc.) }\end{array}$ \\
\hline
\end{tabular}

\subsubsection{Stakeholder Groups in Tourism and Natural Resource Management}

Researchers have applied SA to identify common groups that are usually involved in natural resource management and tourism studies. Sautter \& Leisen (1999) provide a stakeholder map that was adapted from Freeman for the case of tourism seen in the Figure 2 below.

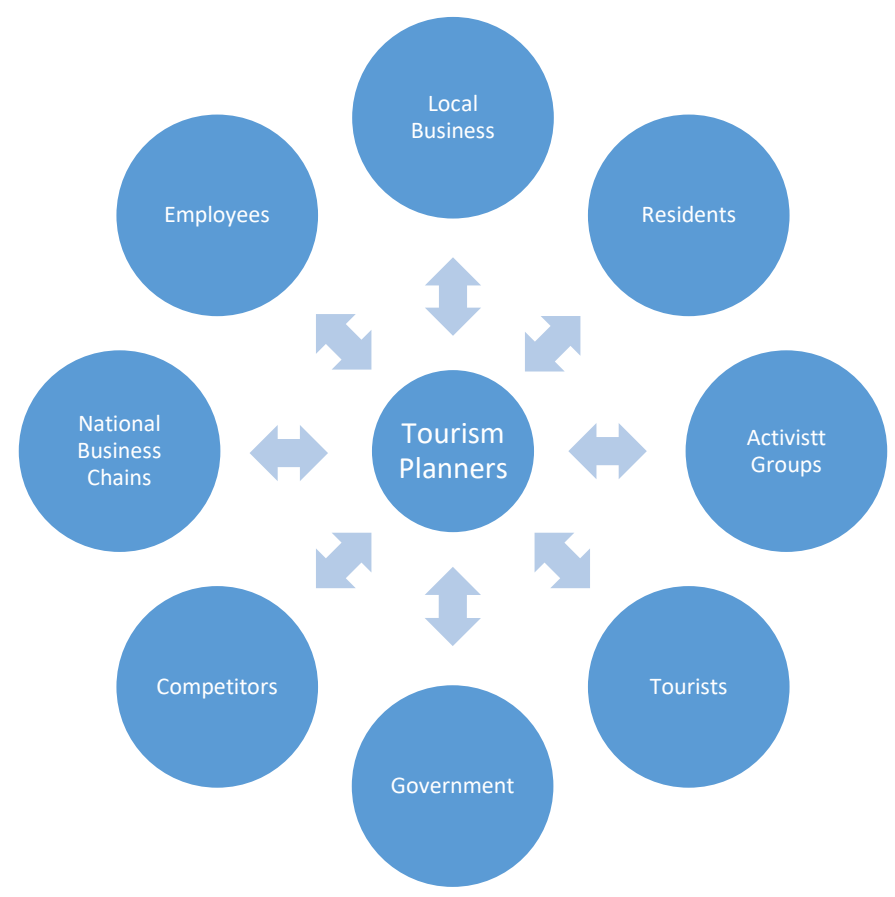

Figure 3 Tourism stakeholder map from Freeman (1984, p.55) 
The map illustrates the stakeholders who are impacted and can be impacted by tourism planners' actions. Each group has inputs and outputs of equal size and are considered equal in importance. This map can be used as a starting point for researchers and revised for the case at hand by using stakeholder identification methods previously discussed.

A study by Lee \& Hseih (2016) identified indicators for sustainable wetland tourism in Taiwan using stakeholders. To identify stakeholder groups the study first used a literature review. The groups based on previous studies were: tourists, hosts, government, non-government organizations, for-profit organizations and tourism related businesses. After completing their own identification and checking the groups they concluded five main groups for their study: tourists, residents, industries, government officials and NGOs. The data collected from these groups aided them in identifying indicators for sustainable tourism. They go as far as to say that the stakeholder dimension is more important than the environmental dimension for assessing sustainable tourism for wetlands used in tourism (Lee \& Hseih, 2016).

Waligo et al., (2013) used a multi-stakeholder involvement management framework to implement sustainable tourism in Cornwall, England. Using a literature review they found six common groups for the case of sustainable tourism: tourists, industry members, local community, government, special interest groups and educational institutions. For their study they customized 8 groups from a total of 50 individual stakeholders. The groups were: businesses, residents, government, social interest groups, employees, and board of directors, educational institutions and visitors. These groups were determined by asking primary stakeholders who were members of the DMO of Cornwall, as they were believed to hold a strong knowledge on the study area. They used focus groups and semi-structured interviews to identify the groups. The groups used in these past studies (Lee and Hseih, 2016; Sautter \& Leisen, 1999; Waligo et al., 2013) will be taken into consideration for this study. It is assumed that the groups will need to be customized for Savusavu.

\subsubsection{Limitations of Stakeholder Theory}

Stakeholder theory while applied and cited widely faces some limitations. There are critics of its vagueness and ambiguity (Wagner et al., 2011). The term stakeholder has been used extensively although there is no definitive definition in the literature (Clarkson, 1994; Wagner et al., 2011). There is no limit defined to be a stakeholder and how many should be included in a study. Questions of who is no longer considered a stakeholder and who should be included are therefore limitations. 
There are multiple ways to define groups for a certain project (Grimble and Chan, 1995). The decision remains with the individual carrying out the analysis which can lead to bias. Stakeholders are usually identified and categorized through a subjective assessment of their power, influence and legitimacy. Stakeholders are grouped and there is an assumption that each group has similar interests and stakes in the issue or project. However, stakeholders in their respective groups can have different interests. The theory suggests that stakeholder groups may be clearly identified as separate entities, which leads to a loss of complexity in their real relationships (Rowley, 1997). Therefore, grouping them can sometimes lead to generalizations. Donaldson and Preston (1995) have argued in favor of stakeholders being identified by their interests, although this position was not seen in the literature.

\subsection{The Tourism Industry}

This section of literature review discusses the tourism industry, sustainable tourism, island tourism and its impacts.

The tourism industry is one of the oldest and largest economic sectors in the world (Davenport \& Davenport, 2006; WTO, 2016). Tourism is a driver of the global economy and a vital contributor to job creation, poverty alleviation and environmental protection (WTO, 2016). If planned and managed appropriately, tourism can produce a large proportion of a country's GDP, government income and foreign exchange earnings (Catibog-Sinha, 2010; Davenport \& Davenport, 2006; Palmer \& Riera, 2003; Wilkinson \& Salvat, 2012; WTO, 2015). Community developments, health, education and the overall quality of life of the destination can be also be improved with the positive impacts of tourism (Aretano et al., 2013; Spenceley, 2010; Sharpley \& Ussi 2014). For example, in Canada tourism GDP increased by $5.7 \%$ in 2016 to $\$ 6.9$ billion. This accounts for $1.6 \%$ of Canada's total GDP (Canadian Tourism Commission, 2016). In Fiji, tourism supported the creation of 41,500 jobs ( $12.3 \%$ of total employment). This is expected to rise to 61,000 jobs (16.3\% of total employment) in 2025 (Fiji Bureau of Statistics, 2015).

Due to its significant economic, social and environmental role there is a vast amount of research revolving around the varying aspects of tourism. This research is specifically concerned with tourism's ability to protect the environment on which it depends for the benefit of all the involved stakeholders. More specifically, this research explores possible environmental instruments that can be recommended to implement on small island destinations to promote sustainable tourism development. 


\subsection{Sustainability}

The term sustainability is used in a wide variety of contexts. The discussion of modern day sustainability began in the mid-1960s in Britain and North America (Bramwell \& Lane, 1993). As more attention was received through public awareness, by the 1980s the sustainable development movement had begun. The Ecological Principle for Economic Development by Raymond Dasmann and Peter Freeman (1984) built on the idea of sustainability and development. The International Union of the Conservation of Nature and Natural Resources also issued a World Conservation Strategy that brought the concept of sustainability to a global level in 1980 . This report was later followed by the widely cited Brundtland Report of 1987, which provided a definition of sustainable development. "Sustainable development is development that meets the needs of the present without compromising the ability of future generations to meet their own needs." (Brundtland, 1987, p.16). The concept of sustainability is applied to a wide range of disciplines, like for the case of tourism.

\subsubsection{Sustainable Tourism}

Since its origins many authors have put forth definitions of the meaning of sustainability for the case of tourism. Butler, a widely cited researcher in the field, describes it as, "tourism which is developed and maintained in an area (community, environment) in such a manner and at such a scale that it remains viable over an infinite period and does not degrade or alter the environment (human and physical) in which it exists to such a degree that it prohibits the successful development and wellbeing of other activities and processes. (Butler 1993, p.29). This definition touches on many characteristics that other authors (De Albuquerque \& McElroy, 1992; Nižić et al. 2010) use when describing sustainable tourism. Sustainable tourism is also cited as a continuous process of learning that requires constant monitoring, formulation and revision of policies, management and preventative measures (de-MiguelMolina et al., 2014). For this research the definition provided by the World Tourism Organization (WTO) is used as a basis. The WTO is a leader in tourism research and has attempted to keep records of the statistics related to tourism since the beginning of the modern tourism industry in the 1940 s. They express sustainable tourism as, "Tourism that takes full account of its current and future economic, social and environmental impacts, addressing the needs of visitors, the industry, and the environment and host communities" (World Tourism Organization, 2015, p.1). The WTO (2015) lists the following sustainable tourism criteria: 
- Make optimal use of environmental resources that constitute a key element in tourism development, maintaining essential ecological processes and helping to conserve natural heritage and biodiversity;

- Respect the socio-cultural authenticity of host communities, conserve their built and living cultural heritage and traditional values, and contribute to inter-cultural understanding and tolerance;

- Ensure viable, long-term economic operations, providing socio-economic benefits to all stakeholders that are fairly distributed, including stable employment and income-earning opportunities and social services to host communities, and contributing to poverty alleviation. (p.1)

Sustainable tourism is a known concept, but it is still not applied to all destinations. Hall (2010) goes as far as to say that despite the amount of publications, conferences and strategies that deal with tourism and sustainability, tourism is less sustainable than it has ever been. This research acknowledges sustainable tourism as an important concept and tool for achieving objectives for destinations and will attempt to further our knowledge on achieving sustainable tourism for island destinations.

\subsection{Island Tourism}

Island destinations attract a significant number of tourists each year and are a popular form of tourism (Butler, 2008; WTO, 2015). Motivations for tourists to travel to island destinations are their geographic locations, exotic wildlife, climate, food, adventure and foreign cultures (Butler, 2008; Davenport and Davenport, 2006; Lockhart et al., 2002). Many of these pull factors identified by researchers are natural and non-renewable resources. The very resources on which island tourism depends are the ones that tourism can deplete (Birdir et al., 2013; Dodds, 2007). Developing a form of sustainable tourism to protect the state of the natural environment for these destinations is therefore imperative for the success of the industry.

\subsubsection{Impacts of Tourism on Small Islands}

Research has identified the impacts created by tourism on island destinations. Dodds \& Graci (2012) formulated a list of various impacts to which island destination are susceptible. The list is based on current and past literature and provides an illustration of the extensive amount of impacts a destination can face.

- Economic dependency of the host community on tourism

- Conflict (e.g., drugs, vandalism, crime, begging, gambling, prostitution)

- Pollution (sea, land, air, noise)

- Leakage 
- Loss of habitat and resources from development and pollution

- Biodiversity loss

- Erosion

- Decline of water resources (quality and quantity)

- Loss of natural and architectural heritage from development

- Loss of local cultural traditions due to changes in lifestyle (e.g., values, morals, sex roles) due to tourism

- Displacement of the local population

- Increased congestion and strains of infrastructure

- Excessive use of natural areas

- Coastline deterioration due to developments (buildings, facilities, roads)

- Crowding (pressure on services)

- Inflation

- Foreign customs and expectations creating conflict (p.7)

From the list above the tourism-related economic, social and environmental costs cannot be overlooked. Negative impacts need to be taken into consideration when determining the true benefits of tourism for island destinations (Boukas \& Ziakas, 2014; Butler, 2008; Davenport \& Davenport, 2006; Dodds \& Graci, 2012; Palmer \& Riera, 2003). This study intends on highlighting the major issues related to tourism in Savusavu.

Examples in the literature of research on the impacts of tourism are from Gossling (2001), who studied the consequences of tourism on the island of Zanzibar in Tanzania. The deforestation of mangroves for development increased the erosion that deposits sediments on coral reefs and contributed to the overall degradation of the coral ecosystems. Tourism nutrient loads (organic and inorganic particles) reaching the ocean also affected the marine ecosystems. The impacts were intensified in combination with other destructive fishing practices and physical modifications like mining. The very resources on which the island's tourism industry depends were being jeopardized, thereby impacting the livelihoods of the coastal dwellers (Gossling, 2001).

The increase in environmental impacts we see created by tourism raises questions with respect to the effectiveness of current sustainable tourism practices, instruments and their implementation (Hall, 2010). It has been said that with proper sustainable development, management, policies and planning, these impacts can be minimized and the benefits of island tourism can be maximized (Dodds \& Graci, 2012; Mitchell \& Reid, 2001). Research is still needed to improve our current practices and overcome challenges islands face when trying to achieve sustainable outcomes. 


\subsubsection{Challenges of Small Island Developing Sates Being Sustainable}

Fiji is considered a Small Island Developing State (SIDS). Research on SIDS did not emerge until 1970 and was initiated and stimulated by the British Commonwealth (Crossley \& Sprague, 2014). SIDS face many challenges when attempting to become a sustainable tourism industry. SIDS usually have smaller population size, are found in remote locations, have limited natural resources, limited economic diversity and are susceptible to natural disasters (Boukas \& Ziakas, 2014; Shareef \& McAleer 2005). Researchers identified that the available space, impacts of climate change (sea level rise) and lack of education also lead SIDS to being vulnerable to negative impacts of tourism (Juvan et al., 2016; Shareef \& McAleer, 2005; Ruckelshaus et al., 2013; WTO ,2004). These states have their own socio-cultural ecology making them unique and difficult to manage (Commonwealth Secretariat, 1985). Due to these characteristics SIDS face challenges when trying to maximize the positives impacts of tourism.

SIDS are also categorized based on their limited economic diversity and high dependence on tourism in terms of exports and contribution to GDP (WTO, 2015). The overdependence of islands on tourism is a major barrier to becoming sustainable as they are susceptible to various global disruptions and crises (Bastin, 1988; Boukas and Ziakas, 2014; Briguglio, 1995; Niles \& Baldacchnio, 2011).This dependence can also cause island destinations to focus on the economic gains and ignore the various social and environmental impacts tourism has on the destination (Butler, 2008; Lewis et al., 2010). For example, Wells et al. (2016) examined how human perceptions and practices related to wastewater management can impact coastal health and livelihoods in tourism-dependent economies in the Caribbean. From qualitative interviews with stakeholder groups they found financial interests of commercial industries, foreign developers, and environmental services complicated the future of new technologies for water and energy systems. Though the stakeholders were aware of the importance of the potable water to the tourism industry and noted the health implications on the surrounding environment, they still resisted the idea of a new centralized wastewater system due to other interests for the funding (Wells et al., 2016). Therefore, even though issues such as wastewater treatment can be apparent they are not considered a top priority as stakeholders are interested in other financial gains. There are many stakeholders involved in island tourism. This makes it difficult to achieve sustainability, as they all have their own personal agendas and desires. If stakeholders do not work towards similar goals it can be difficult for a destination to become sustainable or move towards some sort of sustainability (Bruzzi et al., 2011; Gani et al., 2017; Dodds \& Graci, 2012). Research is still needed to identify ways islands can overcome barriers related to sustainable tourism development. 


\subsection{Environmental Instruments}

Environmental instruments are tools, strategies, laws and institutions that can be used to ensure sustainable tourism development (Ayuso, 2007; Harrington \& Morgenstern, 2007; Yasamis, 2011). This section of the literature review examines and analyzes various environmental instruments that managers can implement to improve the sustainability of a destination's tourism industry. The purpose of this section is to begin to identify instruments that could be implemented for the case of Savusavu to promote sustainable tourism. Table 3 summarizes the findings from the literature on environmental instruments. A brief description, their effectiveness and examples are listed below and are discussed in more detail in the following sections.

\begin{tabular}{|c|c|c|c|}
\hline Instrument & Description & Effectiveness & Examples \\
\hline Regulatory & $\begin{array}{l}\text {-Prohibit and allow certain } \\
\text { acts under the permission } \\
\text { granted by the government } \\
\text { - Use coercion; penalties } \\
\text { for non-compliance on } \\
\text { consumers }\end{array}$ & $\begin{array}{l}\text {-High when applied and enforced } \\
\text { by government } \\
\text {-Associated time, process and } \\
\text { politics are seen as a negative }\end{array}$ & $\begin{array}{l}\text { Command and control, } \\
\text { Environmental Impact Assessment }\end{array}$ \\
\hline Economic & $\begin{array}{l}\text {-Charges imposed on } \\
\text { activities that the } \\
\text { government would like to } \\
\text { encourage of phase out } \\
\text {-Price/costs of different } \\
\text { behaviours on consumers } \\
\text { and resource users }\end{array}$ & $\begin{array}{l}\text {-High when enforced by } \\
\text { government } \\
\text {-Uncertainty in costs needed to } \\
\text { change behaviour; what to } \\
\text { measure; willingness to pay }\end{array}$ & $\begin{array}{l}\text { Taxes, user fees, payments of } \\
\text { ecosystem services, voluntary } \\
\text { funds }\end{array}$ \\
\hline $\begin{array}{l}\text { Educational } \\
\text { and outreach }\end{array}$ & $\begin{array}{l}\text {-Information awareness } \\
\text { initiatives that encourage } \\
\text { favourable public actions } \\
\text {-Uses moral suasions }\end{array}$ & $\begin{array}{l}\text {-Uncertain: some cases of } \\
\text { significant impacts, especially in } \\
\text { conjunction with other } \\
\text { instruments } \\
\text {-Can provide action without } \\
\text { coercion or costs } \\
\text {-Does not always need } \\
\text { government involvement }\end{array}$ & $\begin{array}{l}\text { Community education programs, } \\
\text { school programs }\end{array}$ \\
\hline Voluntary & $\begin{array}{l}\text {-Public challenges to } \\
\text { industries and businesses } \\
\text { to produce more } \\
\text { sustainable outcomes } \\
\text {-Moral suasion; pre- } \\
\text { emption of more coercive }\end{array}$ & $\begin{array}{l}\text {-High and low in some cases. } \\
\text {-Flexible and innovative } \\
\text {-Does not need government } \\
\text { involvement } \\
\text {-More research needed to test } \\
\text { legitimacy and strength }\end{array}$ & $\begin{array}{l}\text { Codes of conduct, best } \\
\text { environmental practices, ecolabels }\end{array}$ \\
\hline
\end{tabular}




\begin{tabular}{|l|l|l|l|}
\hline & $\begin{array}{l}\text { measures for the industry } \\
\text { and resource users }\end{array}$ & \\
\hline Institutional & $\begin{array}{l}\text {-Combination of } \\
\text { informative provision; } \\
\text { coercion; price, costs for } \\
\text { users }\end{array}$ & $\begin{array}{l}\text { - High with high level of } \\
\text { government support, funding and } \\
\text { resources }\end{array}$ & $\begin{array}{l}\text { Protected Areas, Marine Protected } \\
\text { Areas }\end{array}$ \\
\hline
\end{tabular}

Table 3 Summary of Environmental Instruments (information adapted from Winfield, 2016)

\subsection{Regulatory Instruments}

Regulatory instruments prohibit and allow certain acts under permission granted by the government, they are popular for prevention and control of pollution, managing resources and land use planning (Winfield, 2016). These instruments usually have a high level of government involvement and are considered "strong" because of the penalties associated with them. These include fines and imprisonment on conviction of the offence (Winfield, 2016; Keohane et al., 1998).

Command and control is a regulatory environmental instrument which attempts to control the amount and level of pollution in an environment by enforcing laws, measures, rules and standards for environmental protection (He et al., 2012; Yasamis, 2011). This type of instrument has been one of the most dominant forms of environmental instruments and was first implemented in the 1970s (Harrison, 2007; He et al., 2012). Instruments like design standards, requiring a particular technology's usage or performance standard and prescribing the maximum amount of pollution that a source can emit are forms of command and control instruments (Hahn \& Stavin, 1992; Keohane et al., 1998). Command and control is applied to natural resource management to reduce, "the range of natural variation of system structure, function, or both--in an attempt to increase their predictability or stability" (Holling \& Meffe, 1996, p.1).

Regulatory instruments need high levels of government involvement, funding, planning and monitoring to be effective (Winfield, 2016). Hanh \& Stavin (1992) believe that these necessities are what make these instruments, like command and control, inflexible in achieving goals for managers. Annandale et al. (2004) also suggest that these approaches are not providing satisfactory answers to complex environmental problems, like those associated with tourism. The extent to which command and control instruments result in sustainable tourism development is not highly supported due to these limitations and inflexibilities.

Environmental Impact Assessment (EIA) is a regulatory instrument used for land use planning and controls people's actions on the environment before it happens. EIA focuses on modifying the 
decision-making processes with respect to policies and projects that affect the environment before they happen. The objective of EIA as an environmental instrument is to plan development, to predict and mitigate the potential environmental and social effects that could occur before, during and after the project (Morgan, 2012). This is a systematic approach to dealing with environmental issues, with a high level of authority and government involvement (Winfield, 2016). The instrument can be considered regulatory as it is mandatory in some countries.

Since its development in the United States in the 1960s and 1970s, EIA is an instrument that is now widely used in North America and Western Europe. Its use in developing countries is increasing but their processes often fall short of the national standards used in developed countries (Glasson et al., 2013; Li, 2008). In the worst case it is not used at all in some countries. This instrument involves a series of steps and stages, which vary from destination to destination. Figure 3 provides an example of a developed EIA process.

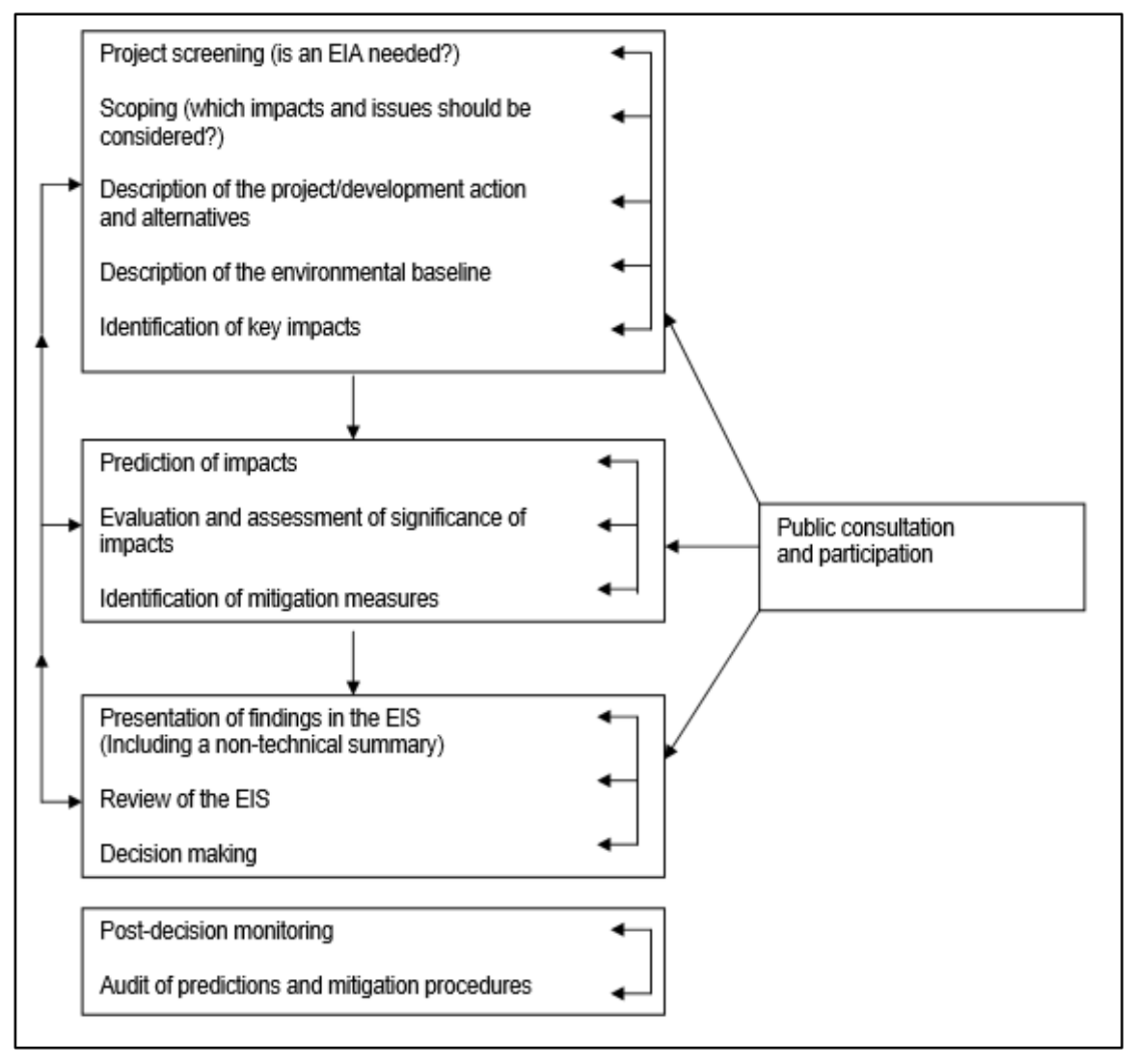

Figure 4 Flow diagram of important steps in the EIA process (Glasson et al., 2013) 
All steps in an EIA are important and have a significant role. However, one step of the EIA process that is viewed as important in the literature is public participation and involvement (Diez et al., 2015; Glasson et al., 2013; Li, 2008). "EIA can be a very useful vehicle for engaging with communities and stakeholders, helping those potentially affected by a proposed development to be much better informed and to be more fully involved in the planning and development process" (Diez et al., 2015, p.2). Public participation mechanisms allow for the public to weigh in on decisions for major developments to attempt to produce more sustainable outcomes. Communities can share their knowledge on environmental and social aspects surrounding a certain project that may be missed. Methods of public participation include online forums and community meetings. Engagement opportunities can occur before, during and after a project so that there is participation throughout the projects lifecycle (Li, 2008).

There is some criticism of the EIA process in the literature. Many countries developed lists of projects which should be subject to EIA; the list considers project type, size and the consequence of likely impacts. There are also lists of 'categorical exclusions' exempt from the EIA requirement (Wathran, 2013). Having such criteria can exempt certain projects from an EIA and the instrument is not used. Another issue studied by Glasson et al. (2013) is that the EIA process can miss key stages (e.g. auditing and monitoring). Many less developed countries use the procedure to introduce only some aspects of environmental planning, often in the absence of any formal land-use planning control system (Guerra et al., 2015; Wathran, 2013). While EIA is a well-developed and used instrument it is a time consuming process and is only effective when it is enforced by the government. The limitations of regulatory instruments has led to other forms of instruments being introduce which are explored in the following sections.

\subsection{Economic Instruments}

This section examines the literature related to economic instruments. Economic instruments are charges that managers impose on activities that the government would like to encourage or phase out (Winfield, 2016; Yasamis, 2011). Economic instruments are applied to the services natural resources provide and funds acquired are used to manage and conserve the resources on which tourism industries rely (Birdir et al., 2013; Thur, 2010).

Due to growing concerns of environmental problems caused by tourism, environmental taxes have attracted increasing attention as environmental instruments (Yasamis, 2011). Environmental taxes 
are instruments designed to increase the price on activities and products that are harmful to the environment. Researchers suggest (Bovenberg \& Mooij, 1994; Palmer \& Reira, 2002; Piga, 2003) that environmental taxes are effective tools in achieving environmental policy objectives and a useful tool for sensitive environmental features like those associated with tourism.

Many researchers have defined what an environmental tax (sometimes referred to as a levy) is and how it should be implemented. The European Commission (2017) believes, "a levy considered as environmental if the taxable base of the levy has a negative effect on the environment" (p.1). The Europeans Environment Agency (1996) describes an environmental tax as "a tax that provides an incentive to avoid the tax by using or generating less of the substance being taxed" (p.1). Palmer and Reira (2000) indicates that a tax is environmental depending on, "its greater or lesser ability to modify the conduct of agents so as to benefit the environment."(p.1). The environmental taxes' interpretation differs in the literature however, the main goal of each definition is to benefit the environment. Taxes limit environmentally harmful behaviour through a price incentive of some sort. They are found in economies around the world and levied on bases such as energy, transportation and pollution (Sustainable Prosperity, 2015).

A form of environmental tax discussed in many papers (Piga, 2003; Pigou, 1920; Palmer \& Riera, 2002) are Pigouvian taxes. A Pigouvian tax aims to set a suitable price for tourism activities that will internalize external costs like social damage caused by pollution (Bovenberg \& Mooij, 1994; Palmer \& Riera, 2002). Pigouvian taxes consists, "of applying a tax equivalent to the external marginal damage produced at the point at which benefits equal the external costs" (Pearce \& Turner 1990 from Palmer 2002, p.3). Other types of taxes proposed by Baumol and Oates (1971) consist of the use of a group of standards and taxes to achieve a certain level of environmental quality. "The aim is not to achieve the social optimum, as is the case of Pigouvian taxes, but a sub-optimum situation, in which a certain standard of environmental quality is achieved" (Palmer et al., 2002, p.3). For this type of tax it is no longer necessary to assess the external marginal damage and measure the amount of correction being done, which can be difficult to assess.

The Balearic Tax is an example of an environmental tax developed and implemented for the case of tourism. This tourist tax was introduced in Balearic Islands in Spain, to internalize part of social end of environmental costs associated with the tourism industry. The purpose of the tax was, "to obtain sufficient financial resources to be able to fund expenditure focused on reducing the environmental damage caused by tourism" (Palmer \& Riera. 2002, p.3). Such expenditures could include the 
rehabilitation of tourist areas, redesign and rehabilitation of tourist resorts, the recovery of natural resources, natural areas and heritage of relevance to tourism. The economic instrument therefore supported other voluntary instruments. Tourists staying in an accommodation were taxed based on the number of nights they stayed. The tax revenue was used solely for the environmental costs associated with the tourism industry (Balearic Island Autonomous Community Department of the Environment, 1999 as seen in Palmer \& Riera, 2002).

Edwards (2009) conducted a study that explored the feasibility of implementing a sustainable economic instrument for ocean and coastal management in Jamaica. The study found that, "an environmental surcharge of US\$2 per person could generate $\$ 3.4 \mathrm{M}$ per year for management with $0.2 \%$ rate of decline in tourist visitation."(p.1). The research believed using the term "environmental tax" rather than a general "tourism development tax" would lead to greater acceptance amongst stakeholders. The language used to describe economic instruments is important to consider when implementing tax instruments (Edwards, 2009; Ramdas \& Mohamed, 2014).

There is uncertainty in costs needed to change behaviour and what is being measured to create a cost. The social and environmental costs related to tourism cannot be easily measured, making environmental taxations a field that is constantly evolving and trying to improve (Bovenberg \& Mooij, 1994; Baumol \& Oates, 1971; Palmer \& Reira, 2003).There is still research needed to identify the most effective method of taxation and how to establish or determine the appropriate tax to be used for a destination that will be accepted.

\subsubsection{User Fees}

User fees are identified in the literature as economic instruments that generate income to aid with natural resource management. User fees are applied to ecosystem services. These services are associated to goods produced by an ecosystem; food, fuel, climate services, soil formation and other supporting services. Other services related to ecosystems include water activities, diving, hiking or other recreational activities that need the support of the environment (Birdir et al., 2013; Sattler \& Matzdorf, 2013). User fees are a cost that can be imposed on tourism related activities, inform tourists of environmental issues and allows them to help to protect or conserve something.

User fees development was in conjunction with the increase in establishment of natural parks around the world. Over the last two decades there has been an increase in the number of parks for tourism use due to public demand (Chung et al., 2011; Van Sickle \& Eagles, 1998). As a result, user fees 
were developed to help fund and support management of parks and nature- based operations related to tourism. The fees aid in the management of natural resources by providing financial support. This way parks do not need to rely on the government of other sources of funding to manage the park effectively. These fees are effective for the case of tourism in that they support the management of resources, conserve biodiversity and tourism management (Catibog - Sinha, 2010; Edwards, 2009; Sattler \& Matzdorf, 2013).

Knapman and Stoeckl (1995) examined the opportunity to create a user fee in the parks of Australia, because the government was not able to provide additional funding. Increasing tourism in the area placed heavy demand on park management and natural resources. The researchers believe that, "entry fees are not only a good potential source of revenue, but also impose smaller efficiency costs than the income taxation system; and that fees may well constitute a progressive tax" (Knapman and Stoeckl, 1995, p.1). The researchers warn that if fees are not priced appropriately they could be rejected by the public. However, this research support user fees as effective natural resource management tools. A study by Catibog - Sinha (2010) looked at the application of a user fee to conserve biodiversity in the Philippines. They support that fees are an important source of revenue and supplementary funding for conservation in developing countries. Chung et al., (2011) support that user fees for access to natural resources can be effective in visitor management and in dealing with social and environmental impacts.

The literature identifies the drawbacks of user fees. For one, the implementation and effectiveness of fees has not been documented greatly in the literature (Engel et al., 2008). They should not be seen as a solution that can address any environmental problem, which they sometimes are. Fees are only charges, they do not guarantee proper management of environmental management or produce a form of collective management. There are also concerns with how to set up a fee, its fairness and stakeholder willingness to pay (Chung et al., 2011; Lee \& Pearce, 2002). Unfair fees could deter tourists and improved management is not realized. However, if people understand the benefits from the fees paid they might be willing to pay (Chung et al., 2011; Cardenas et al., 2015). Information on the purpose of user fees therefore is important for their acceptance.

\subsubsection{Payments for Ecosystem Services}

A framework to set up user fees and overcome some of the limitations seen in the literature is, the Payments for Ecosystems Services (PES). The World Wildlife Fund (WWF) created a document to frame how managers can create a system to pay for the services the environment provides. This 
framework can be applied to tourism activities. Tourism activities can exploit natural resources that will compromise an ecosystem's ability to provide benefits (Bruzzi et al., 2011; Edwards, 2009). The WWF divides ecosystem services into 4 categories, of which PES systems can be created (Table 4).

Table 4 Categories of PES as seen from WWF $(2016, p .1)$

\begin{tabular}{|l|l|}
\hline Service & Explanation of Service \\
\hline Supporting Services & $\begin{array}{l}\text { those services creating conditions necessary for the provision of all other ecosystem } \\
\text { services, for example photosynthesis or soil formation }\end{array}$ \\
\hline Provisioning Services & $\begin{array}{l}\text { all products coming from ecosystems, for example food, fiber, fuel, herbs and } \\
\text { medicinal plants, genetic resources, drinking water }\end{array}$ \\
\hline Regulating Services & $\begin{array}{l}\text { the capacity of ecosystems to regulate important natural processes, for example } \\
\text { regulation of climate, quality and quantity of water, etc. }\end{array}$ \\
\hline Cultural Services & $\begin{array}{l}\text { non-material benefits from ecosystems, for example the aesthetic and recreational } \\
\text { value of landscapes }\end{array}$ \\
\hline
\end{tabular}

The framework rewards the environment for the services they provide with subsidies or market payments (WWF, 2016). This framework is useful for tourism as it provides some guidance to setting up fees outside of nature based tourism and parks. In terms of designing a successful PES, the WWF outlines 5 steps for managers:

1. clearly identified participants;

2. clear definition of the ecosystem service provided;

3. providers comply with the terms of their contract - compliance results in a change in the ecosystem service compared to what would have been without the PES scheme;

4. the existence of compliance penalties;

5. payments are determined on the basis of cost (WWF, 2016, p.1)

There is literature that used this framework. A study by Bohlen et al., (2009) developed a successful PES program using these guidelines. The PES compensated cattle farmers for providing water storage and nutrient retention on private lands in Florida. Issues identified in the literature when setting up frameworks were: identifying buyers, defining the services, agreeing on credible and practical service, complex regulatory issues and attempting to satisfy all stakeholders (Benjamin, 2013; Bohlen et al, 2009). While PES schemes can protect services that support human livelihoods and support environment stewardship, there are still challenges when setting up appropriate schemes (Cavalier \& Munro Gray, 2012). Research is needed to improve setting up PES frameworks as a possible economic instrument used to manage natural resources used in tourism. 


\subsubsection{Willingness to Pay}

While knowledge of economic instruments and their varying forms is known, researchers must determine if tourists are willing to pay them. Tourists may avoid a destination because of associated taxes and fees (Dodds et al., 2010). Willingness to pay studies were examined in order to understand this concept. Many researchers (Dodds et al., 2010; Uyarra et al., 2010; Wang \& Jia, 2012) have studied tourists' willingness to pay because of the benefits fees and taxes can have on improving the sustainability of a destination.

Wang \& Jia (2012) conducted a study in Northern China to determine tourists' willingness to pay for biodiversity conservation. This was done to determine an entrance fee for the Dalai Lake Protected Area. After surveying 200 tourists they found $73 \%$ found would accept a high entrance fee knowing it was for environmental protection and conservation. The remaining $26 \%$ believe it is the government's responsibility to pay for the conservation and protection of the environment and therefore are not willing to pay fees. Factors of income, education and institutional trust influenced the tourists' willingness to pay a higher fee. The study recommended a \$7.54 entrance fee (Wang \& Jia, 2012).

Birdir et al., (2013) conducted a willingness to pay study at three different coastal destinations in Turkey; Kizkalesi, Yemiskumu and Susanoglu. From the 402 respondents 92\% expressed they are willing to pay for the beach to improve. Issues seen on the beaches were litter, washed up debris and erosion. The fee would be used to clean the beach, the provision of more social activities and to sustain the quality of the beaches. The study suggests a fee of around 2.00 for each beach and to include a voluntary donation box to accommodate the fee. Cetin et al., (2017) conducted a qualitative study with tourists in Istanbul, Turkey to determine their perceptions on willingness to pay. They found that the tourists are likely to pay additional fees if they would be used to improve their experience. By improving the environment of Istanbul could result in a better experience for travelers. They also found that the majority of travelers stated their trip would not be negatively influenced if their vacation increased by one third (Cetin et al., 2017).

Dodds et al. (2010) conducted a study on two island destinations, Koh Phi Phi, Thailand and Gili Trawangan, Indonesia. The research examined motivations, tourist perceptions of islands destinations, the level of awareness of environmental issues of the area, the extent to which they feel responsible for preserving and the role they are willing to take in their management. This included a willingness to pay for environment protection (Dodds et al., 2010). The researchers found the tourists surveyed had a 
willingness to pay for sustainability practices, but there were discrepancies on who they felt should be responsible for implementing these measures (Dodds et al., 2010). Dodds (2013) continued the research in Koh Phi Phi Thailand by surveying visitors to determine their attitudes towards sustainability and their willingness to pay to preserve its environment. Dodds (2013) found that travellers are prepared to take responsibility and to pay to help prevent further degradation of the island. Her study also identified that visitors believe that tourists should be a key stakeholder in protection and would pay a tax for this purpose (Dodds, 2013).

Tourists' willingness to pay differs from destination to destination, however there was a trend in acceptance of fee and taxes. Each study determined an appropriate fee based on interviews with tourists. Tourists are the ones who will be paying the fee, therefore understanding how much they are willing to pay is essential in implementing a new fee. The studies also suggest that acceptance and effectiveness of economic instruments might be improved by including education on the benefits of the fees and explaining the benefits resources provide to stakeholders (Birdir et al., 2013; Cardenas et al., 2015; Chung et al., 2011; Edward, 2009). If stakeholders know where the money generated is going and understand how this will impact their destination then they may be more willing to pay (Edwards, 2009). A willingness to donate towards conservation of marine endangered species for tourists visiting Ecuador's Galapagos National Park was studied. By explaining the challenges a species of shark and turtle face the study found that tourists would be more willing to donate to protect the animals (Cardenas et al., 2015). Therefore, education instrument could be used with economic instruments to improve their acceptability and effectiveness in improving sustainability.

\subsection{Education and Public Outreach Instruments}

Public outreach and education instruments involve information awareness initiatives that encourage public actions to help reach goals of a destination. Education and outreach instruments are applied to help bridge the gap of knowledge to inform all stakeholders of the issues related to a destination's tourism industry and how to overcome them (Winfield, 2016). To achieve sustainable tourism the continuing education of all tourism interest groups (i.e. managers, developers, and the public) is suggested in the literature (Bruzzi et al., 2011; Ganii et al., 2017; Prigram, 1990).

Educational instruments can be implemented on a large scale or on a small local level. The objectives can be broad or specifically aimed at addressing one topic. Education instruments do not always involve incentives but they can change behaviour through classroom or informal education. An 
example of a national education instrument is seen from The United Nations Education, Scientific and Cultural Organization (UNESCO). UNESCO implemented "The Decade for Education for Sustainable Development" instrument in 2014-2015. They ask that educators:

1. promote and improve quality education;

2. reorient existing education to address sustainable development;

3. build public understanding and awareness;

4. provide practical training (UNESCO, 2015).

The initiative itself is an instrument of education and encourages others to provide further education opportunities to promote sustainability in all aspects of tourism. The UNWTO also organized its 2013 World Tourism Day education program under the theme, "Tourism and Water: Protecting our Common Future." This is another type of educational instrument implemented by a national organization. Its goal was to, "draw greater attention to tourism's potential role in contributing to more sustainable water management infrastructure and to address water sanitation challenges" (UNWTO, 2013, p.342). These instruments are accompanied by guidelines and information that educators can access online making them accessible to a wide variety of stakeholders in different destinations.

Limitations of these instruments is that their impacts are difficult to measure and the implications of these instruments are not known (Birdir et al., 2013; Windfield, 2016). Researchers struggle to measure the education levels of stakeholders before and after research is done with education instruments (Cardenas et al., 2015). To determine the direct impacts of one instrument may only be possible where other influences are not present and there are variables that can be used to measure the changes. Therefore, it is difficult to determine their effectiveness in producing sustainable outcomes.

There are local and small scale education instruments in the literature. Local Agenda 21 emphasizes the need for education to address local sustainability by educating and involving the public in decision making. The agenda states that sustainable development can only be achieved through planned, democratic, cooperative means, including community involvement in decision making about the environment and community involvement in decision making about the environment (Nations Conference on Environment and Development, 1992). The instrument's aim is to foster community involvement by educating citizens and stakeholders on concerns, priorities and actions regarding the environment, development and social issues (Dodds, 2007; Freeman, 1987). Dodds (2007) conducted a 
study in Calvia, in the Balearic Islands to set up a successful sustainable tourism policy using Local Agenda 21 guidelines. The researcher worked with the destination to aid in producing a long-term sustainability strategy, set goals and to establish social programmes to combat crime and other social issues (Dodds, 2007).

Other examples of environmental education instruments are from Hatipoglu et al., (2014), who conducted a study on an international student program in Kastamonu, Turkey. Its purpose was to educate students on sustainable values to produce effective leadership in sustainable development outcomes in Turkey. It was found that through education, students gained sustainable knowledge, values and skills that they can apply to their daily decisions now and in the future to promote sustainability (Hatipoglu et al., 2014). To measure the effectiveness of the program surveys were conducted before and after the program was implemented. The goals of the program were to define sustainable tourism, attain cross-cultural understanding and engage in bi-national collaborations, and to discuss and recommend how sustainable rural tourism development can aid in the improvement of the quality of life of a destination (Haptipoglu et al., 2014).

These studies illustrate that education instruments can have specific objectives or learning outcomes. Educational programs can be developed specifically for a destination. The programs can focus on goals set out by a destination and administered in a classroom setting or online to reach a small or large audience. Having this flexibility makes these instruments beneficial for destinations attempting to improve their sustainability.

\subsection{Voluntary Instruments}

Policymakers usually rely on legislative and regulatory restrictions to produce protection of environmental quality. Voluntary instruments differ in that they are flexible and promote innovative approaches to reaching policy goals that do not require government involvement (Annandale et al., 2004; Rivera, 2002; Segerson \& Miceli, 1998; Winfield, 2016). These instruments decrease administrative costs and time associated with regulatory instruments (Segerson \& Miceli, 1998). They are non-mandatory initiatives that can promote compliance of environmental policy beyond legal terms (Prakash \&Potoski,2012; Rivera, 2002). Stakeholders can implement these instruments to improve their environmental management at a small local level as well as larger industrial levels. Those who implement voluntary instruments can make their own choices to allow them to meet their environmental protection goals (Ayuso, 2007; Winfield 2016). 
Researchers have studied a variety of voluntary environmental instruments that hotels, tour operators and tourism related businesses can implement (Annandale et al, 2004; Ayuso, 2007; Pavia et al., 2015; Rivera, 2002). Ayuso (2007) provides an analysis of popular voluntary instruments used in the tourism industry (see Table 5). The instrument, its scope, goals and obstacles is indicated for each.

Table 5 Voluntary instrument as seen in Ayuso (2007, p.5)

\begin{tabular}{|c|c|c|c|}
\hline Policy Instrument & Scope & Incentives & Obstacles \\
\hline Codes of conduct & $\begin{array}{l}\text { To show commitment of } \\
\text { improving environmental } \\
\text { performance of a company }\end{array}$ & $\begin{array}{l}\text {-Low effort and costs } \\
\text {-Possible delivery of } \\
\text { specific services }\end{array}$ & $\begin{array}{l}\text {-Lack of knowledge on } \\
\text { effectiveness of existing } \\
\text { codes }\end{array}$ \\
\hline Best Environmental Practices & $\begin{array}{l}\text { To take action to improve the } \\
\text { environmental performance } \\
\text { of the company }\end{array}$ & $\begin{array}{l}\text {-Cost savings in the } \\
\text { medium/long term } \\
\text {-Response to demands of } \\
\text { customers and tour } \\
\text { operators } \\
\text { - Personal awareness of } \\
\text { hotel staff } \\
\text {-Improves company image }\end{array}$ & $\begin{array}{l}\text {-Difficulties in involving } \\
\text { hotel staff } \\
\text {-Lack of collaboration of } \\
\text { customers }\end{array}$ \\
\hline Ecolabels and Awards & $\begin{array}{l}\text { To ensure the environmental } \\
\text { performance of the company } \\
\text { with regard to certain } \\
\text { aspects, and offer the } \\
\text { corresponding information to } \\
\text { the consumer }\end{array}$ & $\begin{array}{l}\text {-Cost savings in the } \\
\text { medium / long term } \\
\text {-Response to demands of } \\
\text { customers and tour } \\
\text { operators } \\
\text {-Personal awareness of } \\
\text { hotel manager /staff } \\
\text { - Official recognition of } \\
\text { environmental } \\
\text { commitment } \\
\text {-Improvement of company } \\
\text { image }\end{array}$ & $\begin{array}{l}\text { - High costs for applying } \\
\text { and maintain the ecolabel } \\
\text {-Confusion due to } \\
\text { existence of different } \\
\text { ecolabel schemes } \\
\text {-Lack of knowledge and } \\
\text { interest of customers and } \\
\text { tour operators }\end{array}$ \\
\hline $\begin{array}{l}\text { Environmental Management } \\
\text { Systems (EMS) }\end{array}$ & $\begin{array}{l}\text { To manage the environmental } \\
\text { performance of the company } \\
\text { and improve it continuously } \\
\text { according to a planned } \\
\text { strategy }\end{array}$ & $\begin{array}{l}\text { - Cost savings in the } \\
\text { medium / long term } \\
\text {-Response to demands of } \\
\text { customers and tour } \\
\text { operators } \\
\text {-Personal awareness of } \\
\text { hotel manager /staff } \\
\text {-Official recognition of } \\
\text { environmental } \\
\text { commitment } \\
\text {-Improvement of internal } \\
\text { management system } \\
\text { - Improved company image } \\
\text {-Compliance with legal } \\
\text { requirements }\end{array}$ & $\begin{array}{l}\text { - High costs for certification } \\
\text { audits } \\
\text {-Difficulties in involving } \\
\text { hotel management and } \\
\text { staff } \\
\text {-Change of routines and } \\
\text { management style } \\
\text {-Lack of support from } \\
\text { public authorities, } \\
\text { suppliers and } \\
\text { subcontractors }\end{array}$ \\
\hline $\begin{array}{l}\text { Environmental Performance } \\
\text { Indicators }\end{array}$ & $\begin{array}{l}\text { To assess and communicate } \\
\text { the environmental } \\
\text { performance of the company }\end{array}$ & $\begin{array}{l}\text {-Cost savings in the } \\
\text { medium/long term } \\
\text {-Response to demands of } \\
\text { tour operators } \\
\text { - Improvement of internal } \\
\text { management system }\end{array}$ & $\begin{array}{l}\text {-Difficult collecting the } \\
\text { necessary data }\end{array}$ \\
\hline
\end{tabular}


Codes of conduct, best environmental practices, ecolabels, environmental management system (EMS) and environmental performance indicators are examples of voluntary instruments tourism stakeholders can implement. The majority of these instruments' objectives are focused exclusively on the environmental dimension of sustainability. Barriers include lack of existing knowledge of data, lack of support and lack of communication between the involved stakeholders (Auyso, 2007).

Pavia et al., (2015) analyzed two certification programs. The researchers studied a project coordinated with the Ministry of Tourism and the Association of Employers in Croatia in 2014 in which they initiated an ecolabel pilot project "Green Business in Hospitality". A total of 21 hotels joined the project. In order to receive the label, stakeholders had to meet a set of criteria outlined by the program. An evaluation by the program managers determined if they had fulfilled all the conditions for obtaining the certificate of "Sustainable Hotel". Direct impacts of the program were not seen and difficult to measure. The researchers state that further research is needed to examine the actual effects of these voluntary instruments on the tourism industry (Pavia et al., 2015). Pavia et al., (2015) also studied The Costa Rican Certification for Sustainable Tourism program. This program is a performance based voluntary environmental program created by the Costa Rican Government in 1997. Certification could be obtained by voluntarily reducing energy consumption, limiting harmful effects on the environment, recycling and further actions like installing green roofs. They found that, "instruments that are implemented have large cost savings, increased awareness and care for environmental protection, as well as social sensibility towards the needy in the community, raises employee motivation and creates better communication with guests" (Pavia et al., 2015, p.8).

Ng et al., (2017) conducted a study on Tioman Island, Malaysia, using a Sustainable Ecotourism Indicator System (SEIS). The system produces a score that allows for comparisons of tourism related business across destinations to evaluate their sustainability level. The researchers believe the scoring provokes positive reactions from the stakeholders to play their parts in order to achieve a greater score. Sustainability for the case of tourism is argued to be achieved by each stakeholder making a positive contribution to others in social, environmental and economic arenas (Ng et al., 2017).

Bruzzi et al., (2011) studied an environmental management system (EMS) applied in Italy as a tool to improve sustainability of a municipality located on the coast of the Adriatic Sea. Their findings concluded that the EMS had a positive impact on the natural environment affected by socio-economic and tourist activities. Rivera (2002) examined the "Tour Operator Initiative" founded in Switzerland. This organization is open to all world tour operators dedicated to promoting sustainability through business 
practices such as the ones outlined by Auyso (2007). This organization brought tour operators together to work voluntarily on implementing new instruments like codes of conduct. However, the success of this work was not found as the operators resided in different areas making the impacts difficult to measure and evaluate (Rivera, 2002).

Though the use of voluntary instruments is growing there is little attention focused on their actual success. There is a need to evaluate the ability of voluntary instruments to generate economic benefits and their effectiveness in environmental management (Annandale et al., 2004; Rivera, 2002). The application of voluntary instruments is largely dependent on whether stakeholders actually chose to use them. "The improvement of sustainability of a tourism destination can be highly favored by a strong commitment of all organizations involved, such as tour operators, travel agencies, hotels, resort facilities and municipalities" (Bruzzi et al., 2011, p.93). The implementation of instruments can be simple actions like recycling, purchasing local produce or implementing environmental certification, however they need to want to participate in these actions for sustainable improvements to occur (Pavia et al., 2015). Therefore, stakeholder motivation could be a limitation of voluntary instruments. Education of the instruments benefits may be able to overcome this. If by educating a destination's stakeholders on the potential benefits of implementing these instruments, such as environmental improvement and improved public perception (Berghoef \& Dodds, 2013), then they may be motivated to use these instruments.

Implementing these instruments can also be costly for developing destinations. "Investment in systems for preservation of energy sources, waste management, and use of eco-friendly materials in the initial phase of the investment is often costly." (Pavia et al., 2015, p.5). Little is known about why firms operating in developing countries would want to participate in these initiatives as they can sometimes be costly to implement and the true benefits are still not known (Pavia et al, 2015).

There is also a large uncertainty in stakeholders' true motives for implementing voluntary instruments. There is no tool to ensure total compliance with voluntary instruments. For example, if a company's main goal is to make profits then their voluntary instruments may not be enforced if they hinder their ability to generate profits. The lack of enforcement and monitoring also creates a risk of having "free riders" who can reap the benefits of showing they are participating without actually practicing it (Bergoehf \& Dodds, 2013). While voluntary instruments are flexible and go above and beyond government regulations there are still questions surrounding their effectiveness in generating sustainable outcomes for tourism. 


\subsection{Institutional Instruments}

Institutional environmental instruments are specific agencies inside or outside of government to act as a focal point for policy development, implementation and evaluation (Winfield, 2016). Institutions play an essential role in environmental instruments implementation and environmental management. The Savusavu Tourism Association (STA) for example could be an institution that can focus on promoting or implementing environmental instruments to benefit the Savusavu tourism industry. Institutions can have the power to provide a means of defending and advancing environmental issues at local and government level decision-making processes (Winfield, 2016).

The creation of Protected Areas (PA) and Marine Protected areas (MPA) are forms of institutional instruments. Within the parks various other environmental instruments can be applied like user fees, voluntary fees and public education instruments. Parks can evaluate and monitor their progress in achieving sustainability goals. PAs provide socio-economic gains, health benefits, carbon sequestration and watershed protection (Sims, 2010). PA's provide recreational experience for tourists and at the same time a conservation method (Eagles, 2002; Nepal, 2000). Parks also create employment opportunities and provide a means of conservation for local resources. Creating a park would create education opportunities for guests and the individuals planning and managing the park (Eagles, 2002). Therefore, a PA as an instrument can have multiple benefits because of the management and conservation opportunities that are available inside the park after it's created.

Creating a PA or MPA is a large scale task that requires many resources. The creation of a park needs a high level of governmental support, funding and natural resources. Parks also require communication and co-operation amongst the involved stakeholders as parks can occupy lands used by local communities (Indrawan et al., 2014). Other issues related to parks include the mismanagement of the park itself. If marks are not managed appropriately they can face many issues. The role the state plays in the institution can also be an issue seen in the management of parks, by limiting or controlling what the park can do. Parks are not easily managed and required constant monitoring and planning (Adam and Hutton, 2007; Eagles, 2002).

Parks can face barriers of sustainable tourism. For example, Kruger National Park in Africa faces extreme political pressure to provide benefits and opportunities for neighboring communities and to be more accessible to the local population. However, attracting larger numbers of visitors can threaten the park's tourist capacity and sustainability (Ferreira \& Harmse, 2014). The establishment of a PA and MPA 
would be a large scale instrument. This may be appropriate for a destination with the available resources and space. However, small size and resource scarcity are issues SIDS face so this instrument likely would not be effective in Savusavu.

\subsection{Environmental Instrument Implementation}

The following section discusses literature on the actual implementation of environmental instruments. The tourism literature relevant to policy implementation is diverse and fragmented. There are few attempts to provide lessons for proper new policy implementation (Krutwaysho \& Bramwell, 2010). With the diverse set of approaches to instruments tourism managers need to ask themselves what instrument will work best for the destination and its goals (Bocking, 2016). Although some policy makers would claim that the only objective of environmental instruments is to protect environmental quality (Keohane et al., 1998), the decision to what instruments to use is more complex, involving economic and social factors (Hahn \& Stavin, 1992).

Winfield (2016) suggests choosing instruments to address a given problem or goal based on the instruments' effectiveness, efficiency and distributional fairness. Effectiveness asks, will the instrument actually produce the desired outcomes and when will they be produced? The time it takes for goals to be achieved by the instrument needs to be considered (Han and Stavin, 1992; Winfield, 2016). Efficiency of an instrument involves how much it will cost to implement the chosen instruments. Costs associated with instrument implementation may need government support which will impact the selection process. Governments usually have competing demands and limited resources so they may look for the cheapest method even though it may not be the most effective (Dodds, 2007; Hahn \& Stavin, 1992; Winfield, 2016). Few studies comment on the actual funding of policy change. Government funding is the main method seen (Rodriguez et al., 2014). Distributional fairness considers the distribution of the costs and benefits of a given strategy. "It asks if the strategy consistent? The strategy should not cost vulnerable sectors of society or misappropriate the benefits" (Winfield, 2016, p. 84).

There is little research on the actual selection of environmental instruments. Logar (2010) conducted a study that examined 8 different instruments for the case of Crikvenica, Croatia. This is one of few studies that actually showed a process of selecting instruments. The researcher identified the dominant negative tourism impacts. Instruments were assessed on mitigating the outlined problems. The researcher then evaluated the instruments acceptability to stakeholders and their economic feasibility (Logar, 2010). The study concluded that for sustainable tourism development economic 
instruments play an important role. Other lessons learned from this study was that the effectiveness of an instrument is crucial for its introduction, but the level of its acceptance among various interest groups should also be taken into account before implementation. "Public acceptance needs to be considered as a best practice for instrument selection and implementation as many instrument can reach the same objective but they will not be accepted" (Logar, 2010, p.16). This study intends to add to the literature where multiple instruments are considered for selection.

\subsubsection{Importance of Public Participation}

Public participation for environmental instruments is an important determinant of effective implementation. Public opposition and lack of knowledge is a widely cited barrier when trying to address environmental challenges found in the literature (Cherry et al., 2012; Dredge \& Jamal, 2015; Hall 2011). The involved public may not accept a new instrument because they do not know what it is being used for. The public may not anticipate the benefits that will be produced and reject the instrument intended to improve a destination. There is a lag in public value and interest in tourism planning and a lack of education. The planning of tourism is complex and involves many disciplines and relates to why there can be public opposition to changes in policy (Dredge \& Jamal, 2015).

Informed participation of stakeholders is an integral step in better understanding how to minimize the negative impacts while maximizing the positive impacts (Byrd et al., 2008; Cardenas et al., 2015; Hall, 2010). Therefore, public participation and stakeholder involvement is supported as a best practice for the implementation of new environmental instruments (Liu et al., 2012; Krutwaysho \& Bramwell, 2010; Waligo et al., 2013; Wang \& Ap, 2013). Sher et al., (2015) conducted a study to examine the influence of community attachment and community involvement towards sustainable tourism development. They found that community attachment and community involvement are to be focused on in order to gain support from local residents in developing sustainable tourism (Sher et al., 2015). However, issues can arise by having everyone participate if some are just looking for personal gain versus the best result for the commons (Waglio et al., 2013). The literature demonstrates putting a focus on acknowledging the society in which the tourism policy implementation is taking place. It is important to recognize local players, national players and NGOS in the implementation of new innovative policy for tourism (Rodrigues et al., 2014). 


\subsection{Conclusions / Research Gaps}

The literature review began with an overview of Tragedy of the Commons and an analysis on Governing the Commons and Stakeholder theory. These theories will support this research as they recognize the multi dimensions that exist within tourism planning and the importance of natural resource management for sustainability. These theories defend that it is important to take into consideration social, political, economic and environmental factors when trying to plan and manage tourism appropriately for the benefit of all stakeholders involved. They also support collective management and stakeholder involvement in proper planning and their application to tourism is believed to be beneficial for this study.

This literature review examined a variety of studies and findings related to sustainable tourism. By reviewing the literature this research explored the true meaning of sustainable tourism and what it means for this study using concepts from the WTO (2015). Tourism's role for island destinations was analyzed. From the literature it was seen that tourism plays a major economic role and community development role for the case of SIDS. However, the benefits seen in the literature are only realized and sustained if a form of sustainable tourism exists. Main barriers in the literature for island's developing sustainably were: lack of knowledge, lack of funding and resources, varying politics and self-motivations of the stakeholders involved. Authors have put forth methods and ideas to overcome these barriers, but sustainable forms of tourism still exist. This study will attempt to use environmental instruments to promote sustainability for an island destination.

The various forms of environmental instruments were examined. The majority of the research is focused on incentive based instruments, which rely on economic gains and provide more flexibility to traditional regulatory style policies and instruments. Instruments that are defended as effective involve high levels of government support and require the most resources: knowledge, funding and power to implement. While the less effective, instruments require less funding and monitoring. However, the impacts of some instruments are difficult to measure and their true effectiveness is not yet known. Each instrument has its own strengths and weaknesses in addressing environmental issues. The instruments are not mutually exclusive and can be used in combination to overcome their individual weaknesses.

The literature shows that managers are capable of identifying environmental problems associated with tourism. The issue remains with how to address these issues. How can managers implement the necessary instruments and make changes to tourism policy? It is still unclear how to 
determine what instruments are best suited to be implemented in a certain scenario because of the lack of research on this actual selection process. There is a lack of research where all instruments are considered for a destination and the best possible method is chosen. Most of the related research focuses on one method and tests its effectiveness in an area without an explanation as to why this one was chosen for the destination. What is shown in the literature as potential best practice was the importance of stakeholder involvement and education. These themes are apparent throughout the majority of the literature. 


\section{Chapter 3: Case Study}

This chapter describes the research setting of the thesis, which took place in Savusavu, Fiji, a coastal town located on Fiji's Vanua Levu Island. This section describes Fiji's environmental, economic and social characteristics as well as a discussion surrounding Savusavu's tourism industry and stakeholders. This information is provided to give context to the discussion of the thesis.

\subsection{Fiji}

Fiji is an island nation dispersed over 1.3 million square kilometers in the South Pacific Ocean. This archipelago is comprised of more than 332 islands and 500 islets that scatter the Koro Sea and have a total area of 18,270 square kilometers (World Atlas, n.d). The islands of Fiji are known for their white sandy beaches, exotic flora and fauna and their warm climate. The archipelago can be found between 17.713371 degrees latitude and 178.065033 degrees longitude (McCoy, 2003). Geographically Fiji has four divisions, which are the Central, Northern, Eastern and Western divisions and one dependency, Rotuma. The four divisions make up 14 provinces and within the provinces are cities, towns and villages. Suva, being the capital of Fiji, is found on the main island, Viti Levu (Fiji Bureau of Statistics, 2017). Figure 4 below is a map of Fiji. 


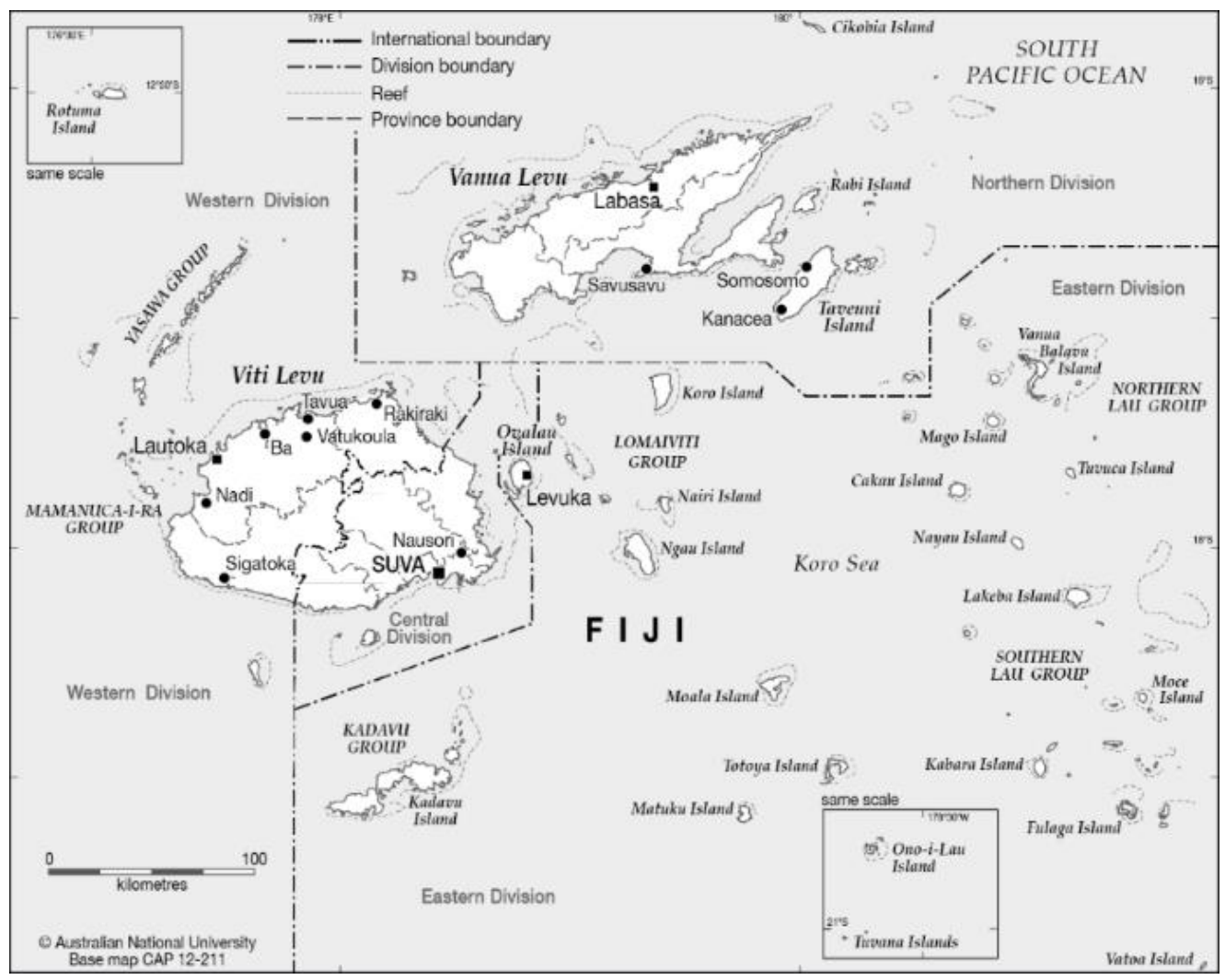

Figure 5 Map of Fiji, from http://asiapacific.anu.edu.au/mapsonline/base-maps/fiji

The Fijian population was estimated at 915,303 in 2016 (Fiji Bureau of Statistics, 2017). The two major islands, Viti Levu and Vanua Levu, account for $87 \%$ of the population. The ethnical makeup of the population is estimated to be $56.8 \%$ iTaukei (Indigenous Fijians), $37.5 \%$ Indian, $1.2 \%$ Rotumans, and 4.5\% is other, which is a mix of European, part European, other Pacific Islanders and Chinese ( Fiji Bureau of Statistics, 2017). Fiji is considered a plural society because it consists of different ethnic groups with diverse culture and multiple access to civil and political rights (Harrison \& Pratt, 2010). The sundry makeup of the society is a result of its history.

Fiji is a member of international organizations such as the United Nations (UN), the World Trade Organization (WTO) and the Pacific Islands Forum. Fiji has bilateral and multilateral relationships with other Pacific countries, which has resulted in the participation in the Melanesian Spearhead Group Trade Agreement (MSGTA), the Pacific Islands Countries Trade Agreement (PICTA) and the Pacific Agreement on Closer Economic Relations (PACER) (Harrison \& Pratt, 2010; United Nations, 2014). 


\subsubsection{History and Culture}

The first settlers of the Fijian islands arrived 3,500 years ago. Tonga, an island nation North of Fiji was home to the Tu'I Tonga Empire. It is believed that the people of this empire were led by a chief named Lutunasobaso and settled on the islands of Fiji to expand their empire (Namena Marine Reserve, 2015). Different groups of Austronesian people, like Melanesians and Polynesian are believed to have followed (Jean-Michel Cousteau Resort, n.d). Due to the diverse cultures of settlers many different customs and languages were brought to Fiji, creating a diverse and unique population.

The first European contact was in 1643 when Dutch navigator, Abel Jansen Tasman discovered the islands now known as Fiji. Tasman described the island's waters as being unnavigable due to the amount of corals, islets and shallow waters. Tasman's interpretations of islands discouraged further exploration (Williams and Calvert, 1860). In 1774 Captain James Cook and English navigators travelled to the islands; however, due the geography and fear of the Fijians, who were said to be savage cannibals, Cook and his navigators did not settle on the island (Namena Marine Reserve, 2015). The first settlers did not arrive until a shipwreck of Australian convicts reached the islands in the beginning of the 1800's. These convicts were the first to live with the Fijians.

Later, more immigrants arrived from Britain who slowly started to populate and control the islands (Williams and Calvert, 1860). Sir Arthur Gordon of Britain set up a native administration that allowed Fijians to participate with governance. Communal lands were protected and land could not be bought by non-Fijians. Plantations and the sugar industry successfully grew, however, due to a shortage in labour on the plantations, Indians were imported as workers. This added another dimension to Fiji's diverse population and by 1916, there were over 60,000 Indians living in Fiji. It wasn't until October $10^{\text {th, }}$ 1970 when Fiji became a self-governing nation and independent from Great Britain. Fiji is now a multicultural country and is one of the leading island nations of the South Pacific (Namena Marine Reserve, 2015).

Traditional Fijian society follow a hierarchy, where chiefs are leaders and status is descended through males and structured as a feudal aristocracy (Namena Marine Reserve, 2015). There are still cases of traditional Fijian communities such as the Kubulau in Savusavu who hold power over lands and knowledge. Fijian culture is tied to the ocean and marine life and is known for its ocean canoes, tapa clothes, pottery, plaited mats, music, dancing and having strong beliefs in religion and lineage. Fiji's official language is Bau along with English and Hindustani (Fiji High Commission, n.d). 


\subsubsection{Political Setting}

The Republic of Fiji is a parliamentary democracy consisting of a president as head of state and a prime minister as head of government. The current president of Fiji is Major General (Ret'd) Jioji Konusi Konrote and the current Prime minister is Hon. Frank Bainanmarama. The Prime Minister is responsible for strategic matters such as defense, natural resources and finance (Fiji Government, 2014).

Fiji's constitution has three separate arms of government - the Legislature (or Parliament), the Executive, and Judiciary (Parliament of the Republic of Fiji, n.d). The Legislature, as of 2013 is unicameral, consisting of an elected House of Representatives and an appointed Senate. The House of Representatives was previously reserved for ethnic Fijians and a small reservation for some ethnic groups but now members are directly elected in a nationwide vote (Common Wealth, n.d). The Legislature makes the laws, represents the community in discussions about issues that affect them, investigates issues of importance to the community and scrutinises the actions of government (Common Wealth, n.d; Parliament of the Republic of Fiji, 2017). The Executive is the administrative arm of government run by the President and is responsible for putting into operation the laws passed by Legislature and administering the programs and services that are delivered by Government. The Judiciary is the legal branch of government responsible for interpreting and enforcing the laws of Fiji (Common Wealth, n.d).

Fiji has undergone four coups that led to political and economic instability amongst the nation (Harrison \& Pratt, 2010; Narayan, 2005). The first two coups were carried out by Sitiveni Rabuka, an army officer in 1987. The coups were a result of native Fijian's concern that the government was perceived to be dominated by the Indian community. The first coup occurred in May and the other four months later in September. The coups resulted in the formation of a military government and changed the Constitution to reinforce the supremacy of Indigenous Fijians. These changes led to an emigration of the Indian population and economic difficulties (Common Wealth, n.d; Central Information Agency, n.d).

In 1997 the government was enacted and elections in 1999 resulted in an Indo- Fijian led government. Due to the formation of a new government, the third violent coup occurred. In May 2000, armed Indigenous Fijians overthrew the newly elected government from 1999. They did so by occupying the parliament building and taking about 40 hostages - including the prime minister at the time, Fiji Labour Party leader Mahendra Chaudhury. Following negotiations between the army and the rebels, a new civilian president and 'emergency' government were appointed and backed by the military. The 
coup leaders were then arrested by the military, led by Commodore Bainimarama, to form an interim government. In March 2001the Soqosoqo Duavata ni Lewenivanua Party (SDL), were elected and remained in power until 2006 (Common Wealth, n.d; Narayan, 2000).

The May 2006 election was once again won by the SDL. In December the fourth coup occurred when the army took control of the government and dismissed the prime minister and the president. The head of the army, Commodore Voreqe Bainimarama assumed presidency. The coup was immediately denounced by the international community. In January 2007 Bainimarama reinstated the president SDL president and became interim prime minister. As a consequence, Fiji was suspended from the regional Pacific Forum and, on September $1^{\text {st }} 2009$, from the Commonwealth of Nations - which it had rejoined only in 1997 after its membership had been withdrawn on becoming a Republic in 1987. In 2014 a credible election was conducted and Bainimarama was re-elected (Common Wealth, n.d).

Although the coups occurred at different times and under different circumstances the ideology of race and ethnicity were constant themes throughout all four. One of the most affected industries from the coups has been Fiji's tourism industry. The coups in 1987, 2000 and 2006 resulted in decreased visitor numbers in the following years and a downward growth in tourism in general (Harrison \& Pratt, 2010; Narayan, 2005). This political instability has also deterred foreign investors from Fiji. The coups therefore have not allowed Fiji to reach its full potential in economic growth.

\subsubsection{Economy}

Despite the political instability and social tensions Fiji has one of the most developed economies in the Pacific. Tourism, agriculture, gold-mining, fishing and timber production the main markets of the Fijian economy (Fiji Bureau of Statistics, 2017; High Commission of Fiji, n,d). Fiji has a narrow resource base and depends on sugar exports as the main source of foreign exchange and employment. Coconut trees and their products (water, sugar, husk and timber) account for $30 \%$ of Fiji's GDP and most smallscale farmers are dependent on coconuts for their livelihoods (United Nations, 2014). Other agricultural products include cassava, rice, sweet potatoes and bananas. The fishing industry is also a major economic pillar, which includes offshore fisheries of albacore, yellowfin, big eye and skip jack (United Nations, 2014).

In recent years, however, the tourism industry has grown rapidly to become the largest foreign exchange earner, surpassing the traditional sugar exports (Narayan, 2005) .Tourism of the Pacific has recorded a 5\% increase in tourist arrivals from 2014 to 278 million tourists. The World Bank reported 
that Pacific Island Countries received 1.37 million overnight visitor arrivals in 2014, a record number. The five most popular destinations in order of visitor arrivals were Fiji, PNG, Palau, Samoa and Vanuatu. Fiji received 100,000 more than the other top 10 countries combined. Two thirds of the market for the Pacific Island countries are visitors from Australia and New Zealand (World Bank, 2014). Fiji's annual number of visitor arrivals reached 754,835 in 2015, which is a 9\% increase from the 692,630 in 2014 (Fiji Bureau of Statistics, 2015). Fiji's tourism industry also directly supports 41,500 jobs ( $12.3 \%$ of total employment). This is expected to rise by $4.0 \%$ to 61,000 jobs (16.3\% of total employment) in 2025 (Fiji Bureau of Statistics, 2015).

\subsubsection{Current Tourism Development}

With a growing industry Fiji developed a new national tourism plan and is involved with other international developments. Fiji's policy settings operate with a range of different international lines including the 2015 UN Sustainable Development Goals and the 2030 Development Agenda, the 2014 SAMOA Pathway concerning development for small island developing states (SIDS), and the UNEP 10YFP for Global Action on Sustainable Production and Consumption . In addition, specifically related to tourism, the South Pacific Tourism Organization (SPTO) has a strategy to build capacity in the region on sustainable tourism (Fiji Bureau of Statistics, 2016). All of which influence its current tourism development.

The Fiji Tourism Development Plan for 2021 was developed by the Fijian Hospitality and Tourism Association and was just released in February of 2017 (Government of Fiji, 2017). The plan has a target of achieving a 2.2 billion dollar industry by the end of 2021 and to:

1) Catalyze visitor expenditure and tourism yield;

2) Create a conductive environment for sustainable increase in visitor arrivals;

3) Support development of a sustainable and inclusive tourism sector. (Government of Fiji, 2017, p.3)

The plan intends to address the fundamental issues facing the continued development of the Fijian Tourism industry over the next 5 years. Nine thematic areas are identified in the plan that the government feels are essential for the foundation of Fiji's rapidly developing industry. The first is to drive the demand for the tourism brand. The objective of this strategy is to ensure that Tourism Fiji effectively market's Fiji and to maximize the return on Government's investment with regards to Tourism Fiji's marketing grant. This grant is used to financially support marketing of Fiji to tourists groups such as the retired population and the Asian market (Government of Fiji, 2017). Second is to 
increase the value of the tourism products. This strategy is to grow the value of the industry by improving the quality of Fiji's tourism product offerings. This is a long term strategy to ensure that Fiji becomes a premium tourist destination in the South Pacific. Third is to facilitate and promote foreign and domestic investment in tourism. The objective of this strategy is to ensure that appropriate investments are realized in the tourism sector in Fiji and that Fiji has sufficient capacity to cater for the increasing accommodation occupancy levels. Forth is to invest in tourism related infrastructure. Examples include improving airports and improving water supply in areas like Savusavu to enhance the growth of the industry. Fifth is to strengthen linkages to the tourism industry. The objective of this strategy is to strengthen the linkage of human resource supply to tourism. For example, a special grant scheme will be administered by the Government for Fijian farmers dedicated to supply the tourism sector. The grant can assist in purchasing seedlings and farming implements and will be managed in partnership with the Ministry of Agriculture. Sixth is to ensure continued sustainable development of the tourism industry. The objective of this strategy is to ensure that protection of the reef and marine areas are mandated by Government. The government planes to engage in protection of reef and marine areas. A policy response is required to develop new legislation to better protect the marine environment. A pilot project is suggested, where a marine protected area will be created in the Mamanuca Islands, in association with the Mamanuca Environment Society. Seventh is to have a conducive and updated legal framework. Eighth is to improve risk management and ninth is to measure the performance of the industry (Government of Fiji, 2017). The strategy discusses many instruments, frameworks and possible new policies, however this is a new plan and major changes have not yet been seen.

The plan does illustrate however that Fiji is preparing for tourism development and identifies some of the instruments currently in place. For example, the plan outlines that it will make the already existing EIA process stronger and mandatory in Fiji. Therefore, there is already and EIA process but it is likely weak and not producing desirable outcomes. The plan also discusses feasibility studies that have been carried out to indicate whether there is room for expansion of the Labasa and Savusavu airports. The reports indicate that there is no room in the current locations. The remaining option for further developing access into Vanua Levu means construction of a new International Airport for the region. Therefore, the government is planning on developing a new airport for the island of Vanua Levu, where Savusavu is located. Another current regulation is the Environmental and Climate Adaptation Levy. The Environment and Climate Adaptation Levy is a charge on plastic bags. The levy must be collected by a 
cashier at the point at which a plastic bag is provided by the business to a consumer. The money from the levy is used to fund various environmental and climate adaptation projects (Government of Fiji, 2017).

The Green Growth Framework for Fiji of 2014 also underscores the national policy's intention to promote sustainable tourism practices. The Green Growth Framework for Fiji is "a tool to accelerate integrated and inclusive sustainable development that inspires action at all levels in the country to build environmental resilience, build social improvement and reduce poverty, build economic growth and build resilience to the anticipated adverse effects of climate change" (Government of Fiji, 2014, p. 7). The framework provides several environmental instruments and policy suggestions to be carried out in Fiji to promote sustainable development. For example creating a Revenue Policy. The framework suggests taxing unsustainable behavior and incentives to assist green industries. Other initiatives include reviewing building codes to ensure that buildings are constructed in a manner to be cyclone proof. Improving local knowledge on sustainable tourism and climate change are other items the framework highlighted as important (Government of Fiji, 2014).

An example of an international project Fiji is a part of concerned with sustainable development is the UNDP's Ridge to Reef program. The Ridge to Reef program incorporates 14 Pacific island countries and is supported by a grant of $\$ 7.4$ million from the Global Environment Facility (GEF). It aims to preserve biodiversity and ecosystem services, sequester carbon, improve climate resilience and sustain livelihoods through a ridge-to-reef management of priority water catchments on the two main islands of Fiji. The goal of the project is to maintain and enhance Pacific Island countries' ecosystem goods and services through integrated approaches to land, water, forest, biodiversity and coastal resource management that contribute to poverty reduction, sustainable livelihoods and climate resilience (Global Environment Facility, n.d).

\subsubsection{Environment}

The island nation formed roughly 150 million years ago through volcanic activity. The larger islands like Vanua Levu have a mountainous landscape with dormant and extinct volcanoes whereas the tropical marine climate of the nation has little variation. The mountains cause orographic rainfall that create wet (November - April) and dry (May - October) seasons. The island has rainforests, mangrove forests, sea grass beds, lagoons, estuaries, oceanic reefs and deep oceanic drop-offs (Fiji Meteorological Service, 2006). Fiji contains $3.12 \%$ of the world's coral reefs including the third largest reef in the world, 
the Great Sea Reef. There are 400 recorded species of coral and 1,200 fish species and invertebrates. The island is home to many rare and endemic species like the bump head parrot fish and the fruit dove (Finau, 2011). The most abundant fish include the delicate round herring, the luminous cardinalfish and the spotted (World Wildlife Fund, 2015).

Fiji is a small island that contains a considerably small population, however it faces many environmental issues. These issues have altered marine and terrestrial environments effecting ecosystem processes. Current environmental issues of Fiji include:

- soil erosion;

- habitat destruction caused by development activities;

- threats of climate change;

- coral bleaching;

- unsustainable fishing practices (explosives, night spear fishing and modern and traditional poisons for fishing)

- introduction of invasive alien species;

- run-off from pollution;

- sewage discharge from urban areas;

- siltation due to dredging;

- illegal fishing (Marine turtles being hunted for their shells and meat, small tropical fish collected for the aquarium trade) (Fiji High Commission, n.d;World Wildlife Fund, 2015)

\subsection{Savusavu}

The study area for this thesis is Savusavu, a town in the Province of Cakaudrove, located on the island of Vanua Levu, Fiji. Vanua Levu is the second largest island of Fiji with an area of 5, 556 square kilometers (Fiji High Commission, n.d). Vanua Levu has a tropical marine environment and a central mountain range with an elevation of 3,386 feet. The range divides the island into the southeastern and northwestern sections. Savusavu is located on the south coast of Vanua Levu in Savusavu Bay. The island is accessible by ferry, flight or boat from Nadi and Suva located on the main island. Savusavu's history is known for being the trading center of sandalwood, beach de-mer and copra (Fiji Travel, n.d). Sugar cane and coconut tree plantations have long been the main economic driver of the island. There is now a focus on developing and improving the tourism industry. The island is being advertised as the "hidden paradise of Fiji" as it is not as popular as the main island, the Mamanoucas Islands or the Yasawa Islands. 


\subsubsection{Savusavu Tourism Industry}

Savusavu has many attractions that can appeal to a wide variety of travellers. Savusavu offers diving, snorkelling, hiking and fishing for adventurous tourists. In addition to the coral reefs that fringe the islands, there are also circular or U-shaped coral atolls and coral barrier reefs that encircle large coastal lagoons. Sun, rest and relaxation are also possibilities as there are five-star luxury resorts such as the Jean Michael Cousteau resort and the Namale resort. Savusavu Bay is a popular yachting destination. Indigenous tourism also plays a role in Savusavu's tourism industry because Savusavu is home to many indigenous communities like the Nakubuluva people. Resorts pattern with local communities and provide excursions to the villages, thus, giving tourists the opportunity to participate in song and dance with the local community while engaging in experiences such as storytelling and the Indigenous Fijian culture.

The downtown core of Savusavu has multiple dive shops and tour operator offices available four tourists to book experiences. The Copra Shed Marina located at the heart of the Savusavu is a staple of the town. The Copra shed was once used to extract coconut oil from dried coconut kernel (copra) and then the extract was sent to the main island. The shed was situated on the coast of Savusavu giving it a prime location to ships and easy access for transportation. Now, the Copra Shed has been transformed into a marina with restaurants, gift shops, tour operator offices and home to the Savusavu Yacht club. Another landmark of Savusavu is the farmer's market, which is located just down the street from the Marina. This roofed market is where farmers come to sell their products. Tourists and locals can visit the market and buy local Fijian vegetables, fruits, eggs, spices and flowers. Outside of the downtown core are private accommodations available for long term and short term rentals, bed and breakfasts, Air BnB rentals and beach house rentals are all available options for tourists. There are also dorm style rentals properties available for backpackers.

\subsubsection{Stakeholders of Savusavu}

Stakeholders are groups or individuals with whom a destination interacts or has interdependencies with and who can be affected by actions, decisions, policies, practices or goals of the destination (Carroll \& Bushholtz, 2003; Grimble \&Chan, 1995). For this research a stakeholder is defined as any group or individual who can affect or is affected by changes to the Savusavu tourism industry. Stakeholders have been grouped in the literature based on commonalities relating to how they manage or are affected by the tourism industry. Figure 5 below is a map outlining the stakeholder groups that 
were customized for this study. These groups include: operators, business owners, regulators, locals and tourists. Chapter 4 provides a description on how these groups were chosen.

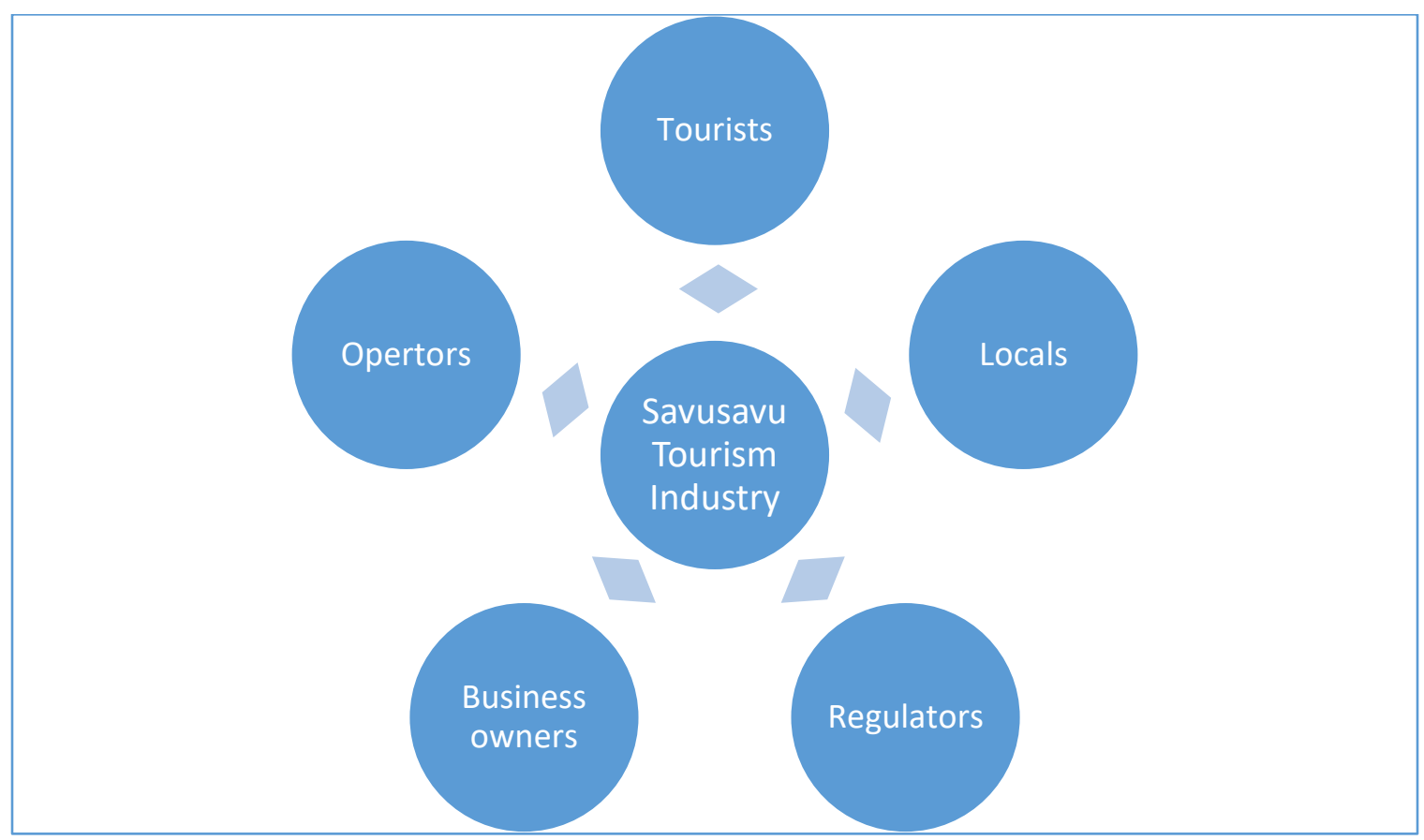

Figure 6 Map of Savusavu stakeholder groups

Each group's actions, decisions, opinions, goals and values are considered important for this research. This research also considers the fact that each group's members may not have the same opinion or interests. The stakeholder groups of the study are defined below.

- Tourists: Individuals visiting Savusavu for non-work related purposes and those who do not live on the island. Those visiting friends and relatives are also placed under this category.

- Locals: Those who currently reside in Savusavu for at least 1 year. In the literature, locals are anyone who lives in the study area (Hardy \& Benton, 2001). However, for the case of Savusavu many expats and retired Australians, Americans and New Zealanders live in Savusavu for several months of the year. They own vacation homes and are considered tourists not locals.

- Regulators: Individuals who take part in the management or play a governing role in Savusavu. Savusavu town council members, government employees and chamber of commerce members are examples of those grouped amongst this category. Government is a group seen in many studies however the researcher was not able to interview government members.

- Business Owners: Individuals who own and operate a business.

- Operators: Employees who play a managerial role for a business. They are operating the majority of the actions of the business but do not own it. 


\subsection{Conclusions}

While Fiji is a considered to be a well-developed economy and tourism industry, Savusavu is still a developing tourism destination. The case study area relies heavily on the state of the natural resources for the success of their tourism industry and faces similar challenges seen for SIDS. If the natural resources are not managed in a collective manner by the stakeholders of the area, they will likely end in tragedy as discussed in Hardin's tragedy of the Commons. Therefore, the success and management of Savusavu's tourism industry is imperative for the livelihoods of the local community. The following chapters present the methodology, the data analysis, a discussion and the recommendations for the study. 


\section{Chapter 4: Methodology}

The purpose of this chapter is to outline the research methodology used to explore environmental instruments to promote sustainable tourism in Savusavu, Fiji. The research employed face-to-face, semi-structured qualitative interviews with stakeholders in the Savusavu community to reach the objectives of this study. The data collected was analyzed and determined the recommendations for the study.

\subsection{Purpose and Objectives of the Study}

The purpose of this research is to recommend environmental instruments to implement in Savusavu to promote sustainable tourism. The research is intended to build on the knowledge of sustainable tourism development specifically for small island states and the application of environmental instruments as a means to promote sustainability. To do so the following objectives are outlined:

1. Review the current literature on sustainable tourism development and environmental instruments and their implementation;

2. Conduct stakeholder interviews to determine the key issues Savusavu faces in becoming a sustainable tourism destination and the goals of the destination;

3. Use information from the literature review and the stakeholder interviews to identify the environmental instruments that can be recommended for implementation in Savusavu;

\subsection{Research Methods}

This research is considered social research as it uses a combination of principles and ideas with a collection of strategies to produce knowledge on sustainable tourism (Neuman \& Robson, 2012). "Social research involves thinking scientifically about questions about the social world and following scientific processes" (Neuman \& Robson, 2012, p.2). This research follows a scientific process to make recommendations on what environmental instruments can promote sustainability for the tourism industry of Savusavu. To do so a sequence of steps were used and outlined in this section.

This research is applied and exploratory. It is applied as it addresses a specific concern and offers a solution to a problem. The problem being unsustainable tourism development for the island destination of Savusavu and the possible solution of recommending environmental instruments that can promote sustainable development. The research is exploratory as it became familiar with the research setting and generated new ideas of recommendations for Savusavu, Fiji. 


\subsubsection{Case Study Approach}

The research is a case study. Case studies examine an individual instance and is often a popular method used in social research. Case study research involves an in-depth analysis of many features over a period of time. The data collected is usually very detailed, diverse and extensive. It is usually in qualitative form (Neuman \& Robson, 2012). The aim of a case study is to concentrate on one instance where insights could be gained, which would not likely be gained in a mass study. Even though case studies focus on one specific location, insights gained from a case study can sometimes have wider implications. For this case study the researcher conducted an in-depth analysis of the tourism industry of Savusavu. The research took place on site. Findings and lessons learnt from this one case could be applied to other small island destination states.

\subsubsection{Qualitative Versus Quantitative Research}

Research usually takes on a qualitative or quantitative form. Quantitative research involves testing a hypothesis. The research process usually follows a linear approach and there is an emphasis put on measuring variables and testing hypotheses that link general casual explanations. "The measures are usually systematically created before the data is collected and standardized" (Neuman \& Robson, 2012, p.82). For quantitative research, the researcher looks for specific answers to research questions using numbers (Neuman \& Robson, 2012).

Qualitative research is more exploratory in nature and the research discovers meaning once the researcher has become immersed in the data. Qualitative research use a nonlinear path, where steps are successive but can move backwards and forwards. Researchers create measures in an ad hoc manner and are usually specific to a research setting. Qualitative research involves data in the form of words, observation and transcripts (Denscombe, 2014). Qualitative data collection can include focus groups, field research and interviews. After the primary data collection, research questions are sometimes adjusted and shaped to address the most important issues that may not have been known previous to commencing the study (Neuman \& Robson, 2012).

For this research qualitative research techniques were used to discover what environmental instruments can be implemented in Savusavu to develop a sustainable tourism industry. The measures to do so were not exact or created to test instruments. The research used qualitative interviews in to create recommendations for the island destination. 


\subsubsection{Interviews versus Questionnaires}

Interviews are a commonly used method of qualitative data collection. Qualitative interviews can "gain an in-depth understanding of the meaning of a social phenomenon from a selected group of people" (Neuman \& Robson, p.19, 2012). The use of qualitative interviews results is a set of highly detailed data from the perspectives of the interviewed individuals. They do not restrict the amount of data an interviewee can provide to answer a question, as for the case of questionnaires. During the interview the interviewer asks questions, listens and records what the interviewee said. The interviewee states their insights and feelings to reveal subjective meanings in the discussion (Neuman \& Robson, 2012). Interviewers are to remain neutral and objective. This process allows the researcher to see the world from the perspective of the interviewee.

Qualitative and quantitative data collection use questionnaires. While questionnaires are effective as they are usually sent out to a large number of respondents without having to make any contact with them, they also have their disadvantages. It is not a guarantee that the respondent will answer all the questions or even return the questionnaire. The researcher is not there to clarify questions for respondents. The researcher also cannot control the environment in which the respondent answers the questions. The surroundings of the respondent can influence their responses and they may not provide truthful or valuable answers (Neuman \& Robson, 2012). For these reasons, questionnaires were not used for this study.

\subsubsection{Interview Styles}

There are many styles of interviews that a researcher can choose to implement for their study. One-on-one interviews are the most common form of interview, where the researcher meets with one respondent, usually in a pre-determined place (Denscombe, 2014). They are common because they are easy to arrange and opinions are only shared from the one respondent. There are no other influences present. These interviews are easy to control and easier in terms of transcribing. The one-on-one interview can take on three forms; structure, semi- structured and unstructured.

For a structured interview the interviewer maintains control over the format of predetermined questions and limits answers (Denscombe, 2014). It is comparable to administering a questionnaire faceto-face. This type of interview structure gives an advantage of being "standardized", making data analysis easier and ensuring each interviewee receives the same questions. 
For unstructured interviews the interviewee's thoughts are the main focus. The researcher is unintrusive, and attempts to introduce a theme or topic to keep the conversation going to get as much information as possible (Denscombe, 2014).

For the case of semi-structured interviews the interviewer has a set of pre-determined questions but is still flexible. Interviewees can speak more widely on issues that are brought up by the researcher and can develop more ideas. Answers are open ended and the interviewee can express their opinions and points of interests (Denscombe, 2014). Interviewees can use their own words and thoughts for answers. This method allows a researcher to explore complex issues better and "discover" versus "checking", like in a structured interview. The study chose to use semi-structured interviews so that participants could express their opinions and not be limited by the questions asked.

\subsection{The Research Approach}

The following section outlines and describes the research methods used for this study. The study aims to identify environmental instruments the Savusavu tourism industry can use to promote sustainability. The design of the study is based on methods used in similar qualitative studies concerned with sustainability and tourism. The study considered ideas behind Ostrom's Governing the Commons and Stakeholder Theory to help shape the study. The study includes stakeholder perceptions to lead to some form of collective management of the tourism industry. The following phases, seen in figure 6 , describe the research process of this exploratory study. 


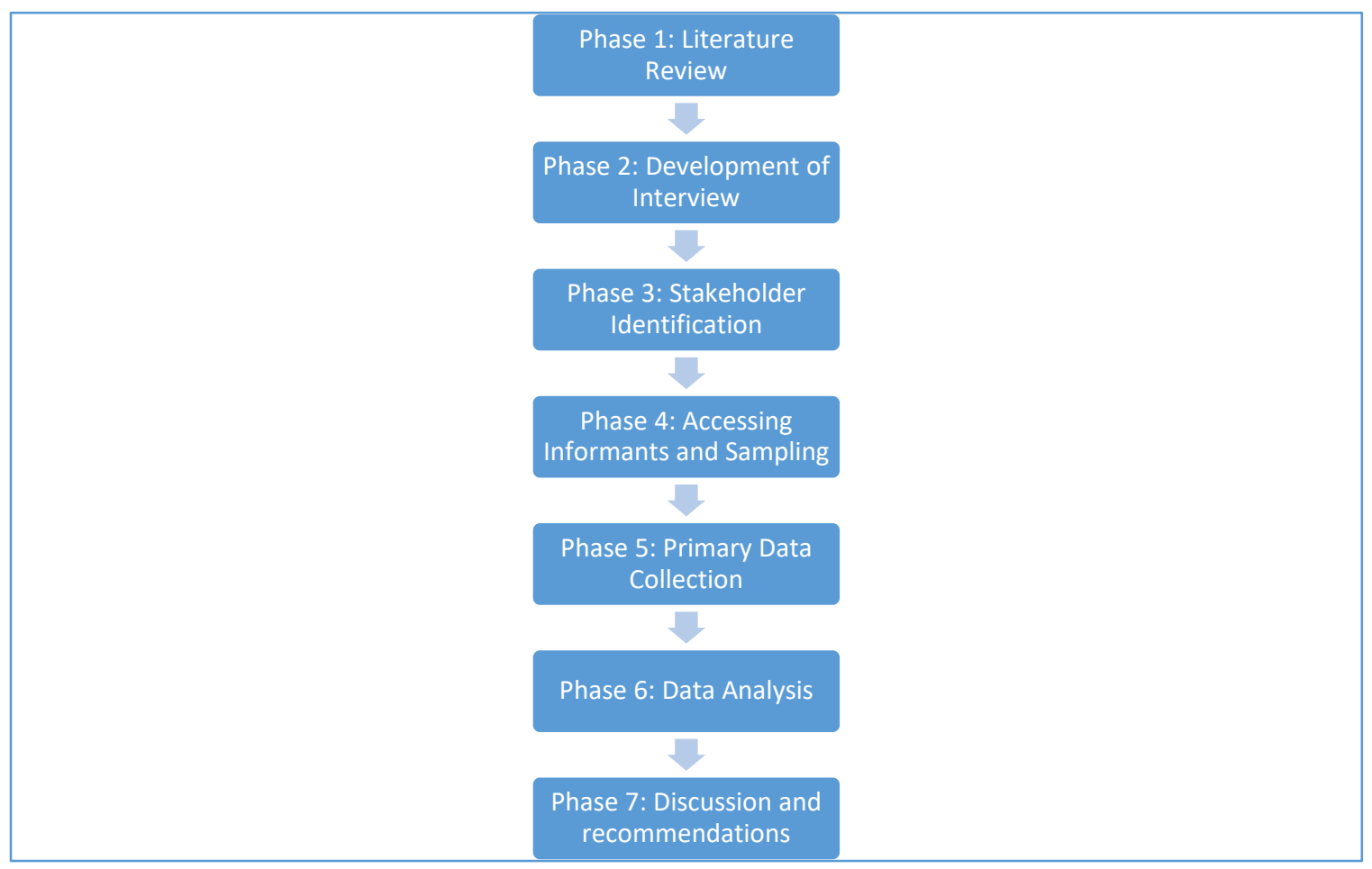

Figure 7 Phases of the research process

\subsubsection{Phase 1: Literature Review}

Phase one consisted of a literature review. The literature review informs a researcher on the current state of knowledge on a topic and gaps apparent in the knowledge they are reviewing (Neuman and Robson, 2012). The literature review occurred in the month of February 2016 and was continuously updated throughout the research process to gain an understanding on the current research findings and methods used in similar studies concerned with sustainable tourism and environmental instruments. Research on the ideas and issues surrounding sustainable tourism, small island tourism, environmental instruments and their implementation was done. The literature identified the gaps in the current state of knowledge on these topics. This phase reached the first research objective of this study. The literature is in Chapter 2.

\subsubsection{Phase 2: Development of Interview}

Phase two consisted of the development of the questions used during the qualitative interviews. Based on the literature review of similar studies face-to-face semi-structured interviews were an appropriate data collection technique. Graci (2013) conducted a study examining the barriers of sustainable tourism development on an in island in Indonesia. She used in-depth, semi-structured key 
informant interviews with twenty-six business owners and managers. This resulted in a 50 percent response rate. Berghoef and Dodds (2013) studied the interests of the members of the Ontario wine industry in an eco-labelling program with face to face interviews (Berghoef \& Dodds, 2013). Maxim (2016) used face-to-face semi-structure interviews as a means of data collection for his study to explore whether local authorities of London, England, implemented policies towards sustainable tourism. Faceto-face interviews capture the attention of the respondent and guarantee the order of the questions because the researcher is reading them out. If a respondent appears confused the researcher may be able to notice and explain its meaning (Neuman \& Robson, 2012). For these reasons the study employed face-to-face semi-structured interviews.

The researcher developed the interview questions in April of 2016. The first questions are introductory to relax the interviewee. The more complex questions are asked later in the interview. To see the interview questions please see Appendix 1 . The first section of questions gained an understanding of the stakeholder group the interviewee was part of by asking their role in the community and in the tourism industry. They were then asked questions related to what environmental resources they use, their issues, the benefits they provide and who owns them as this information is important for management of natural resources and identifying other stakeholders (Hardin, 1968; Grimble \& Chan, 1995; Wilkinson \& Salvat, 2012; Williston, 2012; Ostrom, 2015). They were also asked what they perceived as the major sustainability issues facing Savusavu. The questions intent was to identify the key issues of Savusavu which is the second objective of this study.

The second section of questions introduced environmental instruments and were used to identify current instruments in Savusavu. The questions asked respondents to identify which instrument(s) they want implemented and would be the most effective and accepted in Savusavu. The literature on instrument implementation concludes public acceptance and effectiveness are two major issues when implementing environmental instruments (Bocking, 2016; Dredge \& Jamal, 2015; Winfield, 2016). Asking individual stakeholders which instruments they accept and which they think would be effective and why could potentially overcome these barriers. The interview questions focused on popular environmental instruments from the literature review; education instruments, economic instruments, voluntary instruments and regulatory instruments. The third section of questions gained an understanding of how changes are currently made and funded in Savusavu. This was asked to better understand how new instruments could be implemented. 
Since the research involved human participants the researcher submitted an application for its ethics approval through Ryerson's Board of Ethics before any research took place. Once the research was approved in April 2016, the researcher piloted the interview in May 2016, with an individual who was part of the Savusavu tourism industry. Piloting the interview is an important step in the research process. Pilots are usually done with an individual who is similar to those targeted for the actual study. By piloting the interview you are verifying that you are asking meaningful, clear and important questions that will aid you to answer your research objectives (Neuman \& Robson, 2012). The researcher contacted the individual via email. A previous relationship was already established with the participant as one of the supervisors of this thesis, Dr. Graci, had interviewed them in the past for a different study in Savusavu. The interviewee owned two rental units and was a member of the STA, until they moved back to Canada.

The researcher and interviewee met at a pre-determined location, where the interviewer then introduced herself and the objectives of the study. The interviewer asked the respondent the questions from the interview. During the pilot test the respondent indicated whether the questions were clear and to express their interpretations to see if they understood the intended meaning. The researcher took detailed notes based on the feedback provided by the respondent. After the pilot interview, the researcher revised the interview questions immediately after to improve them. Major issues seen from the pilot was the definition sustainability was in terms of tourism and confusion on what environmental instruments were. To avoid this confusion the researcher defined each term in the introduction of the interview. Repetition seen in similar questions relating to who has power to make changes to the tourism industry. The interviewee only recommended minor changes and an additional ethical review was not needed.

\subsubsection{Phase 3: Stakeholder Identification}

Phase three identified stakeholders specific to Savusavu. Stakeholder groups were first identified based on reviewing the literature from similar studies using stakeholder analysis. Grimble and Chan (1995) define stakeholder analysis as "an approach and procedure for gaining an understanding of a system by means of identifying the key actors or stakeholders in the system and assessing their respective interests in the system" (p.1). The analysis identifies important stakeholders and their outlooks. Stakeholders are groups or individuals with whom a destination interacts or has interdependencies with and who can be affected by actions, decisions, policies, practices or goals of the destination (Carroll \& Bushholtz, 2003). The literature supports including the opinions of all stakeholders 
for decision-making related to tourism management and environmental policy instruments (Prell et al., 2009; Reed et al., 2009).

Studies applying stakeholder analysis to tourism planning and development identify the following relevant stakeholder groups to consider when trying to produce positive outcomes for tourism: residents, local businesses, activist groups, tourists, national business chains, competitors, government, operators and tourism organizations (Grimble \& Chan, 1995; Sautter \& Leisen, 1999). Groups are added or removed depending on the context under which the identification is taking place (Sautter \& Leisen, 1999). Stakeholders groups were customized for the research setting of Savusavu. The research used the reputational approach (Grimble \& Chan, 1995) to continue to identify stakeholders. The researcher used the head of the STA to identify stakeholder groups for this study. This study identified 6 groups: operators, employees, business owners, regulators, locals and tourists. The definitions each group is in Chapter 3.

Stakeholder analysis does have its limitations. One major weakness includes the tendency of stakeholder analysis to treat stakeholders as individuals who fit into one distinct stakeholder group or another. Many identified stakeholders can fit into one or more stakeholder groups depending on their level of involvement (Grimble \& Chan, 1995, Prell et al., 2009; Sautter \& Liesen, 1999). As well, different stakeholders may have large differences in their understanding of important issues that comparing their competing views and grouping them becomes quite challenging (Mitchell et al., 1997). For this research a respondent's primary stake and the "hat" in which they answered the questions of the interview was used to decide the group they were categorized under. These limitations were taken into consideration when making any conclusions or recommendations.

\subsubsection{Phase 4: Accessing Informants and Sampling}

Phase four gained interviewee access to create a sufficient sample of stakeholders to interview for the study. To gain interviewee access the researcher used multiple purposive sampling techniques. Purposive sampling are non-random sampling methods that specifically allows a researcher to use their judgement to target individuals who are of relevance to the research objectives (Sommer \& Sommer, 2002). The researcher is not required to randomly sample the entire population but targets necessary groups or individual stakeholders. This technique lets the interviewer conduct a large number of significant interviews when time is a constraint, like for the case of this research (Sommer \& Sommer, 2002). Individuals targeted for this research were the stakeholders of Savusavu. 
The research used key informants and snowball purposive sampling techniques to gain a sample size. Key informants are knowledgeable and involved people in the tourism industry (Neuman \& Robson, 2012). The key informant for this study was the president of the STA. The president is highly involved in the tourism industry and is why they are a key informant. They hold a strong knowledge of the current and past tourism industry of Savusavu and Fiji in general. Dr. Sonya Graci shared the key informant's contact information after she requested permission to do so. The researcher contacted the informant via email with a letter of introduction. The letter outlined the purpose of the research. After they provided consent to an interview the researcher arranged a day and time to meet.

The research used snowball sampling after they contacted the key informant to gain more interviewees. This is a type of sampling technique that begins with one key informant and allows you to gain new ones through the original contact. The interviewer can gain information about interrelationships in the case, identify other informants and continue to repeat this process to develop a sample of the population (Reed et al., 2009). Using snowball sampling also ensures that the researcher is not solely using their own judgement to gain a sample size (Neuman \& Robson, 2012).

The networks provided by the key informant eventually became saturated. Meaning, there were no more possible interviewees left through the contacts. Therefore, the researcher used a nonstratified sampling technique. This is a non-random sampling technique based on some characteristic or meets a certain definition of the researcher. For this case, it was stakeholders of Savusavu's tourism industry. The study targeted government officials, town council members, hoteliers and resort owners, local businesses (restaurants or souvenir stores), dive shops, employees and the local community members. The researcher targeted two groups each day. The researcher approached individuals who they believed belonged to the targeted groups and asked them to participate in the study. The research targeted the downtown core of Savusavu, as this is main tourist area. The area is described in Chapter 3. The researcher also approached groups outside of the downtown core as larger resorts and local villages are not found in the core. Using a combination of these sampling methods resulted in a sample size of 41.

\subsubsection{Phase 5: Primary Data Collection}

Data collection for the study took place from August $4^{\text {th }}$ until August $25^{\text {th }} 2016$ in Savusavu. This study strived to keep detailed, organized notes as data collection requires organization and accuracy (Neuman \& Robson, 2012). At the beginning of each interview the interviewee was given an 
identification number to organize results. The researcher also made note of the date, time and location of the interview. The interviewer then obtained consent from the interviewee and commenced the interview. Throughout the interview the researcher remained tentative and took comprehensive notes. The researcher took field notes to during the interview or as soon as possible afterwards to avoid misinterpretation (Denscombe, 2014). When interviewees provided consent the interviews the researcher recorded the interviews. This backed up any notes taken. The researcher then thanked the interviewee for participating and transcribed the interviews.

The researcher transcribed and saved the interviews to their laptop as soon as possible following the interview. By doing this right away the interview will be fresh and more accurate notes are made (Denscombe, 2014). Transcribing is a time-consuming process but it is a very valuable part of the research process because it brings the researcher closer to the data. By transcribing, the data is analyzed much easier than the audio recording in its original state (Denscombe, 2014). Annotations and comments were added alongside the words. The researcher wrote up the detailed notes in the same fashion when participants did not consent to being recorded. The majority of the participants did not agree to be audio recorded.

The researcher rechecked and saved the data appropriately. The researcher strived to keep organized and detailed notes. Qualitative data's validity and reliability, which refers to the truthfulness and consistency of the data is often questioned. These limitations are overcome by keeping organized notes (Neuman \& Robson, 2012). By saving and keeping the data other researchers can also check the results.

\subsubsection{Phase 6: Data Analysis}

Phase six consisted of a qualitative data analysis. Using Microsoft Excel the researcher coded the transcribed interviews. Coding interview data encourages a higher-level of thinking about the data and allows the research to make connections in the data (Neuman \& Robson, 2012). The researcher conceptualized the answers from the interviews and organized them into common themes and concepts to make generalizations for the sample. To do this, the researcher read the transcribed interviews in their entirety and then analyzed them. The research was able to identify major themes and notes.

The research coded the interviews by dividing and grouping them by question. For each question, a spreadsheet was created outlining the responses for each interviewee. The answers were then organized into common themes or codes. Labels identify these themes in the responses. The 
researcher counted the frequency of each response. Graphs and charts displayed the frequencies and proportions of the themes. The Appendix 3 provides an example of a coded question. Identifying common themes allowed the researcher to determine the key environmental issues and goals of Savusavu. Coding common themes also revealed potential to environmental instruments to recommend. This phase of the study occurred from September 2016 to March 2017.

\subsubsection{Phase 7: Discussion and Recommendations}

Phase seven is the discussion on the major findings of this research. From the analysis the researcher was able to identify highly used environmental resources, stakeholder involvement and education, current instruments, goals and issues of the destination and possible new environmental instruments that would be accepted. Recommendations on which environmental instruments can promote sustainable tourism in Savusavu were then concluded to overcome the barriers Savusavu faces in becoming a sustainable tourism destination.

\subsection{Limitations of Study}

While the researcher attempted to use the most appropriate research methods to avoid limitations, there were some limitations apparent in this study.

\subsubsection{Interview Reliability and Biases}

The limitations of qualitative interviewing relate to the data's validity and reliability. Researchers transcribe and recall what happens during an interview and after the interview write down the conversation. While some interviews were audio recorded for this study the majority were not. This can result in issues of truthfulness and reliability in the data. To overcome this limitation the researcher took detailed notes and transcribed no later than 40 minutes after the initial interview. To increase the trustworthiness of the data from this research is available to other interested researchers who may want to reanalyze it (Neuman \& Robson, 2012).

There are interviewer biases that can be considered a limitation to this study. Face-to-face interviews can create a situation where respondents may provide bias responses (McBurney \& White, 2009). To avoid biases the interviewer made attempts to ensure the interviewee felt comfortable in expressing their own opinions while being reassured that their responses were important and would remain confidential. The interviewer also attempted to remain neutral at all times and not to express and preference in answers. 


\subsubsection{Time and Sample Size}

The sample size and time of the case study is another limitation with this work. The researcher was only on site for 4 weeks. The researcher interviewed 41 participants during this time. If the researcher had more time they could have collected a larger sample and more data. Since the sample size is small other researchers can question the results and their applicability to a wider population beyond the sample. The research findings are intended to be applied to a wider range of island destinations who are also looking to become more sustainable. While the researcher only conducted 41 interviews, these interviews were done with tourism stakeholders. By targeting these groups meaningful and comprehensive interviews did take place. While the amount of data is limited, the data provided during the interviews were meaningful and relevant for the study.

\subsubsection{Sample Bias}

Limitations exist when using non-random sampling. Sample bias is therefore a limitation of this study. Not all stakeholder groups are represented equally. Certain stakeholder groups make up a larger portion of the sample. This results response biases. Therefore, if one group dominates the sample than their group's views will dominant the type of responses to the interview questions. This bias will limit how the recommendations can be applied to the Savusavu tourism industry as a whole. However, for qualitative research it is often difficult to determine a random sample technique. When using random sampling population parameters are usually known and a reliable sample size is calculated (Banerjee \& Chaudhury, 2010). This was not possible for this study. The goal was to get as many stakeholders as possible. Even though the research cannot make generalizations for the population, it can make important clues for further studies based on the random sample.

\subsection{Conclusion}

This chapter outlines and justifies the research methods used to collect and analyze the data of the study. Though there are limitations in the methods used, the data collected from the stakeholders provided significant information on how Savusavu can become more sustainable through the use of environmental instruments. The following chapter presents the data analysis of the study. 


\section{Chapter 5: Data Analysis}

This chapter presents an analysis of the data collected during the stakeholder interviews. The chapter identifies the stakeholder groups who participated in the study and their personal involvement in tourism related decisions. The analysis reveals the natural resources currently used for tourism purposes by multiple stakeholders and the issues they face. Stakeholder responses identify the barriers Savusavu faces when becoming a sustainable destination. The environmental instruments currently in place are identified. Finally, the chapter explores how to create changes in Savusavu.

\subsection{Stakeholder Groups}

The study interviewed members of the Savusavu community that affect and/or are affected by the changes to the policies, decisions and actions of the tourism industry. Table 6 below illustrates the stakeholder groups that were interviewed and the count of participants from each. For the definitions of each group see Chapter 3.

Table 6 Count of Savusavu stakeholders groups

\begin{tabular}{|l|l|l|}
\hline Stakeholder Group & Count & Proportion \\
\hline Operator & 8 & $20 \%$ \\
\hline Employee & 6 & $15 \%$ \\
\hline Business Owner & 6 & $15 \%$ \\
\hline Regulator & 6 & $15 \%$ \\
\hline Local & 8 & $20 \%$ \\
\hline Tourist & 7 & $17 \%$ \\
\hline
\end{tabular}

$\mathrm{N}=41$

The research conducted a total of 41 interviews. Operators (20\%) and locals (20\%) made up the largest proportion of respondents, then tourists (17\%), employees (15\%), business owners (15\%) and regulators (15\%). Each stakeholder group has a count of $6-8$. All stakeholder perspectives were seen as equal and intrinsic in value. Some stakeholders from the business owner, operator, employee, local and regulator groups are members of the STA, but their primary stake is not with the organization and is why the STA was not categorized as its own group. It is also recognized that the individual members of each group may not have similar opinions and interests in regards to Savusavu's tourism association. 


\subsubsection{Perceived Influential Stakeholder Groups of Tourism Industry}

The researcher asked respondents what stakeholders would be the most influential in the implementation of a new environmental instrument. Respondents indicated who they perceived as the most influential stakeholder groups to be involved in the implementation process of a new environmental instrument in Savusavu. Understanding who is influential in making changes related to tourism is beneficial when recommending new instruments. Developing trust is important for intuitions and collective management (Ostrom, 2015). Involving influential community members could help build this trust. The question also identified and verified stakeholder groups of the study. This question was not used to dictate which stakeholder group's responses are the most important. All stakeholder groups' opinions and perceptions are equal. The Figure 7 illustrates the proportion of each response.

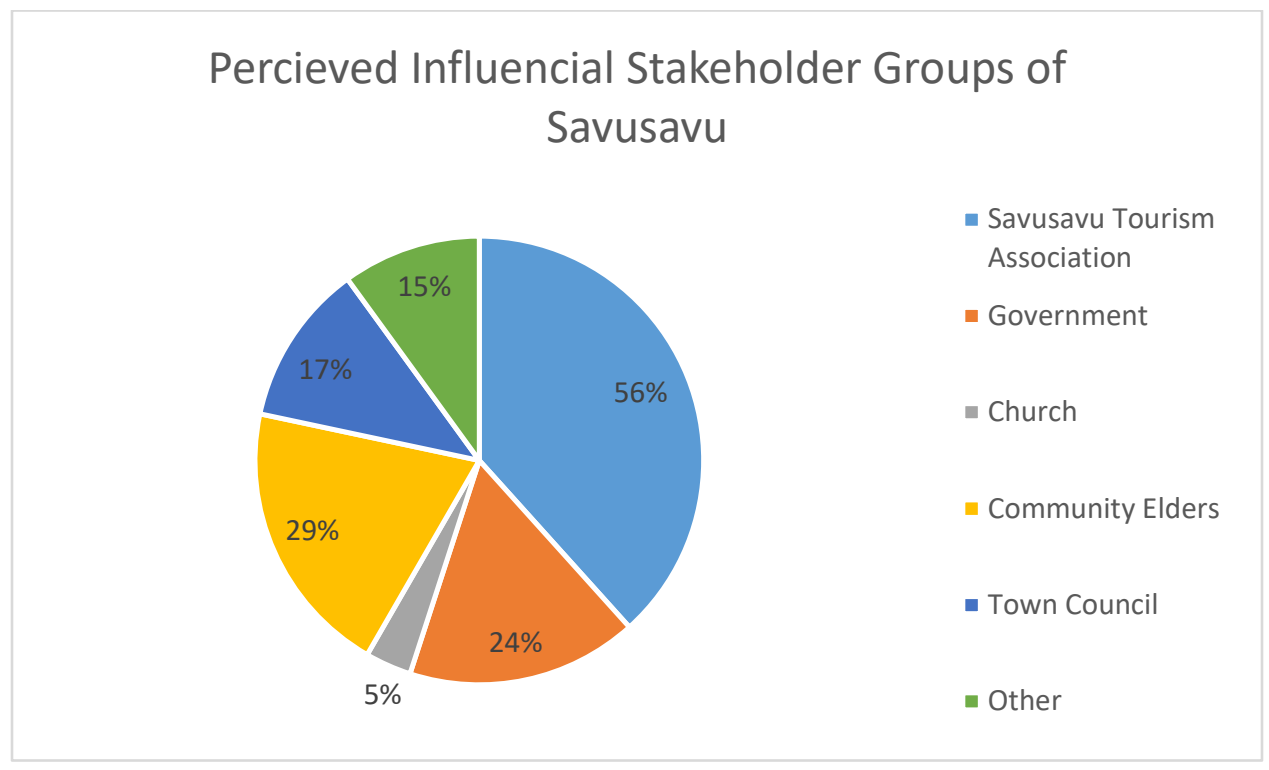

Figure 8 The perceived influential stakeholder groups in Savusavu

The STA is the most common response provided by the respondents with $56 \%$. The other large proportions are made up of the community elders (29\%) and the Fijian government with $24 \%$. The category other (15\%) included responses of the general public, NGOs and one response of school (Interviews \# 11, 12,17,20,23 \& 41, 2016). Town council members (17\%) and the church (5\%) are also suggested. As previously stated the study did interview members of the STA but they are grouped based on their primary stake. 


\subsubsection{Respondent's Personal Involvement in the Tourism Related Decisions}

The interviewer asked respondents to indicate their level of involvement in decisions related to the tourism industry of Savusavu. Public participation in decisions related to sustainable development was seen as a best practice taken from the literature review (Liu et al., 2012; Krutwaysho \& Bramwell, 2010; Waligo et al., 2013; Wang \& Ap, 2013). From the respondents' answers they are either not involved (26/41), somewhat involved (3/41) or highly involved (12/41). 10/12 of those who stated that they are highly involved are members of either the STA or town council (Interviews \#2, $4,6,8,10,16,19,22,31 \& 37,2016)$. These groups are also identified as important stakeholder groups related to changes made to Savusavu's tourism industry. Interview \#4 is an example of one of the respondents who indicated they were highly involved, "very involved, I am on town council and a part of Savusavu Tourism Association". Another example is from Interview \#2, "I am an active member of the Savusavu Tourism Association so I am active in decisions that we make at our meetings". This information suggests that not all the stakeholder groups of Savusavu are highly involved in the decisions or management related to tourism.

$63 \%$ of respondents indicated they are not involved in decisions related to tourism in Savusavu. The table 7 below illustrates the stakeholder groups who indicated this form of involvement.

Table 7 Stakeholder groups who indicated they were not involved in tourism decisions

\begin{tabular}{|l|l|l|}
\hline Stakeholder Group & Count & Proportion \\
\hline Employee & 4 & $15 \%$ \\
\hline Local & 6 & $23 \%$ \\
\hline Operator & 6 & $23 \%$ \\
\hline Tourist & 6 & $23 \%$ \\
\hline Business Owner & 3 & $12 \%$ \\
\hline Regulator & 1 & $3 \%$ \\
\hline
\end{tabular}

$\mathrm{N}=26$

There is a lack of participation from locals, operators, tourists, business owner and employees. This lack of involvement likely influences current environmental management. The involvement of all stakeholders is needed to produce sustainable outcomes for a tourism industry. The current stakeholder involvement for the case of Savusavu's tourism industry is low and in need of improvement. 


\subsubsection{Future Public Participation}

The implementation of new environmental instruments can increase public participation in tourism related decisions. The interviewer asked respondents if they would become more involved in tourism related decisions if they had the opportunity to do so. Fifty-four per cent (22/41) of respondents said they would participate if they were given the opportunity while $46 \%$ (19/41) did not want to become more involved. Examples are from Interview \#9, "yes, we need more members on the Fiji tourism board. So I would get involved". Another example is from Interview \#7, "yes I would for sure."

Reasons given for not wanting to become more involved were because they were already too involved or because the participant was pursuing other interests. For example, Interview \#5 "no, I am moving back to New Zealand but I was so busy while I was here I don't think I would be able to be involved". Interview \#19, "no, trying to get less involved as I am selling my business and moving towards farming". Interview \#37, "probably not, I have a lot on my plate". Many respondents who did not want to participate in the future were tourists. Tourists may not return to Savusavu and therefore would not be able or want to get involved (Interviews \#18, 25,36,38,39 \& 41, 2016). The high number of tourists and members who are already highly involved therefore influence the $46 \%$ that would not want to become more involved if given the chance to do so.

\subsection{Natural Resource Management}

This section presents the data on questions related to Savusavu's natural resources. These questions attempted to determine what natural resources stakeholders use for tourism purposes, the benefits they provide, how they are currently managed and the barriers they face. Destinations like Savusavu rely on the state of their natural resources to bring in tourists. Understanding the natural resource situations that exists in Savusavu is important to begin to try and develop sustainable tourism. The research asked these questions to begin to understand how Savusavu can more effectively manage its natural resources with environmental instruments.

\subsubsection{Impacts on Natural Resources}

Identifying the key issues Savusavu faces in becoming a sustainable destination is the second objective of this study. The researcher asked respondents to identify the major natural resources management issues of Savusavu to begin to reach this objective. Table 8 presents the common responses. 
Table 8 Natural resource management issues of Savusavu

\begin{tabular}{|l|l|l|l|}
\hline Issues & Interviewee & Count & Proportion \\
\hline $\begin{array}{l}\text { Waste Water } \\
\text { Pollution }\end{array}$ & $2,4,6,5,8,16,31,37$ & 8 & $20 \%$ \\
\hline $\begin{array}{l}\text { Physical Waste } \\
\text { (Litter) }\end{array}$ & $4,8,23,24,31,36,41$ & 7 & $17 \%$ \\
\hline $\begin{array}{l}\text { Marine } \\
\text { Environment } \\
\text { Destruction }\end{array}$ & $11,12,14,17,18,20,21$ & 7 & $17 \%$ \\
\hline $\begin{array}{l}\text { Cyclone Winston } \\
\text { damage }\end{array}$ & $7,19,21,30,38,39,40$ & 7 & $17 \%$ \\
\hline None & $\begin{array}{l}1,3,9,10,13,15,22,25,26,27,28,29,32 \\
33,34,35\end{array}$ & 16 & $39 \%$ \\
\hline
\end{tabular}

$\mathrm{N}=41$

The majority of respondents (61\%) did indicate a natural resource management issue. The major issues identified by respondents were: waste water pollution (20\%), physical waste (17\%), marine environment destruction (17\%) and damage from Cyclone Winston (17\%). 39\% of respondents do not believe Savusavu's natural resources face any environmental issues.

Litter and wastewater management are natural resource management issues indicated by $36 \%$ of respondents. Wastewater management pollution responses discuss issues of groundwater pollution, marine pollution from runoff and from motorized boats (Interviews \#2, 4, 6, 5 \& 8, 2016). Interview 16 provides an example of a response indicating a wastewater management issue. They stated, "The groundwater and soil health is facing issues because we only have communal septic tanks and not a sewage system". Interview \# 37 reported, "We have a big issue with waste water management in this town or lack thereof". Interview \#8 also indicated wastewater management issues in saying, "yes the expanding population has been having negative impacts on the environment. Litter and sewage treatment are our main issues". Therefore waste water management is a natural resource management issue and is a barrier to Savusavu's sustainable development.

Physical waste, or litter, is its own category related to waste management. The respondents are concerned with the amounts of litter, the lack of recycling and the costs associated with recycling (Interviews \#8, 23, 36 \& 41, 2016). There is no recycling plant currently in Savusavu. If stakeholders want to recycle they have to send their recycling by boat to the main island of Viti Levu (Interview \#4 \& 8, 
2016). Examples of responses discussing litter as a management issue was Interview \#31, "litter is the biggest issue, physical garbage and sewage." Interview \#24 also stated, "I really only notice that there is a pollution problem from all the litter. I think most of it is generated from the town." Waste management is another barrier of sustainable development.

The destruction of the marine environment was a natural resource issue seen by $17 \%$ of respondents. There are concerns with the mangrove destruction occurring from new developments, the weakening for the fish population and issues of coral bleaching. Interview \#14 with an operator said, "the sea is facing issues, the fish population is weakening, the reefs are becoming more damaged, and these could be from natural causes as well as tourism related impacts". Interview \#12 with an operator who conducts diving tours stated, "reefs are facing issues of breaking and bleaching, this could be a combination of natural causes (climate change) and tourism related causes". Respondents did consider natural causes as factors influencing the marine environment but issues related directly to tourism are also noted. Interview \#20 stated, "The mangrove destruction or removal is a major issue" in discussing creating room for new tourism developments (Interview \#20, 2016). The destruction of the marine environment from tourism and climate change are barriers to Savusavu being a sustainable tourism destination.

Further, $17 \%$ of respondents believe environmental damage to natural resources caused by Cyclone Winston which hit the area in January of 2016 is a current issue. Interview \#7 stated "Cyclone Winston has destroyed and impacted much of the environment." Interview \#30 indicated, "There is environmental damage but I think that is largely due to the Cyclone Winston." Interview \#40 said, "the coral is not the same after hurricane [cyclone] Winston". The study took place in August 2016 and issues from the cyclone were still evident. None of the respondents indicated any current management techniques being used to improve these issues, only that the state of the environment was suffering from the Cyclone's impacts (Interviews \# 21,30,38,39 \& 40, 2016). A barrier taken from these responses is the island's susceptibility to natural disasters.

The issues outlined by the respondents will have implications for the tourism industry if a form of management is not created to attempt to minimize these impacts. Natural resource management issues like waste and wastewater management negatively impact the health of the surrounding aquatic and terrestrial environments. The surrounding aquatic ecosystems of Savusavu are central to the success of the industry as Savusavu is a known diving destination. 
Issues of destruction can impact the quality of the diving tours and therefore the amount of diving tourists. Interview \#38 with a tourist in Savusavu stated, "Well the diving isn't nearly as good as it used to be but that is most likely due to Winston". And Interview \#40 with a diving operator also indicated, "The coral is not the same after hurricane Winston". If Savusavu's reputation as being a world class diving destination becomes tainted it will have wider implications for other tourism related businesses on the island. If tourist numbers diminish because of poor diving conditions then other tourism businesses can suffer as well. While Savusavu cannot control the natural disasters that occur it can prepare and plan in an attempt to minimize and manage the impacts. The impacts on the coral and marine environments need to be managed collectively in order to mitigate the potential negative impacts. If these issues remain unresolved sustainable development for this destination cannot occur.

\subsubsection{Natural Resources Used for Tourism Purposes}

The interviewer asked respondents what environmental resources they use for tourism purposes. Identifying the resources used for tourism purposes by stakeholders can aid in recommending effective environmental instruments and collective management strategies to govern CPRs (Ostrom, 2015). By understanding what resources are used, their boundaries and benefits, recommendations can be made. It can also indicate possible impacts resources are currently experiencing. Table 9 below shows the count of each natural resource that the interviewees are using for tourism purposes.

Table 9 Natural resources used for tourism purposes by stakeholders

\begin{tabular}{|l|l|l|}
\hline Natural Resource & Count & Proportion \\
\hline Ocean & 24 & $58 \%$ \\
\hline $\begin{array}{l}\text { Fijian People and } \\
\text { Culture }\end{array}$ & 4 & $9 \%$ \\
\hline Coral Reefs & 7 & $17 \%$ \\
\hline Rainforests & 9 & $22 \%$ \\
\hline Natural Beauty & 8 & $19 \%$ \\
\hline None & 13 & $31 \%$ \\
\hline
\end{tabular}

$\mathrm{N}=41$

The research grouped the natural resources used for tourism purposes as the following: the ocean, the Fijian people and culture, coral reefs, rainforests and the natural beauty of the island. Some 
respondents (19/41) indicated that they use more than one resource and 13/41 indicated they do not use any natural resources at all.

The ocean and marine environment are the most highly used resources by respondents (58\%). Some respondents pointed out exactly what they use from the marine environment, like the coral reefs for diving purposes. This was coded as its own category (17\%). An example is from Interview \#4 with a regulator: "We use the people, for their culture and personalities. We use the environment for its beauty, the reefs for diving, the rainforest for hikes, mangroves for trips, waterfalls and the salt lake". Another example is from Interview \#39, "I use the ocean and corals here primarily for diving." For respondents who said fishing or the beach were infrequent responses but relate to the ocean and marine environment, so they are categorized under this group. Examples are seen in the Table 10 below.

Table 10 Examples of respondents who indicated using the marine environment

\begin{tabular}{|l|l|}
\hline Respondent & Quote \\
\hline 25 & I use the ocean and the fish \\
\hline 2 & $\begin{array}{l}\text { We use the ocean, the rain forest for hiking and its natural beauty } \\
\text { as we have a spa in the rain forest. }\end{array}$ \\
\hline 19 & $\begin{array}{l}\text { Indirectly use ocean and forest, we outsource activities which use } \\
\text { the environment }\end{array}$ \\
\hline
\end{tabular}

The ocean and marine environment of Savusavu is the most widely used resource and is considered important for tourism purposes.

Twenty-two per cent of respondents use the rainforest for hiking purposes (Interviews \# 2, 12, $19 \& 21,2016)$. The natural beauty category (19\%) refers to the flora, fauna and landscape mainly being used as an attraction for guests. An example for this group is, "The aesthetic beauty of the island, the ocean, fish and gardens" (Interview \#6, 2016). Another example is from Interview \#24, "I use the ocean and the natural beauty of the island to attract tourists". While each category could be considered natural beauty, only the responses that pointed out the use of the actual aesthetic of the natural environment were counted. From these responses the study supports that the state of the rainforest and the natural environment in general are important for the tourism industry.

The majority of the interviewees (68\%) did indicate the natural resources they use for tourism purposes, however some failed to indicate or understand that they are in fact using a resource. Fully 
$31 \%$ of respondents claim to not be using any of the island's natural resources for tourism purposes. However, when asked of their role and involvement in the tourism industry their responses revealed that they are using natural resources in some form.

Interview \#9 is from an operator that conducts diving tours, rainforest hikes and other natural resource based tours (Interview \# 9, 2016). The respondent therefore uses the island's ocean, rainforest and natural beauty for these tours. They did not indicate to using any. Interview \#13 indicated they own a bar, a restaurant, as well as an accommodation for tourists (Interview \# 13, 2016). It is argued that the natural beauty is used to attract guests which then enter their business. They also use the natural resources of the land for food and water. Interview \#16 was a tourist and did not claim to be using resources for tourism purposes (Interview \#16, 2016). If the respondent participated in diving tours, and consumed food and water from the island it is argued that they are using natural resources of Savusavu. Interview \#34 indicated they sell real estate and properties on the island (Interview \# 34, 2016). Though they claimed to not be using any natural resources, the natural beauty is argued as a reason for people's interest in purchasing land in Savusavu. The remaining respondents $(9 / 13)$ who claimed none were locals or regulators who actually do not use natural resources for tourism purposes.

\subsubsection{Perceived Benefits of Natural Resources}

To further explore whether the respondents understand the role natural resources play for the tourism industry and in their lives, the interviewer asked if they benefit from their use. They were then probed to explain how they benefit. Responses could indicate whether the community would understand implementing instruments to protect and conserve the natural resources of the island and if education on natural resources is needed. By asking this question the researcher could also begin to identify incentives for individuals to want to participate in voluntary initiatives and in collective management of resources as discussed by Ostrom $(1990,2015)$. Table 11 illustrates the amount of respondents that felt they did benefit from the use of natural resources and the ones that did not.

Table 11 Stakeholder views on their personal benefit from the use of natural resources

\begin{tabular}{|l|l|l|}
\hline Response & Count & Proportion \\
\hline No / Negative & 13 & $32 \%$ \\
\hline Yes / Positive & 28 & $68 \%$ \\
\hline
\end{tabular}

$\mathrm{N}=41$ 
The majority of respondents (68\%) agreed that they are benefiting from the use of natural resources in some form and 32\% did not. Table 12 illustrates the perceived benefits.

Table 12 Respondents perceived benefits of using natural resources

\begin{tabular}{|l|l|l|l|}
\hline The Benefits & Interview & Count & Percentage \\
\hline Attracts Tourists & $\begin{array}{l}1,2,3,4,6,8,11,16,19,24,25,31, \\
37\end{array}$ & 13 & $46 \%$ \\
\hline $\begin{array}{l}\text { Creates Activities for } \\
\text { Tourism }\end{array}$ & $4,7,17,25,38,40$ & 6 & $21 \%$ \\
\hline $\begin{array}{l}\text { Food/ Water } \\
\text { Resources }\end{array}$ & $5,14,23$ & 3 & $10 \%$ \\
\hline Financial Gains & $\begin{array}{l}6,12,15,17,18,20,21,22,24,30, \\
37\end{array}$ & 11 & $39 \%$ \\
\hline
\end{tabular}

$\mathrm{N}=28$ (only participants who answered positively included)

There is awareness amongst the respondents of some of the benefits the natural resources of Savusavu provide. Major themes for how they benefit in the responses were: the attraction of tourists (46\%), the creation of activities for tourism (21\%), food and water resources (10\%) and for financial gains (39\%). Some respondents indicated more than one way they benefit.

There is a focus from the responses on the economic benefits provided through the use of natural resources. The categories: attracts tourists, creates activities for tourism and financial gains are all related in that they result in a form of economic gain for the stakeholder. The respondents from attraction of tourists $(13 / 28)$ believe they benefit from the natural beauty pulling in tourists to Savusavu. This results in financial gains by tourists visiting the destination and spending money in Savusavu. The creating activities group also relates to the natural resources as a pull factor for tourists. Tourists come to Savusavu for activities like diving and then spend their money at various businesses in Savusavu (i.e. restaurants, accommodations, gift shops, the local market and tour organization). Examples of responses are from Interview \#17, "Yes, I benefit financially and they provide guests with experiences which makes me good income". Interview \#37 describes two benefits, "yes, brings people to our town and aids us financially". Therefore, the greatest benefit perceived by stakeholders from the use of natural resources is based on economic gains from attracting tourists to the destination.

Further, $32 \%$ of respondents expressed they do not receive any benefits from the use of natural resources. Some of these respondents are not aware that they are in fact benefitting. For example, 
Interviewee \#40 works for a diving company that conducts tours with tourists. This involves using the marine environment and coral. They are employed by the diving company which in turn provides them with an income. However, they did not indicate any of these benefits in their response (Interview \#40, 2016). Interviewee \#9 is an office worker that organizes tours, cruises and boat rentals for tourists. The activities they organize use the ocean as amusement and transportation. Their employment is reliant on the natural resources to attract tourists and provide activities for tourists yet they did not indicate any of these benefits in answering the question (Interview \# 9, 2016).

Respondents \#36, 39 and 41 are tourists. They did not indicate they benefit in any way from the use of natural resources. Some tourists of Savusavu are not aware of or understand the role natural resources play in tourism. Therefore, tourists may have a lack of education on the benefits and role natural resources play. There is a need to further educate all stakeholders groups on the role and benefits natural resources play in Savusavu's tourism industry.

\subsubsection{Opinions on Paying For Natural Resources}

Economic instruments can generate funds to protect and conserve natural resources (Birdir et al., 2013; Thur, 2010). The researcher asked respondents to give their opinion on whether or not they believe those using Savusavu's natural resources and benefitting from them should pay to use them. Table 13 displays the results.

Table 13 Respondents opinion on paying for the use of natural resources

\begin{tabular}{|l|l|l|l|}
\hline Response & Interview & Count & Proportion \\
\hline Yes / Positive & $\begin{array}{l}1,2,3,4,5,6,9,10,12,13,17,18,21,22,25, \\
30,36,39,40,41\end{array}$ & 21 & $51 \%$ \\
\hline No / Negative & $\begin{array}{l}7,8,11,14,15,16,19,20,23,24,26,27,28,29, \\
31,32,33,34,35,37,38\end{array}$ & 20 & $49 \%$ \\
\hline
\end{tabular}

$\mathrm{N}=41$

More than half (51\%) of respondents believe those benefiting from the use of natural resources should pay in some manner for their use. Of those who agreed to a form of payment, 7 of these respondents did not indicate that they benefit from the use of natural resources in the previous section. If a respondent does not think they are benefitting they may not understand that they would have to pay. This could influence their answer to this question. If they knew they would have to pay because they use resources, they may not have responded the same. 
There is some real acceptance of paying for resources as 14/21 of the respondents who did indicate yes to a payment did indicate in the previous section that they were benefitting. They, therefore, understand that since they are benefitting they would pay for these benefits.

The researcher asked those that agreed (21/41) in associating a payment with the use of natural resources, to indicate a payment method. Implementing a user fee was the most common (13/21) form of instrument suggested. 8/21 respondents were not sure on how they could set up an economic instrument to associate with natural resource use and only $1 / 21$ suggested an environmental tax (see Table 14).

Table 14 Suggested ways to set up an economic instrument for the use of natural resources

\begin{tabular}{|l|l|l|l|}
\hline How They Would Pay & Interview & Count & Proportion \\
\hline Not sure how & $7,14,15,20,23,24,31,37$ & 8 & $38 \%$ \\
\hline User fee & $\begin{array}{l}8,11,16,19,26,27,28,29,32,3 \\
3,34,35,38\end{array}$ & 13 & $61 \%$ \\
\hline Environmental Tax & 28 & 1 & $4 \%$ \\
\hline
\end{tabular}

$\mathrm{N}=21$

Respondents indicated setting up user fees with landowners as a method to pay for using natural resources. Interview \#35 suggested creating a user fee with the local villages, "yes, they should pay the villages if they use their lands". Interview \#32 also supported paying villages for using their lands, "yes they should, some resorts do pay villages for their use already but some do not and should". Other responses supporting a user fee included Interview \#29, "yes, some should, if they are using them and do not own them". Interview \#27 indicated, "Tour operators using the resources should pay to use them, some do already but some do not and use without permission". Interview \#19 also supported a user fee in saying, "yes, those actually using them, a transparent user fee would work." Therefore, a user fee to pay the owner of the actual resource is suggested for using natural resources. Respondents did not provide a monetary amount associated with the fee to put on the use of natural resources. Further information is needed to set up a user fee scheme.

Slightly less than half (49\%) of respondents (20/41) do not believe they should pay for the use of natural resources. 15 of the 20 indicated in the previous section that they were benefitting from the use of natural resources. This could therefore influence their response as they would be paying for the 
benefits they are receiving. Some respondents did provide a rationale for why they do not agree to an economic instrument associated with the use of environmental resources (Table 15).

Table 15 Reasons for opposing payments for the use of natural resources

\begin{tabular}{|l|l|l|l|}
\hline Reasoning for Not Paying & Interview & Count & Proportion \\
\hline Tourists already pay & $1,3,13$ & 3 & $15 \%$ \\
\hline We already pay & $4,12,17,18,21,30$ & 6 & $30 \%$ \\
\hline No reasoning given & $\begin{array}{l}2,5,6,9,10,22,25,36,39, \\
40,41\end{array}$ & 11 & $55 \%$ \\
\hline
\end{tabular}

$\mathrm{N}=20$

Of the reasons given there is a trend in the responses that either the respondent or the tourists are already paying for the use of natural resources. Respondents do want to pay additional amounts to what they are already paying. The Table 16 below has examples of quotes from respondents.

Table 16 Examples of responses that opposed payments for the use of natural resources

\begin{tabular}{|l|l|}
\hline Respondent & Quote \\
\hline 1 & $\begin{array}{l}\text { No, we use the sea for tours, and the tourists pay for this, even if dolphins aren't } \\
\text { seen. It's an open area shouldn't have to pay. }\end{array}$ \\
\hline 4 & We already do pay, we pay native Fijians to use their lands, and we pay taxes \\
\hline 13 & $\begin{array}{l}\text { Tourists are already paying the tourism operators and the government through } \\
\text { taxes }\end{array}$ \\
\hline 27 & $\begin{array}{l}\text { Tour operators using the resources should pay to use them, some do already but } \\
\text { some do not and use without permissions }\end{array}$ \\
\hline 36 & $\begin{array}{l}\text { No I don't think so, why would you, who are you supposed to pay? You don't know } \\
\text { what the money is going towards }\end{array}$ \\
\hline
\end{tabular}

Respondents may not necessarily oppose paying for natural resources but believe they already are. This could be why they do not support a new method of paying. From this information there are already environmental economic instruments in place in Savusavu. There may also be some private user fee agreements in place between the villages, business owner and operators. 


\subsubsection{Ownership of Natural Resources}

The study aimed to determine who owns the natural resources of the island being used for tourism or if they are open. When setting up and implementing new instruments ownership of resources should be considered. Knowledge on the ownership is also important to determine a collective management technique for open common resources (Ostrom 1990; Walker 2009). The figure 8 below illustrates the ownership of natural resources provided by the respondents.

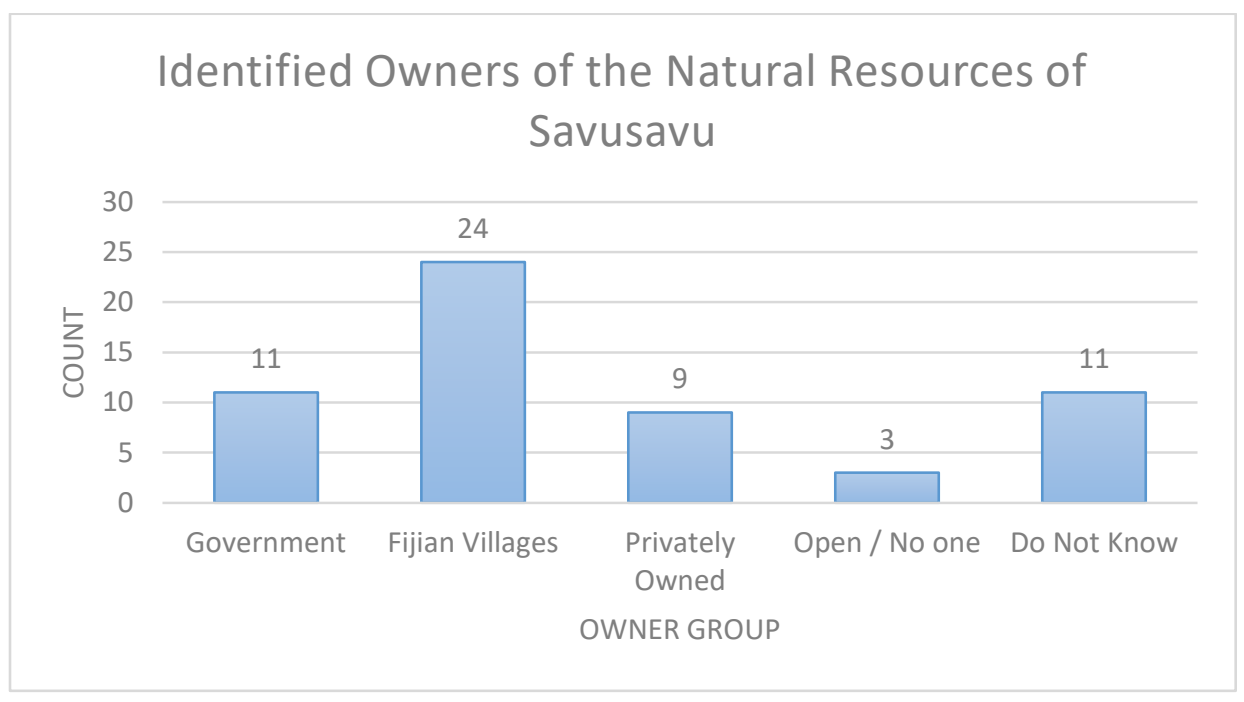

Figure 9 Representation of respondents' beliefs on the owners of natural resources

The Fijian Villages is the most common answer from the respondents (58\%) for who owns the natural resources of the island. Many do not know who owns the resources (26\%) or believe the government does (26\%). Respondents were not able to provide specifics on who owns what. From this information there are multiple owners of the resources of Savusavu. It is still not clear from these responses of what is open or a commons. If the resources are owned privately and by the Fijian villages then government involvement may not be needed which can sometimes be a challenge to receive. This could be seen as an advantage as changes can be made to management without relying on government and eliminating timely administrative processes.

\subsubsection{Voluntary Payments for Use of Natural Resources}

The researcher asked respondents if they would voluntarily pay to for the use of natural resources knowing it would fund environmental initiatives to protect and conserve the natural resources of Savusavu. A voluntary fund gives the option to stakeholders to pay if they so wish and do not have to actually use the resource to contribute. The answers to the question, "If the money generated from 
paying for the use of natural resources was used to fund environmental instruments to conserve and protect these resources would you voluntary pay for their use?" are in Table 17 below.

Table 17 Opinions on voluntarily paying for natural resources

\begin{tabular}{|l|l|l|l|}
\hline Response & Interview & Count & Proportion \\
\hline Yes & $\begin{array}{l}2,7,8,10,11,15,16,18,19,25,26, \\
28,30,31,37\end{array}$ & 15 & $37 \%$ \\
\hline No & $\begin{array}{l}1,3,4,5,6,9,12,13,14,17,20,21,22,23, \\
24,27,29,33,35,39\end{array}$ & 22 & $54 \%$ \\
\hline Maybe & $32,34,36,38$ & 4 & $9 \%$ \\
\hline
\end{tabular}

$\mathrm{N}=41$

A majority (54\%) of respondents would not voluntarily pay to use resources knowing that the money was conserving resources. Therefore, a voluntary payment may not be an instrument to implement. However, in previous sections the study determined that the stakeholders may not fully understand the role natural resources play in its tourism industry. If stakeholders are more educated on the role natural resources play for tourism and the benefits they provide to the community then they may develop voluntary pay. Chung et al., (2011) and Edwards (2009) found that if stakeholders are educated on where the money from economic instruments is spent on supporting sustainable development then they are more likely to accept. There is also the possibility respondents do not realize natural resources of Savusavu are facing negative impacts caused by tourism which the study explored in previous sections. The option on a voluntary payment can still be an option for Savusavu as $37 \%$ still said they would voluntarily pay.

\subsection{Barriers of Savusavu Becoming a Sustainable Destination}

This section of the data analysis explores the barriers that stakeholders of Savusavu believe the destination faces in becoming a sustainable destination. Consulting multiple stakeholders with differing interests and perspectives can encourage more consideration of the varied social, cultural, environmental, economic and political issues affecting sustainable development can be identified (Bramwell \& Lane, 1993). Sustainability barriers can differ from destination to destination so they must be identified before they can begin to manage them with environmental instruments. The perceived social, environmental and economic barriers facing Savusavu are in Table 18. 
Table 18 Perceived barriers to sustainable development of Savusavu

\begin{tabular}{|l|l|l|}
\hline Issue & Count & Proportion \\
\hline Current Airport & 7 & $41 \%$ \\
\hline $\begin{array}{l}\text { Lack of Waste } \\
\text { Management }\end{array}$ & 8 & $19 \%$ \\
\hline $\begin{array}{l}\text { Lack of } \\
\text { Government } \\
\text { Support }\end{array}$ & 6 & $15 \%$ \\
\hline Other & 12 & $31 \%$ \\
\hline
\end{tabular}

$\mathrm{N}=39$ (\#15 and \#28 were not included because they did not understand the question)

The Savusavu airport, the lack of waste management and government support are barriers to Savusavu's sustainable development. There is also the category of other which had a mix of responses. These responses were not frequent enough to create individual groups.

\subsubsection{Barrier One: Airport Transportation}

The airport category relates to answers concerned with the high flight fares, plane and runway size, and the lack of flights in general. Respondents believe this impacts the amount of tourists and return tourists coming to Savusavu. This was a barrier seen by $41 \%$ of respondents (Interviews \#1, 2, 5 , $16,21,27,31,34 \& 38,2016)$. A mix of business owners, operators, employees, tourists and local Fijians are groups who explained this barrier. An example is from Interview \#1 with a business owner, who said:

The current airport and flights are the biggest issues. Fares are way too high and only small planes are able to land on the strip as it is too small. Also not many planes available to consistently bring tourists in and out. I have tried to talk with government about bettering the airport of Savusavu but was unsuccessful (Interview \#1, 2016).

Another example is seen from Interview \#2 with an employee, who said, "The Savusavu airport is the most important issue. It's hard to get tourists here because of high airfares and we can only have small planes land." Interview \#13 also said, "Air travel is the most pressing issue facing the island in terms of becoming more sustainable, it's too small and flights are very expensive". 


\subsubsection{Barrier Two: Waste Management}

The waste management category (19\%) relates to answers concerned with the lack of wastewater and physical waste management. The amount of litter and lack of recycling in Savusavu concerns the respondents. The runoff from new developments and waste produced by yachts into Savusavu Bay is another concern. The main issue linked to this barrier is the impacts the waste has on the health of the surrounding environment like, ground water and ground soil (Interviews \#6, 7, $16,20,22,23 \& 37,2016)$.

This barrier relates to the impacts of tourism on natural resources discussed in section 5.2.1. Waste management is a key issue in terms of being a barrier to sustainable development for Savusavu. Examples from respondents were Interview \#4, “Biggest issue is the waste disposal. Waste is not treated properly or disposed of." Interview \#7, an operator: "most important issue is the lack of waste management in Savusavu. Because of health implications for the environment and for the people". And Interview \#22 a regulator, "biggest issue is the lack of sewage system and therefore the runoff".

\subsubsection{Barrier Three: Lack of Government Support}

The lack of government support category relates to answers indicating that the Fijian government does not support Savusavu tourism industry development. $15 \%$ of respondents indicate they felt as though government funding and attention is more focused on Viti Levu, the Yasawa Islands and the Mamanuca Island group. The needs of their industry are therefore neglected. This barrier has resulted in a lack of funding for community developments and a lack of proper infrastructure (Interviews $\# 1,9,12,16,19,30,2016)$. Examples of these respondents were Interview \#9 in saying, "lack of government support and funding is our barrier". Interview \#30 said, "lack of waterfront infrastructure and other proper infrastructure support from government in the town that could make it a more desirable tourist destination".

\subsubsection{Other Barriers}

The "Other" category (31\%) reflects a mix of barriers of the island. Responses were not frequent enough or related to create their own category. Interview \#14 with an operator indicated that the "biggest issue is that everything needs to be imported into the island. Food, meats, alcohol, pop, tourists. Hard to have a consistent product if the imports don't show up on time." Interview \#18 indicated the "environmental issue of mangrove destruction" as the biggest issue in regards to a new large scale resort development in the Bay of Savusavu. They believe there is a lack of environmental 
impact assessment on new developments and are worried about the consequences for the environment (Interview \#18, 2016). Interviewee \#24 believe the issue is, "The lack of local education on the importance of tourism is the biggest issue. More local involvement can create a better experience for tourists I think." Another example similar to that was from Interview \#32: "lack of village involvement is an issue, they should be involved to provide "real Fiji".

\subsubsection{Summary of Barriers}

From these responses there are many barriers facing Savusavu in becoming a sustainable tourism destination. The concerns related to the airport are the most commonly stated barrier. Respondents are the most concerned with tourist numbers and the amount of tourists returning to the destination. Therefore, it is assumed that stakeholders are concerned with the amount of money coming into the destination. It is perceived that the airport is the major issue impeding Savusavu from becoming a sustainable tourist destination. Economic concerns trump the social and environmental concerns.

Chapter 3 demonstrated that Fiji's tourist numbers have been increasing over the years. There are other sustainability issues like lack of wastewater management and marine destruction seen in section 5.2.1 that need to be overcome to produce sustainable outcomes versus airport improvements. These barriers are currently having impacts on the environment and society of Savusavu. This indicates that participants may not truly understand the concept of sustainability in that it is not only about continuously generating profits and having a steady flow of tourists.

\subsection{Environmental Instruments of Savusavu}

This section will now present the data collected on the current environmental instruments of Savusavu. The study wanted to know what was already being done in terms of environmental management with the use of instruments and attempt to determine if they were effective.

\subsubsection{Current Environmental Instruments}

The researcher read respondents an introductory paragraph to environmental instruments. The definition is in the interview questions in Appendix 1. They were then asked to identify current instruments used in Savusavu. The results are in Table 19. 
Table 19 Current environmental instruments of Savusavu

\begin{tabular}{|l|l|}
\hline \multicolumn{1}{|c|}{ Instrument } & \multicolumn{1}{|c|}{ Interview } \\
\hline Environmental Tax & $\begin{array}{l}1,3,4,6,8,9,11,17,21,22,27,29,31, \\
33,34,35,36,37,38,39,40,41\end{array}$ \\
\hline $\begin{array}{l}\text { Command and Control } \\
\text { / Regulatory }\end{array}$ & $6,7,12,14,21,22,27,29,35,40$ \\
\hline $\begin{array}{l}\text { Marine Protected } \\
\text { Areas / Reserves }\end{array}$ & $10,12,17,19,23,39$ \\
\hline Voluntary Initiatives & $6,16,18,20,23,30,34,35$ \\
\hline $\begin{array}{l}\text { Education/ } \\
\text { Community Programs }\end{array}$ & $16,19,29,31,33,37$ \\
\hline $\begin{array}{l}\text { Environmental Impact } \\
\text { Assessment }\end{array}$ & 2 \\
\hline None & $5,13,15,24,25,26,28,32$ \\
\hline
\end{tabular}

$\mathrm{N}=41$

Fully $80 \%$ of respondents reported some form of environmental instrument already in place in Savusavu, while only $20 \%$ did not report any. The respondents who were not aware of any instruments may not have known what an instrument was or was unclear on the question. Three of these respondents are locals (Interviews \# 5, 28 \&32, 2016), two were business owners (Interviews \# 13 \&15, 2016), one was an employee (Interview \#24), one was a tourist (Interview \#25) and one was a regulator who is part of the Chamber of Commerce and the Town Council (Interview \#26). Examples of quotes from the respondents are seen in Table 20. 
Table 20 Examples of responses related to current environmental instruments in Savusavu

\begin{tabular}{|l|l|l|}
\hline Respondent & Quote & Code \\
\hline 6 & $\begin{array}{l}\text { Levies and voluntary initiatives are currently } \\
\text { in place. Government does have restrictions } \\
\text { in place on fishing and farming }\end{array}$ & $\begin{array}{l}\text { Voluntary } \\
\text { instrument / } \\
\text { Regulatory } \\
\text { instrument }\end{array}$ \\
\hline 18 & $\begin{array}{l}\text { Yes, Cousteau has many initiatives, have seen } \\
\text { mangrove replanting }\end{array}$ & $\begin{array}{l}\text { Voluntary } \\
\text { Instrument }\end{array}$ \\
\hline 33 & $\begin{array}{l}\text { There are taxes I think but I'm not sure on } \\
\text { any others, we have school programs }\end{array}$ & $\begin{array}{l}\text { Environmental } \\
\text { Tax / Education } \\
\text { program }\end{array}$ \\
\hline 40 & $\begin{array}{l}\text { Taxes and some villages have restrictions on } \\
\text { fishing, not sure on others }\end{array}$ & $\begin{array}{l}\text { Environmental tax } \\
\text { / Regulatory } \\
\text { instrument }\end{array}$ \\
\hline
\end{tabular}

\subsubsection{Current Environmental Taxes and Environmental Levy}

The most common instrument identified was an environmental tax (22/41). The researcher expected this majority as the researcher became aware there was a new Environmental Levy introduced to Fiji January 1, 2016. The Fijian government has a $25 \%$ government tax on all products and services. The environmental levy is included in this tax. The tax is made up of:

- $\quad$ Value Added taxes (VAT) (9\%)

- Service Turnover Tax (STT) (10\%)

- Environmental Levy (6\%)

When asked specifically about the environmental levy $80 \%$ of respondents were aware it was in place. Of the respondents who were aware of the new environmental levy only 3 respondents were able to give an indication of what the tax was going towards. These respondents said the money was going towards a cleanup campaign, various initiatives related to environmental management in Fiji and infrastructure projects (i.e. roads) (Interviews \#16, 26 \& 37, 2016). For example interview \#26, "I believe it's going towards the infrastructure projects like roads and airport construction". The lack of knowledge on the environmental levy could be because it is was only recently implemented. It may also be because 
its purpose was not properly communicated by the government or the respondents never sought out its purpose.

Views on taxes have a negative theme associated with them of being too high. An example is from Interview \#3, "taxes are already in place and are currently too high" and with Interview \# 41, "yes, lots of taxes". Some respondents (4/41) had a negative attitude towards the true purpose of the tax and what the tax revenue was going towards. Respondents assume the money is going to the government and would not be coming back into the community. Interview \#8 stated, "Not a clue, government pocket I assume." Interview \#6, a business owner, "no, no designation just a revenue gainer". These opinions and perceptions illustrate that these individuals do not accept taxes and do not trust that the government is using it for environmental management purposes.

\subsubsection{Current Regulatory Instruments and Marine Protected Areas}

$10 / 41$ of respondents reported a form of regulatory instrument on resource use. A common instrument explained was the Fijian village's fishing "tabus". The tabu restricts where native Fijian communities can fish, in an attempt to let the fish population repopulate (Interviews \#14, 21, 22, $23,29,35,40,2016)$ ). Interview \#29 provides an example, "the villages restrict fishing (a tabu) but I think there is taxes and community programs as well". Another example is from Interview \#23, "I know Cousteau has a lot going on but there is also a MPA and tabu set up" and Interview \# 40, "taxes and some villages have restrictions on fishing, not sure on others". The community is therefore, voluntarily setting up a restriction on fishing and managing this resource themselves. Though this is could be seen as a voluntary instrument, the local Indigenous communities enforce the tabu so it is coded as a regulatory instrument.

6/41 respondents identified a Marine Protected Area as a current instrument. For example Interviewee \#12 “There are marine reserves, like Namena, there is also a ban on catching sea turtles". Another example is seen with Interview \#10, "we have a MPA, Namena". Namena is located off the shores of Savusavu and is not managed by Savusavu. It is not considered an instrument of Savusavu.

\subsubsection{Current Voluntary Instruments}

8/41 respondents reported voluntary instruments already in place in Savusavu. An example was from Interview \#18, "Yes, Cousteau has many instruments, I have seen mangrove replanting" and with interview \#34, “...some resorts do some energy saving measures on their own". To further explore current voluntary instruments the researcher asked respondents to identify any voluntary 
environmental instruments they or their employer implement. The researcher asked tourists if they noticed any instruments at their accommodation. The results are displayed in Table 21 below.

Table 21 Current voluntary environmental instruments of Savusavu

\begin{tabular}{|l|l|l|l|}
\hline $\begin{array}{l}\text { Voluntary } \\
\text { Instrument }\end{array}$ & Interview & Count & Proportion \\
\hline $\begin{array}{l}\text { Energy Saving } \\
\text { Measures / } \\
\text { Renewable }\end{array}$ & $1,4,5,6,12,19,20,22,30$ & 9 & $22 \%$ \\
\hline Education Program & $1,4,10,16,17,31,37$ & 7 & $17 \%$ \\
\hline Compost/ Recycle & $2,5,12,35$ & 4 & $10 \%$ \\
\hline Water Catchment & 5,35 & 2 & $5 \%$ \\
\hline Personal Projects & $1,2,4,8,10,11,12,17$ & 8 & $20 \%$ \\
\hline None & $3,7,9,14,15,18,21,23,24,25,26,27$, & 20 & $49 \%$ \\
\hline Did Not Know & $38,29,32,33,34,36,38,40$ & 3 & $7 \%$ \\
\hline
\end{tabular}

$\mathrm{N}=41$

When asked specifically about voluntary instruments $18 / 41$ did indicate some form of voluntary instrument in use by their own business or employer. Energy saving instruments, such as solar panels and low energy efficiency devices (toilets and light bulbs) are a common instrument identified (9/41). Voluntary education programs (7/41), composting and recycling programs (4/41), and water catchment devices (2/41) were common responses seen. Personal projects (8/41) includes responses that discuss beach cleanups and mangrove rehabilitation projects (Interviews \#1, 2,4,10 \& 17, 2016). Examples of these responses are in the Table 22 below.

Table 22 Examples of responses indicating using voluntary instruments

\begin{tabular}{|l|l|}
\hline Respondent & Quote \\
\hline 2 & $\begin{array}{l}\text { We compost, grow our own organic foods, we recycle, use large jugs of water versus } \\
\text { many small ones }\end{array}$ \\
\hline 17 & we conduct harbour clean ups and educate our guests \\
\hline 30 & No, just coral rehabilitation but I think some resorts do that here \\
\hline
\end{tabular}


Interviews $18,23,25,36,38,39$ and 41 did not indicate they knew of any voluntary instruments in place were tourists or had no role in tourism industry. This could have influenced the $44 \%$ who responded to not implementing any environmental instruments or knowing what was meant by the question. Tourists may not be aware of what instruments their accommodation is using, in terms of voluntarily environmental instruments. However, interviews \# 7,9,14, 15, 21, 24, 26, 27, 28, 29, 32, 33, 34 and 40 were operators, employees and business owners who did not know of any or use any instruments voluntarily.

There are a number of respondents (8/41) who claimed to implement multiple environmental instruments voluntarily. Interview \#1, a resort manager, said:

We voluntarily use solar energy as a source of energy for the resort. We tag sea turtles as they are a delicacy in Fiji and want to keep track of their numbers. We also bring in a marine biologist to educate the schools (Interview \# 1, 2016).

Another example is from Interview \#4, with a regulator who shared:

We provide educational opportunities for staff and guests, give back to local communities. By monetary and provide jobs, use local supplies. We have a command and control for a no fishing zone, organic gardens and solar energy (Interview \#4, 2016).

Interview \# 5, with a local said:

We use voluntary instruments, compost, water efficient toilets, solar, water catchment. (Interview \#5, 2016)

There are some stakeholders who are using multiple instruments voluntarily. However, there is still a large portion of respondents who are not using any at all (23/41). This could because of a lack of knowledge on their benefits or even how they can set them up themselves. Education opportunities for stakeholder groups to learn how to implement instruments themselves could increase the amount of instruments voluntarily being implemented.

\subsubsection{Current Education Instruments}

6/41 respondents reported current educational instruments in place in Savusavu. Details on these education programs were not provided. When probed for additional information interviewees only knew there were programs that existed not exactly what they entailed. Interview \#16, who is a regulator working for the Savusavu Town Council and the Chamber of Commerce, was the only respondent who mentioned the education instruments; the " Go Green" program, the "Backyard 
Campaign", as well as the "National Clean-up Campaign/Competition". These programs aim to reduce the amount of litter in Savusavu and encourage the community to dispose of waste properly (Interview $\# 16,2016)$.

The researcher asked respondents to indicate whether they felt as though the Savusavu community is educated on the impacts of tourism, both positive and negative. The question was used to determine if the current education instruments in Savusavu are effective. The degree to which the stakeholders of Savusavu's tourism industry understand tourism impacts can influence tourism management. Figure 9 illustrates respondent's opinions on the level of the community's education on the impacts of tourism.

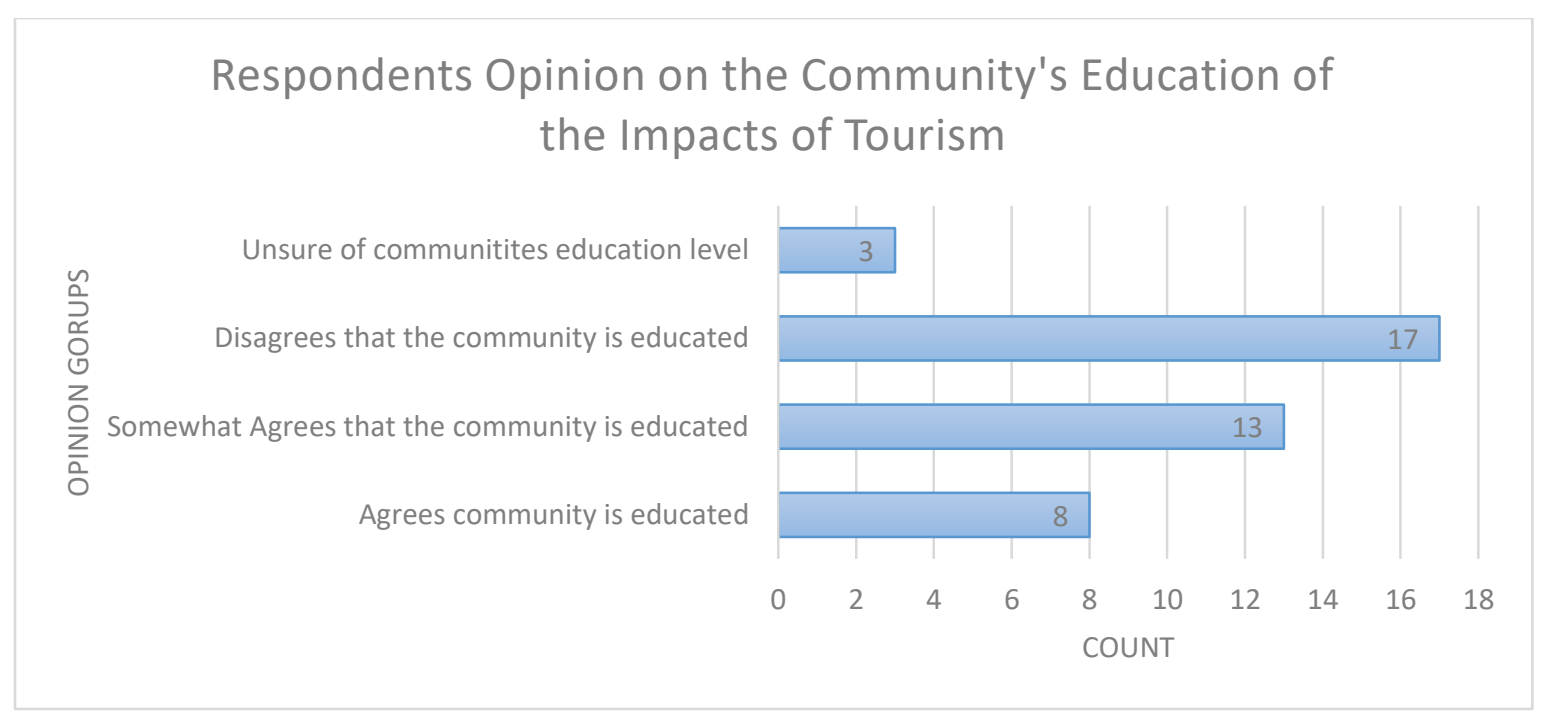

Figure 10 Perceived community understanding of the impacts of tourism on the natural resources

$20 \%$ of respondents believe the community is educated on the impacts of tourism. Examples are from Interview \#31, "yes, the town has been working on educating the residents" and Interview \#18, "yes, more than ever before". There is a trend in respondents stating that the education level amongst the community has been improving. Interview \#22, "I think the community is constantly learning, the new generation is more knowledgeable." Interview \#8 stated, "No not fully, but people are becoming more aware. Cyclone Winston was an eye opener".

From the responses there is also a belief that the community is only somewhat educated, on only the positive impacts (32\%). Interviews \#23, 13, 9, 6, 5 and 4 expressed the community is only partially educated on the positive impacts of tourism. Interview \#13 for example stated "I think they 
realize the positive impacts but not the negatives". Interview \#5, "No, they have a lot to learn, only concerned with or knowledgeable on the economic benefits". From these responses there is a not a strong indication that the Savusavu community is in fact educated on all the impacts of tourism and the current instruments are not effective.

$41 \%$ of respondents do not believe the Savusavu community is educated on the positive and negative impacts of tourism. Interview \#21 with an employee felt this way in saying, "No I don't think they are at all." Another example from Interview \#14 with an operator, “No, they don't and they don't realize the importance of tourism for their livelihoods either". From these responses there is a need to improve the education amongst the Savusavu community on the negative and positive impacts of tourism. Interview \#4 with the Savusavu Community Foundation Executive and STA member, was the only respondent who expressed a desire for new education opportunities: "No, but the community needs to be more educated on their impacts, not necessarily the impacts of tourism but just negative impacts on the environment in general".

\subsubsection{Instruments of Other Islands}

The researcher asked respondents if they have seen instruments used on other islands of Fiji. While 25/41 did not see any other instruments, 16/41 respondents did notice some form of instrument. Respondents reported seeing: wind turbines (14\%), voluntary funds (5\%), marine protected areas (10\%) and other (12\%) which consisted of a mix of answers of education boards for tourists, solar panels and dive tags (Interviews \# 8, 30, 38, 41, 2016). Examples of these answers are in Table 23 below.

Table 23 Example of responses to instruments seen on other Islands

\begin{tabular}{|l|l|}
\hline Respondent & Quote \\
\hline 4 & $\begin{array}{l}\text { I have seen a tagging system used at the Namena Island. Divers need to purchase a } \\
12 \$ \text { tag to be able to dive in the area for a certain period of time. The money from the } \\
\text { tags go towards policing the "tabu" area. }\end{array}$ \\
\hline 7 & $\begin{array}{l}\text { I've seen the Venaka fund, which supports the Fijian villagers. } \\
\text { I know some islands I've been to have energy saving devices and community } \\
\text { programs but I think they might have that here too }\end{array}$ \\
\hline 41 & $\begin{array}{l}\text { I notice a lot more informative boards and education tours on the main Island and the } \\
\text { Yasawas }\end{array}$ \\
\hline
\end{tabular}


Respondents were then asked if they felt as though these instrument should come to Savusavu. This was intended to start to gain an idea of possible new instruments. All of the respondents believed the environmental instrument they saw of or knew of on another islands should be brought to Savusavu. Reasonings for why they felt they should be implemented were provided from interview \#30, an operator: "yes, diver tags could be a good idea here since there is a lot of fishing and diving that goes on." Interview \#17 an operator, "yes, we could use regulations they use for diving and anchoring [referring to regulations of Namena MPA]". Interviewee \# 41 "More information provided maybe at the marina would be nice to teach tourists about the environment of Savusavu" in regards to seeing education boards in the Yasawa Islands of Fiji. Interview \#2 an employee, "[A Recycling plant] this should be brought to Savusavu, people would recycle more if there was an easier way to do so. Currently they have to ship recycling to the main island and pay for this service."

The responses indicated that there is a desire to implement new instruments in Savusavu. From those who did notice a form of environmental instrument in use on other islands only $3 / 21$ felt as though they should not be implemented in Savusavu. Interviewee \#22" I do not think they are an economic viable options for Savusavu as we are too small", in regards to large-scale wind turbine farms. Interviewee \#8 “no, I don't find they actually do anything." in regards to community groups.

\subsection{New Environmental Instruments for Implementation}

This section explores new environmental instruments to implement in Savusavu to promote sustainable development for the tourism industry. The researcher asked respondents to recommend an environmental instrument they would like see implemented in Savusavu to become a more sustainable tourism destination. Their suggestions are seen in the Table 24 below. 
Table 24 Recommended new environmental instruments for Savusavu

\begin{tabular}{|l|l|l|l|}
\hline Instrument & Interview & Count & Proportion \\
\hline Education Instrument & $1,2,6,7,34,40,41$ & 7 & $17 \%$ \\
\hline Economic Instrument & $4,17,30$ & 3 & $7 \%$ \\
\hline $\begin{array}{l}\text { Airport Improvement } \\
\text { Instrument }\end{array}$ & $5,8,11,12,13,19,21,22,38$ & 9 & $22 \%$ \\
\hline $\begin{array}{l}\text { Community } \\
\text { Improvement } \\
\text { Instrument }\end{array}$ & $\begin{array}{l}6,9,10,14,16,21,27,28,29, \\
31,32,33,35,36,37,39\end{array}$ & 16 & $39 \%$ \\
\hline Other & $3,15,18,24,26$ & 5 & $12 \%$ \\
\hline Did Not Know & $20,25,23$ & 3 & $7 \%$ \\
\hline
\end{tabular}

$\mathrm{N}=41$

Education instruments, economic instruments and instruments that could improve the airport and the community were the main themes seen in responses. Other was a mix of restrictions, like banning Indians from selling Fijian culture, stopping AirBnB rentals and the creation of an offshore fishing licensing program (Interviews \# 3, 15 \& 18, 2016). There was also a small group of respondents who did not know what instruments they would like to see implemented (Interviews \# 25, 23 \& 20, 2016).

\subsubsection{New Education Instruments}

7/41 respondents suggested new education instruments for implementation. Implementing these programs specifically in schools is a common theme seen in responses (Interviews \# 1, 2, 6,7,34 \& 40). Interview \#1 with a business owner suggested,

I would start a program at the school to educate youth

on the impacts of tourism on the environment and

the economy. Also would want to highlight the benefits

of including Fijian culture and reenergize it to keep the

Fijian culture alive (Interview\# 1, 2016).

Interview \# 2 with an employee also suggested,

I would give more of an emphasis of education on tourism

in the schooling system of Savusavu. Close the gap of knowledge 
between Fijians and the benefits of tourism. Teach them

about the environment and how it is impacted and how

it plays a vital role in the community (Interview \# 2, 2016).

Interview \#7 with an operator suggested,

Hospitality education programs, at local and university levels.

To teach hospitality management skills, environmental and

social implications in the form of a school program

(Interview \# 7, 2016).

Interview \#41 was the only respondent who suggested an education instrument to educate tourists, "I would say create maybe an information center for tourists if that counts". From these responses there is a desire to improve the community's education on tourism management

\subsubsection{Instruments for Improving the Airport}

9/41 respondents indicated they want an instrument that can improve the airport. Improvements were ideas of increased number of flights, plane size and improved fare prices (Interviews \# 5, 811,12,13,19 \& 38, 2016). An example is from interview \#5 with a local who said, "Better airports, better prices. It is in the best interest of the government, for the tourist industry and for the locals and for importing and exporting". Interview \#22 with a regulator suggested, "I would end the monopoly of the airlines and create competition and add a bigger landing strip." They did not specify an instrument to reach these goals. The respondent's answers focused on what they would like to see happen with a new instrument. There was so no indication on how they can reach these improvements.

\subsubsection{Instruments for Improving the Community}

16/41 respondents suggest instruments to benefit the community. Respondents want to see improved infrastructure, waterfront space, waste management systems and improvements in community relationships (Interviews \# 6,9,10,16,27,28 \& 29, 2016). Specific instruments to do so were not suggested but respondents did outline the goals they want the instruments to have. Examples of these suggestions are from Interview \#31, "I would like to see an instrument that could improve road infrastructure." Interview \# 16 said, "I would want to improve the infrastructure, create a footpath, and create a better waterfront for Savusavu". Respondents may not know how to bring about these changes in the community which is why they responded with a goal rather than a way to achieve it. 


\subsubsection{New Economic Instrument}

3/41 respondents suggest an economic instrument to improve Savusavu's tourism industry. Interview \# 4 with a regulator suggested implementing a tax for tourism operators. The funds from this tax would then go towards various community initiatives; health programs and community education programs (Interview \#4, 2016). Interview \#30 believed a voluntary fund that community members could donate to would be an effective instrument to raise funds for various community projects, like an improved waterfront space (Interview \#30, 2016). While economic instruments are not highly supported, where respondents suggested the funding would go towards was. Supporting community improvements and education was highly supported in the sections above. Respondents of this category have common goals of the respondents from the previous sections, however they suggested an actual instrument to reach these goals. If respondents knew the funds were going towards the goals they outlined then they might accept an economic instrument.

Changes the respondents outlined in the previous section will need funding. Respondents were asked how they could fund their ideas for changes they would like to see in Savusavu. This was asked to begin to understand stakeholder's willingness to pay. The Table 25 illustrates ways in which the respondents would seek funding.

Table 25 Suggested methods for funding changes

\begin{tabular}{|l|l|l|l|}
\hline Theme & Interview & Count & Proportion \\
\hline $\begin{array}{l}\text { Government } \\
\text { Funding }\end{array}$ & $\begin{array}{l}1,4,5,6,7,9,11,12,13,14,15,16,18,19,20,21, \\
22,23,31,32,33,34,36,37,38,39,41\end{array}$ & 27 & $69 \%$ \\
\hline $\begin{array}{l}\text { Voluntary Funds } \\
\text { from STA or large } \\
\text { Resorts }\end{array}$ & $2,3,24,30,31,36$ & 6 & $18 \%$ \\
\hline Private Partnerships & $6,8,12,17,22,26,29,40$ & 8 & $21 \%$ \\
\hline Wouldn't Need Any & 10,27 & 2 & $5 \%$ \\
\hline NGOs & $24,26,40$ & 3 & $8 \%$ \\
\hline
\end{tabular}

$\mathrm{N}=39$ (\#25 and \#28 did not provide an answer)

The majority of respondents (69\%) believe the Fijian government is responsible for funding changes made to improve the tourism industry. An example is from Interview \# 1, "The government should be the one funding any changes to the tourism industry". Some of the respondents mention the municipal government specifically as being responsible for acquiring the necessary funding for the 
changes in Savusavu (Interviews \#33, 34, 36 and 41, 2016). 18\% of respondents believe voluntary funds and donations can acquire funds to make changes. Expat families, resorts and donations from the STA members are common sources of these donations. When respondents consider STA as a source of funding they are indicating that the members of STA would donate funds or raise funds by asking for donations from members (Interviews \# 2, 24 and 30). 21\% believe private partnerships is another way to access funding. Examples of respondents who provided a reasoning and explanation with their response is in Table 26.

Table 26 Examples of responses indicating sources of funding for new instruments

\begin{tabular}{|l|l|}
\hline Interview & Quote \\
\hline 2 & $\begin{array}{l}\text { Funding can be gained voluntarily. Expats and other families will support changes if they } \\
\text { will benefit the tourism industry }\end{array}$ \\
\hline 6 & $\begin{array}{l}\text { Funds can be acquired through advanced payments and private partnerships. People will } \\
\text { fund because they will be able to develop further and because of the benefits they would } \\
\text { receive from having a wastewater management facility. By having the town payments in } \\
\text { advanced funds could be acquired to fix the problem now. Government should } \\
\text { contribute as well }\end{array}$ \\
\hline 7 & $\begin{array}{l}\text { All resorts already pay a levy, this levy should go towards these education programs. Set } \\
\text { up something permanently in Savusavu and in each district of Fiji versus the current } 3 \\
\text { day programs that occur monthly [in relation to a new tourism education program] }\end{array}$ \\
\hline 14 & $\begin{array}{l}\text { the government and the minister of transportation could make these changes happen } \\
\text { and should fund them }\end{array}$ \\
\hline 16 & $\begin{array}{l}\text { to do this I would, seek funding from the ministry of the local government and use the } \\
\text { "challenge funds" provided by the government }\end{array}$ \\
\hline 30 & $\begin{array}{l}\text { Well it would be voluntary so I think big resorts would donate if they know changes will } \\
\text { actually happen }\end{array}$ \\
\hline 37 & government funding would be needed, council could send in a request \\
\hline
\end{tabular}

The respondents believe it is the role of the government to help fund changes, but they also suggest private partnerships and voluntary funds to create the changes they want. The issue with this is who will initiate these partnerships. And private partnerships may mean private benefits and goals being realized but not the community as a whole. A voluntary fund can fund multiple goals. 


\subsubsection{Acceptance of an Economic Instrument to Promote Sustainability}

Economic instruments can collect funding to help destinations manage and develop their tourism industry in a sustainable manner. Common economic instruments were user fees, taxes and voluntary funds seen in Chapter 2. Respondents revealed if they believed a new tax, user fee or voluntary fund would be accepted by the stakeholders of Savusavu. Responses are in Table 27.

Table 27 Stakeholders' perceptions of the community's acceptance of a new environmental instrument

\begin{tabular}{|l|l|l|l|}
\hline Response & Interview & Count & Proportion \\
\hline Rejected / no & $1,4,5,12,17,23,24,25,36,40$ & 10 & $24 \%$ \\
\hline Maybe / not sure & $3,9,13,27,28,32,33,39,41$ & 9 & $21 \%$ \\
\hline Accepted / yes & $\begin{array}{l}2,6,7,8,10,11,14,15,16,18,19,20,21,22, \\
26,29,30,31,34,35,37,38\end{array}$ & 22 & $54 \%$ \\
\hline
\end{tabular}

$\mathrm{N}=41$

$54 \%$ believed some form of instrument would be accepted. $21 \%$ were not sure if a new economic instrument would be accepted and $24 \%$ believed it would be rejected. Respondents were then asked to explain their response.

For the respondents who were unsure whether an economic instrument would be accepted Table 28 provides some of the reasoning as to why.

Table 28 Respondents reasoning's for maybe accepting a new economic instrument

\begin{tabular}{|l|l|}
\hline Interview & Quote \\
\hline 32 & It might be, not a tax but an optional one. \\
\hline 33 & $\begin{array}{l}\text { A tax wouldn't but a voluntary might. A lot of rich people own resorts and lands here } \\
\text { that might want to voluntarily pay. Some would want to donate but might not be able } \\
\text { to afford it. }\end{array}$ \\
\hline 39 & it might be if it actually was being used to improve the environment \\
\hline 41 & it might if those giving to it knew where it was going \\
\hline 25 & I'm not sure, I don't think people would want to be forced to pay anything though. \\
\hline 27 & no I don't, no one wants to pay more, maybe if it was voluntary \\
\hline 41 & it might if those giving to it knew where it was going \\
\hline
\end{tabular}


The responses in this group are unsure because they do not trust that the funds collected would go towards the instrument's purpose. A document providing information on what the money went towards may increase the acceptability amongst the Savusavu community of a new economic instrument.

Table 29 below provides multiple responses as why an economic instrument would be rejected.

Table 29 Reasonings for rejection of an economic instrument

\begin{tabular}{|l|l|}
\hline Interview & Quote \\
\hline 1 & $\begin{array}{l}\text { I think it would be rejected, resorts and property owners do their fair share already to } \\
\text { conserve the natural resources }\end{array}$ \\
\hline 4 & $\begin{array}{l}\text { No, stakeholders are doing their own personal projects and initiatives. I feel like we } \\
\text { have what we need already }\end{array}$ \\
\hline 5 & $\begin{array}{l}\text { no, people don't have money and do their own personal projects } \\
\text { trust }\end{array}$ \\
\hline 12 & $\begin{array}{l}\text { no our taxes are already too high } \\
\text { realistically no, I don't think it would actually achieve any goals so people wouldn't } \\
\text { accept them }\end{array}$ \\
\hline 23 & $\begin{array}{l}\text { I don't think a tax would because people are already taxed enough. } \\
\text { right now }\end{array}$ \\
\hline 24 &
\end{tabular}

These respondents believe the current taxes, personal projects and environmental levy are already enough economic instruments in place and reasons for rejection. The fact that there are currently no other economic instruments to be paid are reasons for rejection seen in the responses as they do not want to pay more. There is also a theme of lack of trust as to where the generated funds will go towards in these responses similar to the table above.

Table 30 below provides multiple reasons as to why an economic instrument would be accepted. 
Table 30 Reasonings for acceptance of a new economic instrument

\begin{tabular}{|l|l|}
\hline Interview & Quote \\
\hline 2 & $\begin{array}{l}\text { yes, there are many expats and families that care about Savusavu that would be willing } \\
\text { to voluntarily pay for the conservation of the islands natural resources. Fijians would } \\
\text { not accept it, maybe expats }\end{array}$ \\
\hline 6 & $\begin{array}{l}\text { yes, if the fund was only for the Savusavu area and it was transparent and credible } \\
\text { then it would work }\end{array}$ \\
\hline 10 & yes, voluntary fund would be because it would benefit everyone \\
\hline 16 & $\begin{array}{l}\text { yes I do, if it was completely transparent, people like to know where their money is } \\
\text { going }\end{array}$ \\
\hline 19 & $\begin{array}{l}\text { user and voluntary fee would be a good idea, as long as the people knew where their } \\
\text { money was going }\end{array}$ \\
\hline 20 & $\begin{array}{l}\text { Yes to voluntary or user fee, people would if they had money } \\
\text { already are taxed so might not be a good idea. }\end{array}$ \\
\hline 26 & $\begin{array}{l}\text { I think a diving user fee would be accepted, Nemena uses one. I don't think taxes } \\
\text { would be widely accepted because people are paying taxes already. }\end{array}$ \\
\hline 31 & \begin{tabular}{l} 
if it was actually helping the environment and sustaining the industry then yes \\
\hline 37
\end{tabular} \\
\hline
\end{tabular}

If a new economic instrument was introduced a voluntary fund would be the most accepted form of economic instrument. Respondents believe transparency and having the option to pay is an important consideration for a new instrument. There would need to be transparency in where the funds were going and would have to go towards common goals of the community. Common reasons for rejection of economic instruments were because Savusavu is already highly taxed and some stakeholders feel as though they are already doing their part in managing the natural resources of Savusavu. Savusavu has many taxes in place that are mandatory; having a transparent and open instrument is something new. This might influence acceptance.

\subsection{Creating Changes in the Tourism Industry}

The following section presents the data that explored how changes are made in Savusavu.

Implementing a new environmental instrument would cause changes in the current tourism policy and management of Savusavu. In order to make informed recommendations the researcher 
wanted to understand how changes are made in Savusavu. Respondents were asked how current changes are made and their responses are in Table 31.

Table 31 Respondents' answers to how changes are made to Savusavu's tourism industry

\begin{tabular}{|l|l|l|l|}
\hline Response & Interview & Count & Proportion \\
\hline $\begin{array}{l}\text { Savusavu Tourism } \\
\text { Association }\end{array}$ & $\begin{array}{l}1,6,10,11,13,16,17,26,30,31, \\
32,33,37,40\end{array}$ & 14 & $34 \%$ \\
\hline Government of Fiji & $\begin{array}{l}2,3,4,5,6,7,8,9,10,12,14,16, \\
18,19,22,31,35,37,39\end{array}$ & 19 & $46 \%$ \\
\hline $\begin{array}{l}\text { Savusavu Town } \\
\text { Council }\end{array}$ & $7,16,20,26,28,29,31,34,37$ & 9 & $30 \%$ \\
\hline Fijian Villages & $13,16,18,27$ & 4 & $10 \%$ \\
\hline Does Not know & $15,21,23,24,25,36,38,41$ & 8 & $19 \%$ \\
\hline
\end{tabular}

$\mathrm{N}=41$

Respondents indicate that changes to Savusavu's tourism industry are made by either the STA (14/41), the Government of Fiji (19/41), Savusavu Town Council (9/41), the Fijian villages (4/41) or they did not know (8/41). Examples of responses are in Table 32.

Table 32 Quotes indicating the stakeholders involved in tourism decisions

\begin{tabular}{|l|l|}
\hline Interview & Quote \\
\hline 37 & $\begin{array}{l}\text { The Savusavu Tourism Association, the town council and the government work together } \\
\text { to make changes }\end{array}$ \\
\hline 1 & Well the Savusavu Tourism Association makes most of the decisions \\
\hline 6 & Government, STA and Savusavu town council are currently the ones making changes \\
\hline 12 & Government, mainly from main Island, little influence made by our local environment \\
\hline
\end{tabular}

From these responses there is a mixture of key stakeholders involved in the tourism related changes. This is useful information for creating recommendations as knowing the roles stakeholders play in tourism is supported in the literature as a best practice for implementing environmental instruments (Liu et al., 2012; Krutwaysho \& Bramwell, 2010; Waligo et al., 2013; Wang \& Ap, 2013 


\subsection{Conclusions}

This chapter presented an analysis of the data collected from the qualitative interviews with stakeholders in Savusavu, Fiji. The following chapter will provide discussion and summary of the environmental issues identified from the data analysis. The chapter will also present recommendations on what environmental instruments Savusavu should implement to reach sustainable outcomes. 


\section{Chapter 6: Discussion and Recommendations}

This study used stakeholder opinions to identify the key issues Savusavu faces in developing a sustainable tourism industry and to determine the goals of the destination. The study also identified current environmental instruments in Savusavu. Therefore, the focus of the following discussion is on:

1) Lack of waste management

2) Lack of education and participation amongst stakeholders

3) Economic focus amongst stakeholders

4) Susceptibility to climate change and natural disasters

5) Current environmental instruments

The key issues from this research are similar to other studies regarding sustainable tourism development for SIDS (Gossling, 2001; Juvan et al., 2016; Ruckelshaus et al., 2013; Well et al., 2016). The discussion presents each issue and the connections between them. Current instruments impacting the development of Savusavu will then be discussed. Recommendations to address the issues are made following the discussion. The recommendations focus on the implementation of environmental instruments to address the issues discussed and meet the goals outlined by the stakeholders for Savusavu.

\subsection{Lack of Waste Management}

Waste management is a key issue for sustainable development in Savusavu. Savusavu currently does not have adequate waste management systems in place to sustain the tourism industry. In section 5.2.1 respondents indicated waste management for water and physical waste is a natural resource management issue of Savusavu (Interviews 2,4,5,6,8,16,23,24,31,33,36 \& 41, 2016). In section 5.3.2 19\% of respondents perceived waste management as a barrier to Savusavu developing sustainable tourism. This lack of planning and management is a key issue for the destination in terms of developing a sustainable tourism industry because of the detrimental impacts on the surrounding natural environment. An island's natural resources play a central role in attracting tourists to a destination and the overall success of a destination (Birdir et al., 2013; Dodds, 2007).

Stakeholders explained that there is no centralized wastewater treatment system in Savusavu (Interviews \#2, 4, 6, 5, 8, 16 \& 37, 2016). The majority of residences and establishments are on communal septic tanks. However, some large resorts with the available financial resources are able to install their own centralized waste water treatment systems, like the Namalea Resort (Interview \#4, 
2016). The research assumes the lack of wastewater management is having negative impacts on the groundwater, soil and the surrounding resources. Sustainable management of wastewater was found to be especially important for small islands as it plays an integral role for human health and ecosystems services (Gossling, 2001; Wells et al., 2016). The very resources stakeholders use for tourism purposes, natural beauty, rainforests and coral reefs that are outlined in section 5.2.2 are at risk of depletion and contamination.

Interviews revealed there is no recycling plant on the island and there is an issue of littering. Some stakeholders (Interviews \# 4, 8, 23, 24,31,36,41, 2016) were aware of this issue and did express concerns in section 5.2.1 and section 5.3.2 of the data analysis. If an individual wants to recycle, they have to pay for their recycling to be shipped to the main island. This is not considered sustainable for multiple reasons. Firstly, not all stakeholders can afford to have their recycling shipped (Interview 4, 2016). The key informant of this study revealed that some stakeholders will burn or dump their waste and recycling to avoid paying the costs associated with waste disposal.

Secondly, the emissions and environmental footprint created with the shipping of the recycling to the main island is an issue. After the recycling is loaded onto the ships, it travels nearly 4 hours by ferry to reach Suva, the capital located on Viti Levu Island. The ferry runs on fossil fuels and emits harmful emissions into the atmosphere and water. The loading dock for the ships is no more than 4 kilometers from the popular marina in the downtown core of Savusavu and in sight from some of the accommodations. This is seen as an issue because of the emissions, noise and the visual pollution. The ships can be seen and smelled by tourists who are likely swimming, fishing or diving near the loading dock, thereby affecting the natural beauty of the island, which was said to be used by $19 \%$ of stakeholders for tourism purposes in section 5.2.2. Degradation of natural resources through man-made causes can weaken the tourist appeal of the destination, bringing economic decline (Bruzzi et al., 2011).

Stakeholders wishing to recycle and dispose of waste properly are left with minimal options. Groundwater, parts of the ocean and soil of Savusavu can be considered a common resource. The implications of the mismanagement of waste goes beyond just the tourism industry because the impacts will be shared on common resources. Farming and agriculture are the other main industries of Savusavu discussed in Chapter 3. If groundwater and soil contamination occur, which they likely will as there was no indication changes to the current management, crops of farmers who are on the same watershed may face problems from high nutrient loads (Wells et al.,2016). 
While this researcher considers this issue of waste management central in terms of being a barrier to Savusavu developing sustainably, the stakeholder interviews do not. In section 5.5.3 only $(16 / 41)$ respondents indicated they would introduce an instrument to improve the Savusavu community. Three respondents specifically indicated improvement to waste management. The lack of attention given to improvement of waste management is believed to be linked to a lack of education amongst the stakeholders.

\subsection{Lack of Education and Participation amongst Stakeholders in Tourism}

The lack of education amongst stakeholders is a key issue to sustainable development in Savusavu. The community is not educated on both the positive and negative impacts of tourism. $41 \%$ of respondents indicated that the Savusavu community is not educated on the impacts of tourism. Some stakeholders believe the community is only partially educated on the positives impacts of tourism (Interviews \# 9,6,5,4,12,13,14,21,23,34,35,39,41, 2016). This is likely affecting how the industry is currently managed. The literature seen in Chapter 2 emphasized the need for all stakeholders involved in a tourism industry to be educated on the various impacts of tourism in order to produce sustainable outcomes (Bruzzi et al., 2011; Emilsson \&Hjelm, 2007; Gani et al., 2017; Littau et al., 2010). The lack of education amongst the community is revealed in this section under many instances.

When stakeholders were asked what they perceived to be the barriers to sustainable development, the majority of respondents $(41 \%)$ in section 5.3 believe the airport size is the major barrier. Even though tourist numbers to Fiji have been increasing in recent years, the stakeholders believe this is a sustainability issue. This suggests that they are not educated on what sustainable development truly means for the tourism industry. This research used the definition of sustainability provided by the WTO (2015) as a basis: "Tourism that takes full account of its current and future economic, social and environmental impacts, addressing the needs of visitors, the industry, and the environment and host communities" (World Tourism Organization, 2015, p.1). Sustaining a tourism industry with constant tourist numbers is not what sustainable development truly means. The needs of the host communities, for example, are not being met in terms of proper waste water management. However, new instruments to solve this issue were not highly supported by stakeholders.

Respondents (Interviews \# 1,3,9,10,13, 15,22,25,26, 27,28,29,32 33, 34, 35, 2016) further proved the lack of knowledge in the community when they did not report a barrier that Savusavu faces in becoming a sustainable tourism destination. In reality, Savusavu is facing many issues that can be 
seen as barriers common to SIDS that were revealed in section 5.3 and in section 5.2 where natural resource management issues were discussed.

When investigating the role natural resources play for the tourism industry, many respondents failed to identify their vital roles. Respondents $(9,13,14,16,18,26,27,29,31,32,33,34,35)$ denied they used natural resources for tourism purposes altogether. However, from other questions in the interview it was proven in section 5.2.2 some were in fact using natural resources. $32 \%$ of respondents also indicate that they do not benefit from the use of natural resources. They lack an understanding of the many benefits natural resources provide to the community. The majority of respondents (68\%) did agree that they are benefiting from the use of natural resources in some form. However, the benefits had an economic focus. This lack of knowledge and awareness amongst the tourism stakeholder groups on the role natural resources play is likely negatively impacting how the natural resources are currently managed. It could also influence their understanding and acceptance of new environmental instruments recommended to protect and conserve them (Cherry et al., 2012; Dredge \& Jamal, 2015; Hall 2010). Respondents did not mention the health, recreation and community benefits resources provide (Gani et al., 2017; WWF, 2016). The economic focus amongst stakeholder is discussed in section 6.3.

There is a knowledge gap in the role natural resources play for tourism and tourism in general amongst the Savusavu tourism stakeholders. Improving stakeholders' knowledge on the role natural resources play for the tourism industry could positively influence the way in which they use and manage them (Bruzzi et al., 2011; Gani et al., 2017; Graci \& Dodds, 2012; Ostrom, 2001). This knowledge gap is an issue because it is not influencing collective management of the issues Savusavu is experiencing. Ostrom's main point was that individuals will be more likely to create and conserve a commons when they have credible and reliable information about the costs and benefits of resource decisions (Foryth \& Johnson, 2014; Ostrom 2015). If the level of education is not improved in Savusavu sustainable development of the tourism will likely not occur.

\subsubsection{Lack of Stakeholder Participation in Tourism}

Participation amongst stakeholders in tourism related decisions is low and is considered a key issue of Savusavu developing a sustainable tourism industry. $63 \%$ of respondents said they do not participate in tourism related decisions. The majority of respondents who stated to be involved and actively participating within the tourism industry are members of the STA (Interviews \#2, $4,6,8,10,16,19,22,31 \& 37,2016)$. This finding raises the concern that there are not many options for the 
public to get involved in tourism related decisions unless you are a member of the STA. To be a member of the STA however, there is a membership fee associated (Interview 4, 2016). This may deter the public from joining and enable them to provide potentially helpful information on tourism related decisions. Public participation is an integral component of sustainable development (Sher et al., 2015; Waligo et al., 2013; Wang \& Ap, 2013). Having all stakeholders involved in tourism related decisions can reveal conflicts, benefits, costs and knowledge that can support sustainable development and collective management (Dietz et al., 2003).

Respondents are unaware of how current changes to the tourism industry are made (Interviews \# 15, 21, 23, 24, 25, 36, 38, 41, 2016). Stakeholders do not know who or how changes are made and likely do not influence or participate in tourism related decisions. Locals, operators, business owners and employees stated they are not involved in tourism related decisions. Another indicator of low stakeholder participation was that the public was not suggested as an influential stakeholder group in section 5.1.1. However, studies on the impact of public acceptance and participation in tourism related changes is seen a major contributor to developing effective policy for tourism (Byrd et al., 2008; Cardenas et al., 2015). Stakeholder theory also supports that all stakeholders need to be involved in order to make informed decisions and create sustainability (Khazaei et al., 2015).

\subsection{Economic Focus}

Tourism is often only seen as important for the economic benefits it can provide to the involved stakeholders. These findings are seen in many studies from Chapter 2 (Bramwell \& Bernard, 2005; Brendehaug et al., 2016; Dodds 2007; Dodds \& Butler, 2009). For the case of Savusavu there is an economic focus amongst the tourism stakeholders. This is an issue to sustainable development and is closely related to a lack of education. There are several instances where stakeholders illustrate an economic focus on the benefits of tourism that are displayed in this section.

The benefits discussed on the use of natural resources for tourism purposes relate to financial gains (Interviews \# 1, 2,3 , 4, 6, 11, 12, 15,16 , 17 ,18 19 20, 21, 24, 24, 31, 37, 2016). Stakeholders perceive financial gains, attraction of tourists to the destination and the creation of activities for tourists to be the benefits from natural resource used for tourism purposes. Natural resource use in tourism can produce benefits other than those associated to economic gains. Improved infrastructure, education and health care amongst communities, justification of environmental protection, as well as promoting community involvement and strengthening community relationships can be created by using natural 
resources (Davenport and Davenport, 2006; Catibog-Sinha, 2010;Palmer \& Riera, 2003; WTO, 2015; Wilkinson \& Salvat, 2012). Participation in recreation and tourism can also bring many benefits such as family cohesiveness and relaxation (Gani et al., 2017). However, none of these benefits were stated from the stakeholder interviews.

The most commonly perceived barrier discussed in terms of Savusavu being a sustainable destination was the fact that the airport is not big enough and does not have frequent affordable flights to bring in more tourists (Interviews \#1, 2, 5, 16, 21,27,31,34 \& 38, 2016). Stakeholders believe this affects the amount of tourists and money entering Savusavu. This is not seen as an actual issue of sustainability as there are still tourists coming to Savusavu and there is the option of boating to get to Savusavu. Section 2.5.1 on impacts on natural resources and section 5.3 discussing the barriers of Savusavu highlight much more critical issues of climate change, marine environment destruction and lack of waste management that were not of concern for these stakeholders. Again, this illustrates the majority of stakeholders primary focus is on the economic gains of the tourism industry.

This economic focus is likely influencing the management of the island's natural resources and tourism industry. Pressing issues like the lack of wastewater management system may be seen secondary to airport expansion. Each stakeholder is exploring self-interests of financial gain, as seen in Harding's Tragedy of the Commons, ignoring the shared costs of environment degradation (Hardin, 1968). All stakeholders need to be properly informed and have the necessary resources to understand the positive and negative economic, environmental and social impacts of tourism. If the economic benefits of tourism are the main focus of stakeholders, tragedy will likely occur for the open resources they share. Economic success depends on the user's ability to solve individual and collective problems (Ostrom, 1990). If stakeholders are not equipped with the knowledge to support sustainable development then problems will continue to exist. This issue further supports the need to improve stakeholder education.

\subsection{Susceptibility to Climate Change and Natural Disasters}

As a coastal town, Savusavu is at risk of facing the impacts of climate change and natural disasters. This is common for SIDS like Fiji as discussed in Chapter 2 and is a key issue of the destination (Boukas \& Ziakas, 2014; Shareef \& McAleer 2005). In section 5.2.1 respondents indicate coral bleaching as a natural resource management barrier of Savusavu. An interview with an operator stated, "Reefs are facing issues of breaking and bleaching, this could be a combination of natural causes (climate change) 
and tourism related causes" (Interview \#12, 2016). Savusavu is primarily known for its diving tourism and plays a significant role in attracting tourists to the island. The continuation of coral bleaching of the reef ecosystems can have detrimental impacts on Savusavu's economy and society. Savusavu must adapt and consider a plan to mitigate these impacts. From the data there is little being done to combat or prepare for the impacts of climate change.

Savusavu was hit by Cyclone Winston in January 2016 and there are still areas that are suffering from the impacts. Physical damage caused by Cyclone Winston was a concerned raised by respondents. Interviews \#7, 19, 21, 30, 38, 39, 40 addressed the issue of Savusavu being susceptible to natural disasters. Coral breakage, rainforest destruction and infrastructure damage were reported impacts of the Cyclone on Savusavu. Coral for diving and the rainforest were highly used recourses for the tourism industry in section 5.2.2. The state of these natural resources is crucial to the success of the industry.

While Savusavu cannot control when natural disasters occur, it can prepare and plan in an attempt to minimize and manage the impacts. Current management strategies or instruments addressing these risks were not seen. When discussing current environmental instruments in section 5.4, there was only 2 instances where instruments were addressing these issues. Coral rehabilitation programs are being implemented by 2 large resorts. Other instruments addressing the impacts of climate change on the island were not indicated. There was no suggestion of what the town does for the case of risk management and climate change impact management.

\subsection{Current Environmental Instruments}

Stakeholders identified environmental instruments currently in place in Savusavu. Section 5.4 of the data analysis presents the information on current environmental instruments. Environmental taxes, regulatory instruments, MPAs, voluntary initiatives, education programs and EIAs were instruments identified. Therefore, Savusavu currently has measures in place that influence the development of the tourism industry.

The Fijian villages currently implement traditional fishing "tabus". The tabu restricts where stakeholders can fish in an attempt to let the fish populations repopulate (Interviews \#14, 21, 22, $23,29,35,40,2016)$. The tabu supports Ostrom's theory of Governing the Commons, as it provides an example of self-governance of open natural resources. The local Fijian villages have developed their own form of collective management to manage the fish populations of Savusavu. The village chiefs set out the physical boundaries for the tabu and the length in which the tabu will stay in place. The government 
is not involved and does not need to use its resources to monitor the tabus as it is agreed upon by the whole community that they will adhere to the restrictions. The surrounding community realizes that there is overfishing and a decline in fish stocks. By temporarily restricting all fishing in these areas the fish populations will regenerate. It is assumed that these restrictions are adhered to because the communities realize the benefits that will come by following the tabu. Identifying the incentives and the costs of a natural system is supported by Ostrom in developing forms of collective management (Ostrom, 2015). Local communities need fish for their everyday diets and to sell. While resorts and local restaurants need fish to feed tourists. Therefore they all adhere to the rules of the tabu. This tabu is considered a regulatory instrument in Savusavu because it is enforced and penalties can occur if the tabu is not followed.

A current economic instrument that is in place not only in Savusavu but for all of Fiji is the Environmental Levy imposed by the Fijian government. The levy was introduced in January 2016. The Fijian government has a $25 \%$ government tax on all products and services. The environmental levy is included in this tax. The tax is made up of:

- $\quad$ Value Added taxes (VAT) (9\%)

- Service Turnover Tax (STT) (10\%)

- Environmental Levy (6\%)

The environmental levy rate is 6 per cent and is levied on the "turnover" of prescribed service providers. "Turnover" meaning the total charges for prescribed services billed to consumers. The environmental levy payable is computed by applying the tax rate to the fee for the prescribed service (Fiji Revenue \& Customs Service, 2016). The environmental levy is charged or levied on prescribed services listed under the Schedule of the Environmental Levy Act. Therefore, the levy is not imposed on actions that the government would like to encourage or phase out like the examples seen from the literature review (Birdir et al., 2013; Thur, 2010; Winfield, 2016). Prescribed services include the provision of:

- accommodation, refreshments and any other services in licensed hotels or tourist vessels;

- meals, beverages and any other services in licensed restaurants, bars, clubs, bistros and coffee shops with an annual gross sales of $\$ 1.25$ million or more;

- all services in licensed nightclubs;

- travel, tour and sightseeing services by inbound tour operators;

- all hired or rented car services with "LH" and "LR" license number plates excluding taxis with "LT" license number plates; 
- all services including entry ticket fees provided within cinema premises;

- all water sports activities such as river safaris by water sports operators;

- accommodation and any other services by a registered homestay operators;

- recreational activities by recreational activity operators such as skydiving;

- live entertainment by personal participation of artistes or exhibition of products where entry fees is charged for events venue; and

- charter flight services by aircraft operators except flights for medical or natural disaster relief evacuation services (Fiji Revenue \& Customs Service, 2016, p.1).

Service providers need to register for the environmental levy before they can start charging consumers. Owners or managers must account for the environmental levy in monthly returns. The levy return must be completed with either cheque or cash for that month by the end of the following month (Fiji Revenue \& Customs Service, 2016). There are penalties and offences related to the levy. For example, any levy remaining unpaid after the due date for payment will receive a $25 \%$ late payment penalty. The courts can impose a maximum fine of $\mathrm{FJ} \$ 15,000$ or to imprisonment for a term not exceeding 12 months or to both a fine and imprisonment for the following offences:

- Failure to file environmental levy return;

- Failure to comply with obligations under Tax Administration Decree;

- failure to produce any books or records relating to the turnover and collection/payment of environmental levy (Fiji Revenue \& Customs Service, 2016, p.2)

Only 3 respondents were able to give an indication of what the money generated from the levy was used for (Interviews \#16, 26 \& 37, 2016). This illustrates a lack of education or a lack of concern of what the levy's purpose. While the government may not have clearly communicated what levy's purpose was, it is also possible that the stakeholders did not care to ask. This further questions Savusavu stakeholder's involvement and knowledge of the tourism industry. According to the Fijian Revenue and Custom services website the levy will be used to support environmental protection programs. The levy "reinforces the Government's commitment for all Fijians the right to a clean environment" (Fiji Revenue \& Customs Service, 2016, p.1). The funds will be used, " to promote conservation of the forests, flora, fauna, wildlife, ecosystems and biodiversity of Fiji, provide funding to assist programs, projects and activities associated with climate change, including climate change mitigation and adaptation activities and engage in any environment or climate change related activity approved by the Minister" (Fiji Revenue \& Customs Service, 2016, p.1) . Therefore, the levy is intended to protect and conserve that natural resources of Fiji. What was clear from the stakeholder interviews were that taxes and levies have a negative association with them. Interviewees felt that the taxes were too high and are just used a 
revenue gainer for Government, without an intention to benefit the tourism industry (Interviews \#3, $6,8,41,2016)$.

Respondents were also asked to indicate whether they knew of instruments currently in place on other islands. In section 5.4.6 multiple instruments were seen identified by 25/41 respondents. Examples seen were wind turbines, voluntary funds, MPAs and a mix of answers like education boards and dive tag programs. All of the respondents believed the environmental instrument they saw of or knew of on another islands should be brought to Savusavu. Public acceptance is a major issue seen in the literature surrounding the implementation of new environmental instruments (Cherry et al., 2012; Dredge \& Jamal, 2015; Hall 2010). Therefore, this is an indication new instruments will be accepted by the Savusavu community. Though 16 of the 41 respondents did not indicate they know of any other instruments, 14/16 indicated that they would like to see them brought to Savusavu if they will have a positive impact on the management of the tourism industry. Again, enforcing the idea that the Savusavu stakeholders would be accepting of new instruments that would promote sustainable tourism.

\subsection{Recommendations}

This section outlines the recommendations of the study. These recommendations are made based on the information gathered from stakeholder interviews and lessons learned from the literature review. The recommendations aim is to overcome the key issues previously discussed. The recommendations also intend to manage Savusavu's natural resources in a collective manner by the involved stakeholders to avoid tragedy (Ostrom, 2015). This study acknowledges that including the perspectives of all stakeholders for natural resources management can lead to sustainable development (Bramwell \& Lane, 1993; Grimble \& Chan 1995; Reed et al., 2009). Ultimately, the goal of these recommendations is to promote sustainable development for Savusavu's tourism industry.

The recommendations provided below are realistic and specific. The study considered a variety of environmental instruments seen in the literature as methods to improve sustainable development in Savusavu. Environmental instruments are tools that can control actions of stakeholders or influence them to creating sustainable tourism development (Ayuso, 2007; Harrington \& Morgenstern, 2007; Winfield, 2016; Yasamis, 2011). Instruments were chosen that would be the most effective based on their acceptability, distribution of benefits and their ability to meet the goals of Savusavu. These characteristics are the best practices from effective instrument implementation reviewed in Chapter 2 (Bocking, 2016; Logar, 2010; Hahn \& Stavin, 1992; Winfield, 2016). 


\subsubsection{Recommendation 1: Increase Stakeholder Participation}

The first recommendation is to increase stakeholder participation in tourism related decisions in Savusavu. This is recommended to improve decisions related to the tourism industry by incorporating multiple stakeholder viewpoints. Stakeholder theory defends that the inclusion of all stakeholders and their perspectives leads to effective resource management. By incorporating all stakeholders, managers can better anticipate and deal with stakeholder opposition, conflict and better incorporate the interests of the stakeholders involved (Grimble \& Chan, 1995; Hall, 2010; Freeman 1987; Khazaie, 2015; Mason \& Mitroff, 1981).

The following stakeholder engagement instruments are recommended to improve stakeholder participation:

1. Community meetings. Community meetings should be held to present new developments or changes occurring in Savusavu. They should also provide updates on current and ongoing developments. Stakeholders should be engaged throughout the full life cycle of developments so that proper decisions are made (Diez et al., 2015). Meetings can discuss possible new instruments for implementation and changes stakeholders want to see in Savusavu. The intent of the meetings is for stakeholders to be able to learn and understand tourism developments and to be able to contribute to decision making.

2. Online forum. Create an online forum where new and current development projects are listed. Information on the projects should be listed in detail and any upcoming meetings regarding the developments should be posted. Having an online component can include stakeholders who are not able to make meetings and who feel more comfortable participating online versus in person. The online forum can also be a place where stakeholders can discuss changes they want to make in Savusavu.

It is recommended that the STA spearheads these engagement activities. This organization is dedicated to improving tourism in Savusavu and is already well established. This would not require the time and resources it would take to develop a new organization whose goal is to engage stakeholders in tourism related decisions in Savusavu. The STA already has many members with connections to the indigenous community, business sector and regulators which can be used to promote the meetings and online forum to a variety of stakeholders. Locals, operators, regulators and other stakeholders play an important role in tourism management through their planning activities, policies, programs and monitoring (Bruzzi et al., 2011; Emilsson \& Hjelm 2007; Larson \& Lach, 2008). The meetings and forum should be open to all stakeholders, not just members of the STA. 
It was seen in this study that there is a desire amongst the Savusavu stakeholders to become more involved in the planning and decisions related to tourism. $54 \%(22 / 41)$ of respondents said they would participate if given the opportunity to do so. Participants who did not want to become more involved were either tourists or individuals who already felt as though they were too involved. It is assumed that the instruments recommended would therefore be accepted. Community participation is viewed as an important tenet of tourism planning and researchers agree that engaging all stakeholder groups contributes to tourism sustainability (Bramewell \& Lane 1993; Grimble \& Chan 1995; Reed et al., 2009).

The goals of these instruments is to improve tourism decisions and natural resource management. By increasing public participation stakeholders will better understand when changes are made to the tourism industry and the introduction of new policy and environmental policy instruments (Liu et al., 2012; Krutwaysho \& Bramwell, 2010; Waligo, 2013; Wang \& Ap, 2013). In the literature stakeholder opposition of new instruments is a major barrier in their implementation (Cherry et al., 2012; Dredge \& Jamal, 2015; Hall 2010). This recommendation could therefore lead to wider acceptance of the instruments in the following recommendations.

\subsubsection{Recommendation 2: Voluntary Fund}

The study was able to identify several goals outlined by the stakeholders of Savusavu. In order to reach these goals financial resources are needed. Therefore, it is suggested that a voluntary fund is implemented in Savusavu. The "Savusavu Fund" can help the destination overcome obstacles of sustainable development and reach its goals.

Multiple economic instruments were explored for implementation in Savusavu in section 5.5.4. The data analysis revealed a voluntary fund is assumed to be the most accepted and effective method of implementing an economic instrument. $54 \%$ of respondents indicated that a new economic instrument would be accepted in Savusavu if the funding would aid in the management and development of the tourism industry. When respondents were asked questions concerning the acceptability of a new instrument, taxes had a negative association with them (Interviews \# 17,2432,33, 2016).

From the interviews which provided reasonings for acceptance of a new economic instrument, the fund must be: 
- Transparent. Information on what the funds are spent on have to made available to the public. It is suggested that an annual report be created outlining where funds are going and the amounts.

- Set up by a trusted group. The fund should be set up by the STA or the Savusavu Town Council. These are considered influential stakeholder groups and have the resources available to set up the fund.

- Have a public engagement element. Public participation of stakeholders groups is encouraged to determine where the funds should go. This could also persuade stakeholders to donate to the fund if they can have an influence on where the money is going. Adding an educational element of why funds are needed and where they will go towards may aid in getting tourists, large businesses and other stakeholder groups to donate funds as well (Chung et al., 2011; Edwards, 2009).

A study in Koh Phi Phi Thailand and in Gili Trawangan, Indonesia, highlight the importance of understanding the needs and wants of the stakeholders of a destination in order to determine what economic instrument will be effective. These islands are found in Southeast Asia and share similar characteristics to Savusavu. They are all popular tourist destinations because of their natural beauty, beaches, rest and relaxation. Gili Trawangan is also known for its diving. It was found that the majority of tourists in both Koh Phi Phi and Gili Trawangan expressed a willingness to pay a tax to help fund initiatives for environmental and social protection (Dodds, et al., 2010). Dodds et al., (2010) identified what was valuable in terms of producing an enjoyable vacation for the tourists specifically for the destinations. For example, cleaning up waste on the beaches and providing fresh water. By identifying what was important to the tourists they could then justify the purpose of the tax that would be imposed on the tourists. Stakeholders are more likely to except economic instruments if they are aware of its purpose (Edward, 2009). Of the 400 interviews, more than $84 \%$ of Koh Phi Phi and $87 \%$ of Gili Trawangan tourists were willing to pay more than 2 US dollars. Like Fiji, Gili Trawangan already has taxes in place on diving, yet the tourists were still willing to pay for a new tax to support environmental management that would improve their vacation (Dodds et al., 2010). Therefore, it is assumed that stakeholders will accept and donate to the voluntary fund if it will be used to support their needs and wants to improve Savusavu.

The voluntary fund for this study was chosen based on the acceptability of the stakeholders. The study asked stakeholders if they would pay a tax knowing it would go towards helping the environment and the majority said no. But they did indicate a voluntary fund would be accepted if would be used to improve the destination. The fund will therefore be used to reach goals outlined by the stakeholders. 
From this study it is recommended that the funds should go towards the goals that were identified in the data analysis and discussion. Money from the Savusavu Fund should be used for: improvements to waterfront infrastructure (sidewalks), improvements of waste management programs, education programs and towards a coral and mangrove rehabilitation program. These were topics discussed in section 5.3 "Barriers of Savusavu Becoming a Sustainable Destination" and section 5.2.1 "Impacts on Natural Resources".

User fees are instruments that raise funds for natural resource management. From the responses it was not clear how to set one up. In order to set up a user fee or some form of payment for ecosystem service, the owner and a fee for the usage must be determined (WWF, 2016). These aspects were not determined in this study. It was also seen in section 5.4 discussing current instruments that the local villages may already have user fees set up with tour operators and businesses. Respondents also explained why they did not support paying for natural resources in section 5.2.4, because they or tourists are already paying (Interviews \#1, 3, 4,12,13,17,18,21,30, 2016). For these reasons a user fee is not recommended. However, in the next recommendation it is suggested to educate stakeholders on how to set up user fees, if they so wish to do so voluntarily.

\subsubsection{Recommendation 3: Environmental Education Instruments for all Stakeholders}

The third recommendation is to increase the education level of all stakeholder groups by implementing various education instruments. Public outreach and education instruments involve information awareness initiatives that encourage public actions to help reach policy goals. Education and outreach instruments can inform all stakeholders of the issues related to a destination's tourism industry and how to overcome them (Winfield, 2016).

When questioned about current education instruments in Savusavu only one respondent gave a description of what the programs entailed. Interview \#16 with a regulator (who worked for the Savusavu Town Council and the Chamber of Commerce) was the only one who mentioned the education instruments, the "Go Green" program, the "Backyard Campaign", and the "National Clean-up Campaign/Competition" (Interview \# 16, 2016). The research therefore assumes that there is a need to incorporate more effective education programs in Savusavu.

\subsubsection{Justification of Education Instrument Content}

Some respondents (17\%) support the implementation of new education instruments in Savusavu (Interviews \#1, 2, 6, 7,34,40,41, 2016). The literature supports education as a means to 
promote sustainable tourism development. When all stakeholders are informed on the various impacts of tourism and natural resource management it is supported in Stakeholder and Governing the Commons Theory that sustainable development can occur (Grimble \& Chan, 1995; Prell et al., 2009; Ostrom, 1990). Informed stakeholders can make informed decisions which lead to sustainable tourism development (Hall, 2010; Wells, et al., 2016). The study believes improving education will lead to better management.

Some $41 \%$ of respondents do not believe the community is educated on the impacts of tourism, both positive and negative. $39 \%$ of respondents could not indicate or did not believe there were any negative impacts on Savusavu's natural resources when the data analysis in section 5.2.1 illustrates that wastewater pollution, physical waste and marine environment destruction are all current issues. There is also a lack of knowledge amongst stakeholders on the role natural resources play for tourism. $31 \%$ of respondents did not even claim to be using resources when they in fact were. There is also an economic focus on the benefits of the use of natural resources that was explained in the discussion. Therefore, the benefits and services natural resource produce is recommended in the education instruments below.

Respondents were able to indicate barriers to Savusavu becoming a sustainable destination in section 5.3. However, their education on what it means to be sustainable is questioned as there was focus on improving the airport in terms of a barrier by $41 \%$ of respondents. Therefore, the concept of sustainable tourism and what it means for SIDS is recommended to be addressed in these education instruments.

The education instruments suggested in the following sections focus on the needs for the Savusavu. The instruments are to aid in developing sustainable tourism. Shakeela et al., (2012) explored the role of tourism education as a contributor to sustainable tourism development in the Maldives. The study reviewed a successful tourism university and certificate program in the Maldives. However, the study highlighted the need for tourism education opportunities at all levels and for the curriculum to be specific to the destination. The Maldives is an archipelagic nation located in the Indian Ocean and relies on the success of tourism for economic development, like Savusavu. The lack of education in the Maldives has created an insufficient workforce that enables sustainable development. There are only opportunities for education in the capital and at a university level. Locals do not have equal opportunities to learn from a young age about the importance of tourism. Due to the lack of tourism education in primary and high school programs there is was a lack of local interest in tourism education and in tourism related jobs. The education that is offered mirror the content from western programs of 
hospitality and tourism (Shakeela et al., 2012). Therefore, current education opportunities are not tailored for tourism and hospitality situations in the Maldives. The study urges that there needs to be stakeholder involvement in creating tourism education curriculum so the program can contribute to the sustainable development of tourism. The program should be developed in the social, cultural and economic context of the destination (Shakella et al., 2012). Lessons from this study influenced the education programs that are discussed below. There is a focus on developing curriculum suited for Savusavu's tourism industry and to have stakeholders involved.

The three following programs are recommended to be implemented as education instruments in Savusavu: primary education school program, public education instrument and tourist education instruments. These instruments can help Savusavu overcome key issues outlined in the discussion. The programs and their recommended content are below.

\subsubsection{Primary Education School Program}

Community elders and members from the STA are recommended to create a program that visits the schools Savusavu to educate the youth on tourism and natural resource management. The STA and community elders are seen as influential stakeholder groups. Their involvement in these instruments could provide effective outcomes. Tourism is the main economic driver for the Savusavu community. The livelihoods of the community largely rely on the success of the tourism industry. Education on the role tourism plays for the local community and its impacts on the natural environment should therefore be provided to the youth of the community. It is recommended that the following lessons are taught to primary school classes:

- The concept of sustainability and what it means for tourism development;

- The role natural resources play in tourism, with a focus on coral reefs and the marine environment;

- Natural resource management;

- How to incorporate local Fijian culture into tourism;

- How students can get involved in tourism.

Educating Savusavu youth is a long term solution to sustainable development issues in Savusavu. It is important for the youth of the community to learn about these concepts so that they can continue to create sustainable development in the future for Savusavu. 


\subsubsection{Public Education Resources}

Savusavu's stakeholders have varying education levels on tourism policy and natural resource management. From the discussion the stakeholder groups are not educated on important topics of natural resource management. Resources should be made available so that the public can educate themselves and participate in developing a sustainable tourism industry for Savusavu.

It is recommended that monthly workshops are created and administered at the Marina or Planters Club of Savusavu. These locations are accessible to all stakeholders by public transportation and are staples of Savusavu's tourism industry. The sessions should be led by or in a combination of Savusavu Town Council members, village elders and STA members, as they are influential groups of the tourism industry. Members who have a strong knowledge on the tourism industry and time to take on this initiative should lead the sessions and develop their content.

An online database should be created to complement the sessions. This way those who cannot attend are still able to obtain the information that is shared during the sessions. It is recommended that each session has a goal and learning outcome for the participants. Each session should encourage stakeholders to participate in tourism related decisions in Savusavu. As a starting point it is recommended that the first sessions have the following goals based on this study's data analysis and discussion:

- Session 1: Introduction to sustainable tourism and tourism policy. Education on how changes are made to Savusavu's tourism industry and how to get involved.

- Session 2: Education on the importance of proper waste disposal and wastewater management and its impacts on natural resources.

- Session 3: Climate change and natural disaster management

Sessions related to environmental instruments are recommended. Sessions should educate stakeholders on how to set up voluntary instruments and the possible benefits of implementing these instruments. Instrument like codes of conduct, best environmental practices, ecolabels, composting, renewable energy devices and performance indicators were discussed in Chapter 2. This is suggested because voluntary instruments can be set up by anyone at any time. Little government involvement is needed and stakeholders can use them to work on personal sustainability goals. These sessions can provide stakeholder with the skills and information to independently make sustainable choices. 
These session topics are suggested to help Savusavu overcome barriers to being sustainable and to help the destination reach its goals. After the outlined sessions have been completed the leaders of the education instruments can take recommendations from participants and make informed decisions on other topics they should discuss to continue sustainable development.

\subsubsection{Tourist Education}

Tourists need to be educated in order to develop a sustainable tourism industry. The actions of tourists can impact the natural resources of Savusavu and the community. The study recommends that education boards are produced and set up in the downtown core of Savusavu. Boards can be placed in the Savusavu farmers market, at the Savusavu marina, the sailing club park, the Savusavu airport and on public hiking trails. These are areas that see high levels of tourists. The goals of the boards are to improve the education level of tourists to minimize their impacts while in Savusavu. Boards should focus on:

- Current environmental, social and economic issues Savusavu faces;

- Natural resources used for tourism;

- The history and culture of Savusavu;

- Information on the agriculture sector;

- Information on the obstacles coral face from climate change and man-made destruction;

- Information on how they can get involved. Suggest local tourism operators to use and suggest donating to the voluntary fund.

The information on these boards can also educate other stakeholders as well. Public participation in the creation of these boards is also suggested.

\subsubsection{Recommendation 4: Follow-Up Study}

The final recommendation of this study is for someone to conduct a follow-up study in Savusavu in the near future. A study could investigate whether these recommendations were implemented and if they were effective. The study could focus on one recommendation or all recommendations. After they are implemented the study could attempt to measure their effectiveness and could make suggestions on how this study could have been improved. There is limited literature on the effectiveness of voluntary and education instruments (Birdir et al., 2013; Pavia et al., 2015; Winfield, 2016). A follow-up study could focus on measuring these instruments. 


\subsection{Conclusions}

The discussion presented the key issues Savusavu faces in terms of developing a sustainable tourism industry. The findings of: lack of stakeholder education and participation, lack of proper waste management, susceptibility to natural disasters and climate change and the economic focus of stakeholders were explained. Four recommendations based on the information collected in the literature review and stakeholder interviews were presented. The recommendations are intended to improve sustainable development for Savusavu's tourism industry. The following chapter presents the limitations and conclusion to the thesis. 


\section{Chapter 7: Conclusion}

Fiji is a SIDS found in the Pacific Ocean. Like most SIDS Fiji faces challenges of limited natural resources, high dependency on the tourism sector, high susceptibility to climate change and natural disasters. Without proper planning in place negative impacts of tourism like habitat destruction, pollution, resource depletion, erosion and coastline depletion can occur (Boukas \& Ziakas, 2014; Shareef \& McAleer, 2005). Savusavu, a coastal town found of Fiji's Vanua Levu, is known for its pristine natural environment, marine ecosystems and is a sought after diving tourism destination. Therefore, the success of the tourism industry is largely dependent on the state of the natural environment. Savusavu is considered the hidden paradise of Fiji but it is growing in popularity. With increasing tourist numbers travelling to Fiji each year the destination will continue to develop. If some form of collective management and education opportunities are not created the common resources used for tourism purposes will likely see tragedy (Ostrom, 1990). The impacts will be shared by all those who rely on tourism for their livelihoods.

The aim of this study was to provide Savusavu with recommendations on how to develop a sustainable tourism industry through the use of environmental instruments. The instruments are recommended to improve tourism, natural resource management and to overcome barriers impeding Savusavu in developing a form of sustainable tourism. Information collected during stakeholder interviews influenced the recommendations. Stakeholders' perceptions were used to form a type of collective management to develop a sustainable tourism industry and avoid natural resource management issues.

\subsection{Limitations of the Study}

This section outlines how the study would have been done differently in order to improve the accuracy of the study's findings.

The questionnaire used in the interviews would be improved. The questionnaire could have included questions to collect demographic information like the age, sex, ethnicity and the income of respondents. By recording demographic information the data could have been further analyzed. Trends in the responses from different demographic groups may have been seen. Understanding the perceptions of major natural resource issues and acceptability of different instruments amongst different demographic groups could have produced different recommendations or further support the recommendations that were made. 
The study should have included a question collecting information on the annual income of participants. This could have been used to help identify a price for a tax and user fee. These economic instruments were not suggested but additional information could have been useful if these instruments were recommended. In addition to asking how stakeholders benefit from natural resource use the question should have asked what costs they would experience if the tourism industry and natural resource were to degrade. This information could have been useful for developing a form of collective management.

The questionnaire would also be changed to include Likert scale questions and ranking questions. The questionnaire used many open and in-depth questions for determining the major barriers to sustainability of Savusavu and to identify recommendations. Incorporating a scale question could have improved the recommendations of the study by having respondents list the most to least accepted instruments. They could also have created a scale for the barriers of the island. Using these types of questions would have also allowed for quantitative data analysis. The qualitative data was done through coding which faces issues of reliability and validity. By incorporating quantitative analysis the results of the study could have been strengthened.

The study would have also benefited from the use of an interpreter when interviewing respondents whose first language was not English. While the majority of respondents did speak English, their understanding of the actual questions was questioned in some cases. Some responses gave short responses to open ended questions and did not fully explain answers they provided. Having an interpreter who could speak Fijian may have resulted in more detailed and comprehensive responses to the questions. This could have provided additional data that would have been coded.

\subsection{Contribution of Knowledge}

This study identified environmental instruments to recommend for a SIDS to develop sustainable tourism. The study focused on natural resource management as island destinations have limited resources and heavily rely on their natural state for success. Governing the Commons and Stakeholder Theory was used to defend including the perspectives of all stakeholder groups to influence the recommendations. Sustainable tourism research is by no means a new subject in the literature. There is a plethora of research on what sustainable tourism is and different methods of developing sustainable tourism. However, unsustainable forms of tourism still exist and this study has contributed to sustainable tourism and environmental instrument knowledge in a variety of ways. 
The research built on our knowledge of sustainable tourism development specifically for SIDS. The literature identified the barriers and impacts for SIDS. Each case experiences different obstacles in terms of reaching sustainable development. The study identified the barriers specific to Savusavu. The findings from other related studies involving islands had similar issues, like lack of proper wastewater management infrastructure. The study supports that each case study must identify the barriers specific to that location in order to start to develop management strategies to overcome them. The study also supports that SIDS have their own cultures and systems making them unique. SIDS therefore should not be managed as groups.

The study built on the knowledge of the application of environmental instruments as a means to promote sustainability. Environmental instruments are applied in a variety of management studies. There are few studies which examine multiple environmental instruments for implementation to promote sustainable tourism. This study provided a case that considered multiple instruments and selection was based on qualitative research. Stakeholder perceptions influenced the selection of the instruments. Specific recommendations of what instruments to use were based on questions related to natural resource management, stakeholder perceptions on acceptance of new instruments and what they wanted to see change for their tourism industry. This study supports that stakeholder involvement and public acceptance are best practices for implementing environmental instruments to support sustainable tourism.

The study built on the knowledge of environmental instruments to implement policy. Instruments with high levels of government involvement and control are often supported as effective in the literature. The study determined that education instruments, a voluntary fund and instruments to increase public participation would be the most effective in developing sustainable outcomes for Savusavu's tourism industry. The instruments are flexible and tailored to reach the goals of a destination. They do not require a high level of government involvement. The community holds the power. These instruments are voluntary and give stakeholders the choice to participate to create their own form of collective management. They also involve stakeholder participation which can combat public opposition of changes to tourism management. The study suggests that voluntary instruments are effective in reaching the goals of a destination.

The study highlights the importance of stakeholder education and stakeholder participation. Even though most stakeholders could identify the key issues of Savusavu, they did not know how to make the changes they desired. There was also a lack of knowledge on the role natural resources play 
for the tourism industry. These knowledge gaps are influencing how the tourism industry is currently being managed. This finding further supports stakeholder education as a best practice of sustainable tourism development.

\subsection{Achievement of Thesis Objectives}

This thesis had 3 objectives. The following sections will discuss how the objectives were met.

\subsubsection{Objective 1}

The first objective of the study was to review the current literature on sustainable tourism developments, environmental instruments and their implementation. This was done in Chapter 2, before the research took place. The literature review was updated again after the research to gain further knowledge on environmental instruments. The literature review revealed the current state of knowledge on topics of sustainable tourism, island tourism, the application of various environmental instruments and their respective benefits and limitations. Governing the Commons and Stakeholder Theory were also researched, which shaped this study.

\subsubsection{Objective 2}

The second objective of the study was to determine the key issues Savusavu faces in becoming a sustainable tourism destination and the goals of the destination through stakeholder interviews. This objective was met by creating an interview guide that collected valuable data from stakeholder groups of Savusavu. The key issues Savusavu faces can be seen in Chapters 5 and 6. The issues were; lack of proper waste management, lack of education and participation amongst stakeholder groups in tourism, an economic focus amongst the stakeholders and susceptibility to the impacts of climate change and natural disasters. Goals of the destination were to increase stakeholder participation in tourism related decisions, improve stakeholder education, improve waterfront infrastructure, and improve waste disposal programs.

\subsubsection{Objective 3}

The third objective was to identify environmental instruments to recommend for implementation in Savusavu. The recommendations are presented in Chapter 6. The recommendations were developed based on the findings in the literature review and on the results seen in the data analysis. Four recommendations were made to overcome the barriers and reach the goals of Savusavu. To increase stakeholder participation stakeholder engagement was recommended through the use of town meetings and through the creation of an online forum. The second recommendation was to create 
a voluntary fund to financially support desired changes to the tourism industry. The third was to use various environmental education instruments to improve the education of all stakeholder groups. The final recommendation was to conduct a follow-up study.

\subsection{Future Research}

There are recommendations to continue research in Savusavu. This study had to first identify the barriers and goals of the destination in order to identify environmental instruments to implement. The actual implementation was not done because there was not enough time to do so. The next step for a future study would be to implement the recommended instruments and evaluate their effectiveness. There is lack of research which illustrates the actual implementation process from start to finish of new environmental instruments. By conducting this study it would also be able to check if the recommendations from this thesis were effective. Education instruments and voluntary instruments in the literature lack studies evaluating their effectiveness and this would be a great opportunity to improve our knowledge on these instruments. It could aid in pointing out the flaws of this study and make further recommendations on how to improve the instruments for Savusavu to promote a sustainable tourism industry.

Another study could focus on developing the content for the primary school education program or the stakeholder education sessions. The researcher could use the literature and stakeholder perceptions to develop the content for the education program. It is suggested to ask stakeholders to rate their knowledge on various sustainability topics and ask them what they would like to learn. Having a researcher produce this study with content for the education instruments as a result would be beneficial for Savusavu. 


\section{Appendices}

\section{Appendix 1: Interview Questionnaire}

Interview Identification:

Date:

Location and Time:

\section{INTRODUCTION:}

My name is Logan Van Vliet and I am a graduate student from Ryerson University in Toronto, Canada in the Yeates School of Graduate Studies. I would like to ask you some questions about the Savusavu tourism industry. Your responses will help me in understanding your views on some important issues related to the tourism industry. By completing this interview, you indicate that the information gathered may be part of this research. All information will be kept confidential. These questions will take approximately 20 to 30 minutes to complete. You may withdraw from the interview at any time.

1. What is your role/position within the Savusavu Community?

2. How are you involved in the tourism industry (tourist, business owner, employee, etc)?

3. Of the island's natural resources which do you use for tourism purposes?

4. Do you benefit from the use of any of these resources? How so?

5. Do you know who owns the natural resources of the island? If so who?

6. Do you think the community is educated on the impacts of tourism on the island's natural resources? (positive and negative)

7. Do any of the natural resources that you use face any issues? I.e. Degradation or pollution

8. Do you think those using natural resources and benefiting/profiting from them should pay to use them? How?

Intro to environmental Instruments: Environmental instruments come in many forms and have been created and implemented by researchers to solve environmental related issues. They can be implemented and managed in a variety of forms as these tools are available to private sector and public 
authorities. They are designed and implemented to solve issues or reach certain goals outlined by a destination or group of destinations. The goal of this research is to identify instruments that could be implemented in Savusavu to promote sustainable tourism and solve environmental issues the island is facing. The following questions are related to possible instruments that could be implemented.

9. Are any environmental instruments currently in place on Savusavu?

10. Are you aware of the new environmental levy that is in place?

11. Do you know what the money from this levy is being used for?

12. Does your business/employer implement any environmental instruments voluntarily?

13. Have you seen any environmental instruments in use on other islands of Fiji?

14. Do you think they should be implemented in Savusavu? Why?

15. In your opinion what are the most important issues facing the island in terms of sustainable tourism? Why?

16. If the money generated from paying for the use of natural resources was used to fund environmental instruments to conserve and protect these resources would you voluntary pay for their use?

17. If an environmental instrument such as a tax, voluntary or user fee was introduced to help promote sustainability of Savusavu's tourism industry do you think it would be accepted? Why or why not?

18. Do you believe the stakeholders of Savusavu's tourism community would accept the introduction of a tax or voluntary fund? Why or why not?

19. Who would be most influential in the implementation of a new environmental instrument?

20. How are changes to tourism policy and management made in Savusavu?

21. How involved are you in decisions related to changes to your tourism industry?

22. If you had the opportunity to become more involved in decision making would you participate? 
23. If you were to establish a funding mechanism (tax, user fee, voluntary fund) to raise money for environmental initiatives to better manage Savusavu's natural resources how would you do so?

24. Do you think there is another way to gain access to funds that can be used to better manage the natural resources the Savusavu tourism industry relies on?

\section{Appendix 2: Stakeholder Group Identification}

\begin{tabular}{|c|c|}
\hline Interviewee & Stakeholder Group \\
\hline 1 & Business owner \\
\hline 2 & Employee \\
\hline 3 & Employee \\
\hline 4 & Regulator \\
\hline 5 & Local \\
\hline 6 & Business Owner \\
\hline 7 & Operator \\
\hline 8 & Business Owner \\
\hline 9 & Operator \\
\hline 10 & Operator \\
\hline 11 & Business Owner \\
\hline 12 & Operator \\
\hline 13 & Business Owner \\
\hline 14 & Operator \\
\hline 15 & Business Owner \\
\hline 16 & Regulator \\
\hline 17 & Operator \\
\hline 18 & Tourist \\
\hline 19 & Local \\
\hline 20 & Employee \\
\hline 21 & Employee \\
\hline 22 & Regulator \\
\hline
\end{tabular}




\begin{tabular}{|c|c|}
\hline 23 & Tourist \\
\hline 24 & Employee \\
\hline 25 & Tourist \\
\hline 26 & Regulator \\
\hline 27 & Local \\
\hline 28 & Local \\
\hline 29 & Local \\
\hline 30 & Operator \\
\hline 31 & Regulator \\
\hline 32 & Local \\
\hline 33 & Local \\
\hline 34 & Employee \\
\hline 35 & Local \\
\hline 36 & Tourist \\
\hline 37 & Regulator \\
\hline 38 & Tourist \\
\hline 39 & Tourist \\
\hline 40 & Operator \\
\hline 41 & Tourist \\
\hline
\end{tabular}




\section{Appendix 3: Example of Qualitative Interview Data Coding}

Question 6: Do you benefit from the use of natural resources? If yes, how?

Table 33 Code book for question 6

\begin{tabular}{|l|l|l|l|}
\hline Theme & Code & Sub Theme & Code \\
\hline Positive & Y & Attracts Tourists & A \\
\hline & & Creates Activities & B \\
\hline & & $\begin{array}{l}\text { Food / Water } \\
\text { Resources }\end{array}$ & C \\
\hline & & Finically & D \\
\hline Negative & N & & \\
\hline Interesting Comment & & & \\
\hline
\end{tabular}

Table 34 Example of coded responses

\begin{tabular}{|c|c|c|c|}
\hline $\begin{array}{l}\text { Respondent } \\
\text { Number }\end{array}$ & Response & Code & $\begin{array}{l}\text { Sub } \\
\text { Code }\end{array}$ \\
\hline 1 & $\begin{array}{l}\text { The resources we use is what attract the tourists. It's really the } \\
\text { culture of the people here that benefits us. }\end{array}$ & $\mathrm{Y}$ & A \\
\hline 2 & $\begin{array}{l}\text { Yes, the resources are what attracts tourists to the resort. We } \\
\text { also benefit from them in terms of educational opportunities for } \\
\text { the guests. }\end{array}$ & $\mathrm{Y}$ & $A, B$ \\
\hline 3 & Yes, the ocean attracts the tourists. & $\mathrm{Y}$ & A \\
\hline 4 & $\begin{array}{l}\text { Benefit in that it attracts tourists and creates an experience for } \\
\text { our guest. }\end{array}$ & $\mathrm{Y}$ & $A, B$ \\
\hline 5 & $\begin{array}{l}\text { We benefit for the food it provides of us and our guests, the } \\
\text { natural woods for furniture we benefit from solar energy and } \\
\text { from rain in our catchment }\end{array}$ & $\mathrm{Y}$ & $\mathrm{B}, \mathrm{C}$ \\
\hline 6 & Yes, brings in people and financially & $\mathrm{Y}$ & $C, D$ \\
\hline 7 & $\begin{array}{l}\text { Resources provide activities for our guests, but we also give } \\
\text { back. We have relationship with the environment }\end{array}$ & $Y$ & B \\
\hline 8 & Yes, environment is what attracts tourist to Savusavu & $\mathrm{Y}$ & A \\
\hline 9 & No & $\mathrm{N}$ & \\
\hline 10 & No & $\mathrm{N}$ & \\
\hline
\end{tabular}




\begin{tabular}{|l|l|l|l|}
\hline 11 & Yes, attract guests & Y & A \\
\hline 12 & $\begin{array}{l}\text { I benefit economically and personally, develop sense of pride by } \\
\text { sharing Fiji with guests }\end{array}$ & Y & D \\
\hline 13 & No & N & \\
\hline 14 & $\begin{array}{l}\text { Benefit in that using these resources is cheaper then importing } \\
\text { from other islands }\end{array}$ & Y & D \\
\hline 16 & People are attracted to my town & Y & A \\
\hline 17 & $\begin{array}{l}\text { Yes, I benefit financially and provide guests with experiences } \\
\text { which makes me good money }\end{array}$ & Y & B,D \\
\hline
\end{tabular}




\section{Reference List}

Aall, C. (2014). Sustainable tourism in practice: Promoting or perverting the quest for a sustainable development? Sustainability, 6, 2562-2583. doi:10.3390/su60x000x.

Aguilo, E., Alegre, J., \& Sard, M. (2005). The persistence of the sun and sand tourism model. Tourism Management, 26(2), 219-231.

Albaladejo, I. P., González-Martínez, M. I., \& Martínez-García, M. P. (2016). Non-constant reputation effect in a dynamic tourism demand model for Spain. Tourism Management, 53, 132-139.

Annandale, D., Morrison-Saunders, A., \& Bouma, G. (2004). The impact of voluntary environmental protection instruments on company environmental performance. Business Strategy and the Environment, 13(1), 1-12.

Araujo, L. M. D., \& Bramwell, B. (1999). Stakeholder assessment and collaborative tourism planning: The case of Brazil's Costa Dourada project. Journal of Sustainable Tourism, 7(3-4), 356-378.

Aretano, R., Petrosillo, I., Zaccarelli, N., Semeraro, T., \& Zurlini, G. (2013). People perception of landscape change effects on ecosystem services in small Mediterranean islands: A combination subjective and objective assessments. Landscape and Urban Planning, 112, 63-73.

Ayuso, S. (2007). Comparing voluntary policy instruments for sustainable tourism: The experience of the Spanish hotel sector. Journal of Sustainable Tourism, 15(2), 144-159. doi:10.2167/jost617.0.

Banerjee, A., \& Chaudhury, S. (2010). Statistics without tears: Populations and samples. Industrial Psychiatry Journal, 19(1), 60.

Bastin, R. (1988). Small Island tourism: Development of dependency? Development Policy Review, 2(1), 79-90.

Baumol, W., \& Oates, W. (1971). The use of standards and prices for protection of the environment. Swedish Journal of Economics, 73, 161-173.

Benjamin, A. H. (2013). Payment for ecosystem services. PER: Potchefstroomse Elektroniese Regsblad, $16(2), 0-0$.

Berghoef, N., \& Dodds, R. (2013). Determinants of interest in eco-labelling in the Ontario wine industry. Journal of Cleaner Production, 52, 263-274. doi:10.1016/j.jclepro.2013.02.020. 
Bimonte, S. (2008). The "tragedy of tourism resources" as the outcome of a strategic game: A new analytical framework. Ecological Economics, 67(3), 457-464.

Birdir, S., Ünal, Ö., Birdir, K., \& Williams, A. T. (2013). Willingness to pay as an economic instrument for coastal tourism management: Cases from Mersin, Turkey. Tourism Management, 36, 279-283.

Bocking, S. (2016). Chapter 6: Science and Canadian environmental policy. In D. L. VanNijnatten, The Challenges of Austerity and Ambivalence, (97-111) Oxford University Press.

Bohlen, P. J., Lynch, S., Shabman, L., Clark, M., Shukla, S., \& Swain, H. (2009). Paying for environmental services from agricultural lands: an example from the northern Everglades. Frontiers in Ecology and the Environment, 7(1), 46-55.

Boukas, N., \& Ziakas, V. (2014). A chaos theory perspective of destination crisis and sustainable tourism development in islands: The case of Cyprus. Tourism Planning and Development, 11(2), 191-209. doi:10.1080/21568316.2013.864995.

Bovenberg, A. L., \& De Mooij, R. A. (1994). Environmental levies and distortionary taxation. The American Economic Review, 1085-1089.

Bramwell, B., \& Bernard, L. (2005). From niche to general relevance? Sustainable tourism, research and the role of tourism journals. Journal of Tourism Studies, 16(2), 52-62.

Bramwell, B., \& Lane, B. (2011). Critical research on the governance of tourism and sustainability. Journal of Sustainable Tourism, 19(4-5), 411-421.

Brendehaug, E., Aall, C., \& Dodds, R. (2016). Environmental policy integration as a strategy for sustainable tourism planning: Issues in implementation. Journal of Sustainable Tourism, 1-18. doi:10.1080/09669582.2016.1259319.

Briassoulis, H. (2002). Sustainable tourism and the question of the commons. Annals of Tourism Research, 29(4), 1065-1085. doi:10.1016/S0160-7383(02)00021-X.

Briguglio, L. (1995). Small island developing states and their economic vulnerabilities. World Development, 23(9), 1615-1632.

Brundtland, G. H. (1987). Our common future-Call for action. Environmental Conservation, 14(4), 291294. 
Bruzzi, L., Boragno, V., Serrano-Bernardo, F. A., Verità, S., \& Rosúa-Campos, J. L. (2011). Environmental management policy in a coastal tourism municipality: The case study of Cervia (Italy). Local Environment, 16(2), 93-113. doi:10.1080/13549839.2011.558075.

Butler, R. W. (1980). The concept of a tourist area cycle of evolution: Implications for management of resources. The Canadian Geographer, 24(1), 5-12.

Butler, R. W. (1993). Tourism - An evolutionary perspective. In J. G. Nelson, R. Butler, \& G. Wall (Eds.), Tourism and sustainable development: Monitoring, planning, and managing (pp. 26-43). Waterloo: Heritage Resources Centre, University of Waterloo.

Butler, R. (2008). Islands. In M. Lück (Ed.), Encyclopedia of Tourism and Recreation in Marine Environments (p. 254). Wallingford: CABI.

Byrd, E. T., Cárdenas, D. A., \& Greenwood, J. B. (2008). Factors of stakeholder understanding of tourism: The case of Eastern North Carolina. Tourism and Hospitality Research, 8(3), 192-204.

Canadian Tourism Commission. (2016) Annual Report 2016. Retrieved May $20^{\text {th }}, 2016$, from https://www.destinationcanada.com/sites/default/files/201705/AboutUs_Publications_AnnualReport_2016_EN.pdf.

Carasuk, R., Becken, S., \& Hughey, K. F. (2016). Exploring values, drivers, and barriers as antecedents of implementing responsible tourism. Journal of Hospitality and Tourism Research, 40(1), 19.

Cárdenas, D. A., Byrd, E. T., \& Duffy, L. N. (2015). An exploratory study of community awareness of impacts and agreement to sustainable tourism development principles. Tourism and Hospitality Research, 15(4), 254-266.

Carlowitz, H.C., (1732). Sylviculturaoecnomicaoderhausswirthliche Nachricht und naturgemassige Anweisungzurwilden Baum - Zucht. Kessel Norbet, Reprint der zweitenAuflage von 1732 24-112009.

Carroll, A. B., \& Buchholtz, A. K. (2003). Ethics and stakeholder management (5th ed.) Business and Society. Cincinnati: South-Western.

Castellani, V., \& Sala, S. (2010). Sustainable performance index for tourism policy development. Tourism Management, 31(6), 871-880. 
Catibog-Sinha, C. (2010). Biodiversity conservation and sustainable tourism: Philippine initiatives. Journal of Heritage Tourism, 5(4), 297-309. doi:10.1080/1743873X.2010.517841.

Central Intelligence Agency. (n.d). The World Fact book: Fiji. Retrieved April $7^{\text {th }}, 2017$, from https://www.cia.gov/library/publications/resources/the-world-factbook/geos/fj.html.

Cherry, T. L., Kallbekken, S., \& Kroll, S. (2012). The acceptability of efficiency-enhancing environmental taxes, subsidies and regulation: An experimental investigation. Environmental Science \& Policy, $16,90-96$.

Cetin, G., Alrawadieh, Z., Dincer, M. Z., Istanbullu Dincer, F., \& loannides, D. (2017). Willingness to Pay for Tourist Tax in Destinations: Empirical Evidence from Istanbul. Economies, 5(2), 21.

Choi, H. C., \& Sirakaya, E. (2006). Sustainability indicators for managing community tourism. Tourism Management, 27(6), 1274-1289.

Chung, J. Y., Kyle, G. T., Petrick, J. F., \& Absher, J. D. (2011). Fairness of prices, user fee policy and willingness to pay among visitors to a national forest. Tourism Management, 32(5), 1038-1046. doi:10.1016/j.tourman.2010.08.016.

Clarkson, M., Starik, M., Cochran, P., \& Jones, T. M. (1994). The Toronto conference: Reflections on stakeholder theory. Business and Society, 33(1), 82.

Clarkson, M. E. (1995). A stakeholder framework for analyzing and evaluating corporate social performance. Academy of Management Review, 20(1), 92-117.

Cole, D. H., Epstein, G., \& McGinnis, M. D. (2014). Digging deeper into Hardin's pasture: The complex institutional structure of 'the tragedy of the commons'. Journal of Institutional Economics, 10(3), 353. doi:10.1017/S1744137414000101.

Common Wealth Secretariat. (1985). Educational Development: the small states of the Commonwealth. In Report of a pan-Commonwealth experts meeting, Mauritius.

Common Wealth. (n.d). Fiji: Constitution and politics. Retrieved April 6 ${ }^{\text {th }}, 2017$, from http://thecommonwealth.org/our-member-countries/fiji/constitution-politics.

Crossley, M., \& Sprague, T. (2014). Education for sustainable development: Implications for small island developing states (SIDS). International Journal of Educational Development, 35, 86-95. 
Davenport, J., \& Davenport, J. L. (2006). The impact of tourism and personal leisure transport on coastal environments: A review. Estuarine, Coastal and Shelf Science, 67(1), 280-292.

De Albuquerque, K., \& McElroy, J. L. (1992). Caribbean small-island tourism styles and sustainable strategies. Environmental Management, 16(5), 619-632.

De-Miguel-Molina, B., de-Miguel-Molina, M., \& Rumiche-Sosa, M. E. (2014). Luxury sustainable tourism in small island developing states surrounded by coral reefs. Ocean and Coastal Management, 98, 86-94.

Denscombe, M. (2014). The good research guide: For small-scale social research projects. McGraw-Hill Education: United Kingdom.

Dietz, T., Ostrom, E., \& Stern, P. C. (2003). The struggle to govern the commons. Science, 302(5652), 1907-1912.

Díez Rodríguez, J. J., Oliver, C., Vicente, L., \& Ahumada Cervantes, B. (2015). Addressing strategic environmental assessment of Mexico's transition towards renewable energy. In AEIPRO 2015: International Congress on Project Engineering (pp. 1121-1132).

Dodds, R. (2007). Sustainable tourism \& policy implementation: Lessons from the case of Calviá, Spain. Current Issues in Tourism, 10(1), 296-322.

Dodds, R. (2013). Will tourists pay for a healthy environment? Assessing visitors' perceptions and willingness to pay for conservation and preservation in the island of Koh Phi Phi, Thailand. International Journal of Tourism Anthropology, 3(1), 28. doi:10.1504/IJTA.2013.054407.

Dodds, R., \& Butler, R.W. (2009). Inaction more than action: Barriers to the implementation of sustainable tourism policies. In S. Gössling, M. Hall, \& D. B. Weaver (Eds.), Sustainable tourism futures (pp. 43-57). London: Routledge.

Dodds, R., \& Graci, S. (2012). Sustainable tourism in island destinations. Routledge.

Dodds, R., Graci, S. R., \& Holmes, M. (2010). Does the tourist care? A comparison of tourists in Koh Phi Phi, Thailand and Gili Trawangan, Indonesia. Journal of Sustainable Tourism, 18(2), 207-222. doi:10.1080/09669580903215162. 
Donaldson, T., \& Preston, L. E. (1995). The stakeholder theory of the corporation: Concepts, evidence, and implications. Academy of management Review, 20(1), 65-91.

Dredge, D., \& Jamal, T. (2015). Progress in tourism planning and policy: A post-structural perspective on knowledge production. Tourism Management, 51, 285-297. 10.1016/j.tourman.2015.06.002.

Dredge, D., \& Jenkins, J. (2011). Stories of practice: Tourism policy and planning. Ashgate Publishing, Ltd.

Dyck, P. R. (1993). Canadian politics: Critical approaches. Scarborough, Ont.: Nelson Canada.

Edwards, P. E. T. (2009). Sustainable financing for ocean and coastal management in Jamaica: The potential for revenues from tourist user fees. Marine Policy, 33(2), 376-385. doi:10.1016/j.marpol.2008.08.005.

Emilsson, S., \& Hjelm, O. (2007). Managing indirect environmental impact within local authorities' standardized environmental management systems. Local Environment, 12(1), 73-86.

Engel, S., Pagiola, S., \& Wunder, S. (2008). Designing payments for environmental services in theory and practice: An overview of the issues. Ecological Economics, 65(4), 663-674.

European Environment Agency, EEA (1996). Environmental taxes. Implementation and Environmental Effectiveness. EEA, Copenhagen.

European Commission. (2017). Environmental tax statistics. Retrieved March 25 ${ }^{\text {th }}, 2016$ from http://ec.europa.eu/eurostat/statistics-explained/index.php/Environmental_tax_statistics.

Fabricius, C., \& Collins, S. (2007). Community-based natural resource management: Governing the commons. Water Policy, 9(S2), 83-97.

Feeny, D., Berkes, F., McCay, B. J., \& Acheson, J. M. (1990). The tragedy of the commons: Twenty-two years later. Human Ecology, 18(1), 1-19.

Ferreira, S., \& Harmse, A. (2014). Kruger national park: Tourism development and issues around the management of large numbers of tourists. Journal of Ecotourism, 13(1), 16-34.

Fiji Revenue and Customs Authority. (2015). Environmental levy. Retrieved March 25 ${ }^{\text {th }}, 2016$, from http://www.frca.org.fj/environmental-levy-2/. 
Fiji Bureau of Statistics. (2015). Economic statistics. Retrieved January $26^{\text {th }}, 2016$, from http://www.statsfiji.gov.fj/index.php/economic.

Fiji Bureau of Statistics. (2017). Fiji statistics at a glance. Retrieved April $6^{\text {th }}, 2017$, from http://www.statsfiji.gov.fj/.

Fiji Bureau of Statistics (2016). Feasibility report: Measuring Fiji's sustainable tourism. Retrieved August $20^{\text {th }}, 2017$, from http://www.unescap.org/sites/default/files/Measuring\%20Fiji\%27s\%20 Sustainable\%20Tourism.pdf.

Fiji Bureau of Statistics. (2015). Tourism and migration. Retrieved January $26^{\text {th }}, 2016$, from http://www.statsfiji.gov.fj/index.php/migration-a-tourism.

Fiji Bureau of Statistics. (2015). Social statistics. Retrieved January $26^{\text {th }}, 2016$, from http://www.statsfiji.gov.fj/index.php/social.

Fiji High Commission. (n.d). About Fiji: History. Retrieved Feb $1^{\text {st }}, 2016$, from http://www.fijihighcommission.org.uk/about_1.html.

Fiji High Commission. (n.d). About Fiji: Economy. Retrieved 1 ${ }^{\text {st }}, 2016$, from http://www.fijihighcommission.org.uk/about_3.html.

Fiji Travel. (n.d). Vanua Levu. Retrieved April $6^{\text {th }}, 2017$, from http://www.fiji.travel/us/destinations/vanua-levu.

Fodness, D. (2016). The problematic nature of sustainable tourism: Some implications for planners and managers. Current Issues in Tourism, Annals of Tourism Research, 1-13. doi:10.1080/13683500.2016.1209162

Forsyth, T., \& Johnson, C. (2014). Elinor Ostrom's legacy: Governing the commons and the rational choice controversy: Legacy: Elinor Ostrom. Development and Change, 45(5), 1093-1110. doi:10.1111/dech.12110.

Freeman, R. E., \& Reed, D. L. (1983). Stockholders and stakeholders: A new perspective on corporate governance. California Management Review, 25(3), 88-106.

Freeman, R. E. (1984). Strategic planning: A stakeholder approach. Pitman, Boston. 
Freeman, R. E., \& Gilbert, D. R. (1987). Managing stakeholder relationships. Business and Society: Dimensions of Conflict and Cooperation, 397, 423.

Gani A.A., Awang K.W., Mohamad A. (2017). Exploring the public participation practices in planning for sustainable tourism in Malaysia. In: Saufi A., Andilolo I., Othman N., Lew A. (Eds) Balancing Development and Sustainability in Tourism Destinations. Springer, Singapore.

Garay, L., \& Cànoves, G. (2011). Life cycles, stages and tourism history. Annals of Tourism Research, 38(2), 651-671. doi:10.1016/j.annals.2010.12.006.

Glasson, J., Therivel, R., \& Chadwick, A. (2013). Introduction to environmental impact assessment. Routledge.

Global Environment Facility. (2017). Ridge to reef project launch in Fiji. Retrieved, August $20^{\text {th }}, 2017$, from https://www.thegef.org/news/novel-ridge-reef-project-launched-fiji.

Goeldener, C. R., \& Ritchie, J. B. (2007). Tourism principles, practices, philosophies. John Wiley \& Sons.

Gössling, S. (2001). The consequences of tourism for sustainable water use on a tropical island: Zanzibar, Tanzania. Journal of Environmental Management, 61(2), 179-191.

Government of Fiji. (2014). A green growth framework for Fiji: Restoring the balance in development that is sustainable for our future. Retrieved, August $20^{\text {th }}, 2017$, from http://www.fijiroads.org/wp-content/uploads/2016/08/A-Green-Growth-Framework-forFiji.pdf.

Government of Fiji. (2017). Fijian Tourism 2021. Retrieved, August $20^{\text {th }}, 2017$, from https://fhta.com.fj/wp-content/uploads/2017/03/FHTA-Submission-Fijian-Tourism-

Development- Plan-Fijian-Tourism-2021.pdf

Graci, S. (2013). Collaboration and partnership development for sustainable tourism. Tourism Geographies, 15(1), 25-42.

Grimble, R., \& Chan, M. (1995). Stakeholder analysis for natural resource management in developing countries. Natural Resources Forum, 19(2), 113-124. doi:10.1111/j.1477-8947.1995.tb00599.x.

Grimble, R., \& Wellard, K. (1997). Stakeholder methodologies in natural resource management: A review of principles, contexts, experiences and opportunities. Agricultural Systems, 55(2), 173-193. 
Guerra, F., Grilo, C., Pedroso, N. M., \& Cabral, H. (2015). Environmental Impact Assessment in the marine environment: A comparison of legal frameworks. Environmental Impact Assessment Review, 55, 182-194.

Hall, C. M. (2010). Changing paradigms and global change: From sustainable to steady-state tourism. Tourism Recreation Research, 35(2), 131-143. doi:10.1080/02508281.2010.11081629.

Hall, C. M. (2011). Policy learning and policy failure in sustainable tourism governance: From first-and second-order to third-order change? Journal of Sustainable Tourism, 19(4-5), 649-671. doi: 10.1080/09669582.2011.555555.

Hahn, R. W., \& Stavins, R. N. (1992). Economic incentives for environmental protection: Integrating theory and practice. The American Economic Review, 82(2), 464-468.

Hardin, G. (1968). The tragedy of the commons. Journal of Natural Resources Policy Research, 1(3), 243253. doi:10.1080/19390450903037302.

Hardy, A. L., \& Beeton, R. J. (2001). Sustainable tourism or maintainable tourism: Managing resources for more than average outcomes. Journal of Sustainable Tourism, 9(3), 168-192.

Hartig, G. (1803). Anweisung zur Taxation und Beschreibung der Forste. Zweyte, ganz umgearbeitete un stark vermehrte Auflage. Georg Friedrich von Heyer, Giessen und Darmstadt.

Harrington, W., \& Morgenstern, R. D. (2007). Economic incentives versus command and control: What's the best approach for solving environmental problems? Acid in the Environment (pp. 233-240). Springer US.

Harrison, D., \& Pratt, S. (2010). Political change and tourism: Coups in Fiji. Tourism and Political Change, R. Butler and W. Suntikul, (eds,) 160-174.

Haase, D., Lamers, M., \& Amelung, B. (2009). Heading into uncharted territory? Exploring the institutional robustness of self-regulation in the Antarctic tourism sector. Journal of Sustainable Tourism, 17(4), 411-430.

Hatipoglu, B., Ertuna, B., \& Sasidharan, V. (2014). A referential methodology for education on sustainable tourism development. Sustainability, 6(8), 5029-5048. doi:10.3390/su6085029. 
He, G., Lu, Y., Mol, A. P., \& Beckers, T. (2012). Changes and challenges: China's environmental management in transition. Environmental Development, 3, 25-38.

Holden, A. (2009). The environment-tourism nexus: Influence of market ethics. Annals of Tourism Research, 36(3), 373-389.

Holling, C. S., \& Meffe, G. K. (1996). Command and control and the pathology of natural resource management. Conservation Biology, 10(2), 328-337.

Hunter, C., \& Shaw, J. (2007). The ecological footprint as a key indicator of sustainable tourism. Tourism Management, 28(1), 46-57.

Indrawan, M., Lowe, C., Sundjaya, Hutabarat, C., \& Black, A. (2014). Co-management and the creation of national parks in Indonesia: Positive lessons learned from the Togean Islands national park. Journal of Environmental Planning and Management, 57(8), 1183-1199. doi:10.1080/09640568.2013.788834.

Jean-Michel Cousteau Resort.(n.d). Explore. Retrieved January 31 ${ }^{\text {st }}, 2016$, from http://www.fijiresort.com/explore/.

Jean-Michel Cousteau Resort. (n.d). History. Retrieved January 31 ${ }^{\text {st }}, 2016$, from http://www.fijiresort.com/discover/people/history/.

Juvan, E., Ring, A., Leisch, F., \& Dolnicar, S. (2016). Tourist segments' justifications for behaving in an environmentally unsustainable way. Journal of Sustainable Tourism, 24(11), 1506-1522.

Keohane, N. O., Revesz, R. L., \& Stavins, R. N. (1998). Choice of regulatory instruments in environmental policy. The Harvard Environmental Law Rev., 22, 313.

Khazaei, A., Elliot, S., \& Joppe, M. (2015). An application of stakeholder theory to advance community participation in tourism planning: The case for engaging immigrants as fringe stakeholders. Journal of Sustainable Tourism, 23(7), 1049. doi:10.1080/09669582.2015.1042481.

Knapman, B., \& Stoeckl, N. (1995). Recreation user fees: An Australian empirical investigation. Tourism Economics, 1(1), 5-15.

Krutwaysho, O., \& Bramwell, B. (2010). Tourism policy implementation and society. Annals of Tourism Research, 37(3), 670-691. doi:10.1016/j.annals.2009.12.004. 
Larson, K. L., \& Lach, D. (2008). Participants and non-participants of place-based groups: An assessment of attitudes and implications for public participation in water resource management. Journal of Environmental Management, 88(4), 817-830.

Lee, T. H., \& Hsieh, H. P. (2016). Indicators of sustainable tourism: A case study from a Taiwan's wetland. Ecological Indicators, 67, 779-787.

Lee, D., \& Pearce, P. L. (2002). Community attitudes to the acceptability of user fees in natural settings. Tourism and Hospitality Research, 4(2), 158-173.

Lewis-Cameron, A., \& Roberts, S. (2010). Small Island developing states: Issues and prospects. In A. Lewis Cameron \& S. Roberts (Eds.), Marketing Island destinations: Concepts and cases (pp. 1-8). London: Butterworth-Heinemann.

Li, J.C. (2008) Environmental impact assessments in developing countries: An opportunity for greater environmental security? Retrieved March $24^{\text {th }}, 2016$, from, http://research.fit.edu/sealevelriselibrary/documents/doc_mgr/338/Global_EIAs_in_Developin g_Countries_-_Li_2008.pdf.

Littau, P., Jujagiri, N. J., \& Adlbrecht, G. (2010). 25 years of stakeholder theory in project management literature (1984-2009). Project Management Journal, 41(4), 17-29. doi:10.1002/pmj.20195.

Liu, Z. (2003). Sustainable tourism development: A critique. Journal of Sustainable Tourism, 11(6), 459475. doi: 10.1080/09669580308667216.

Liu, C. H., Tzeng, G. H., \& Lee, M. H. (2012). Improving tourism policy implementation-The use of hybrid MCDM models. Tourism Management, 33(2), 413-426.

Lockhart, D. G., Schembri, P. J., \& Smith, D. W. (Eds.). (2002). The development process in small island states. Routledge.

Logar, I. (2010). Sustainable tourism management in Crikvenica, Croatia: An assessment of policy instruments. Tourism Management, 31(1), 125-135.

Lloyd, W. F. (1833). Two lectures on the checks to population, Oxford: Oxford University Press.

Lumley, S., \& Armstrong, P. (2004). Some of the nineteenth century origins of the sustainability concept. Environment, Development and Sustainability, 6(3), 367-378.

Lupu, N. (2016). Contemporary approaches and challenges of tourism sustainability. The Amfiteatru Economic Journal, 18(S10), 1-740. 
Malthus, Thomas. (1803). Essay on the principles of population as it affects the future improvement of society .London: T. Bensley.

Maxim, C. (2016). Sustainable tourism implementation in urban areas: A case study of London. Journal of Sustainable Tourism, 24(7), 971-989.

McBurney, D. H., \& White, T. L. (2009). Research methods. Cengage Learning.

McCoy, J. F. (2003).Fiji. Retrieved April 1 ${ }^{\text {st }}, 2017$, from

go.galegroup.com.ezproxy.lib.ryerson.ca/ps/i.do?p=GVRL\&sw=w\&u=rpu_main\&v=2.1\&it=r\&id= GALE\%7CCX3406600071\&sid=summon\&asid=07fd5ac470f39b5a018d76f0fc672b2c.

Mickwitz, P. (2003). A framework for evaluating environmental policy instruments: Context and key concepts. Evaluation, 9(4), 415-436. doi:10.1177/1356389003094004.

Mitchell, R. K., Agle, B. R., \& Wood, D. J. (1997). Toward a theory of stakeholder identification and salience: Defining the principle of who and what really counts. Academy of Management Review, 22(4), 853-886.

Mitchell, R. E., \& Reid, D. G. (2001). Community integration: Island tourism in Peru. Annals of Tourism Research, 28(1), 113-139.

Morgan, R. K. (2012). Environmental impact assessment: the state of the art. Impact Assessment and Project Appraisal, 30(1), 5-14.

Namena Marine Reserve (n.d). Park management. Retrieved February $1^{\text {st }}, 2016$, from http://www.namena.org/park-management/.

Namena Marine Reserve. (n.d). About the park. Retrieved February $1^{\text {st }}, 2016$, from http://www.namena.org/about-2/.

Narayan, P. K. (2000). Fiji's tourism industry: a SWOT analysis. Journal of Tourism Studies, 11(2), 15.

Narayan, P. K. (2005). Did Rabuka's military coups have a permanent effect or a transitory effect on tourist expenditure in Fiji: Evidence from vogelsang's structural break test. Tourism Management, 26(4), 509-515. doi:10.1016/j.tourman.2003.11.022.

Neuman, W. L., \& Robson, K. (2012). Basics of social research: Qualitative and quantitative approaches. Boston: Pearson. 
Niles D, Baldacchino G. (2011). Introduction: on island futures. In island futures: Conservation and development across the Asia-Pacific region, Niles D, Baldacchino G (eds). Springer: New York; 18.

Nižić, M. K., Ivanović, S., \& Drpić, D. (2010). Challenges to sustainable development in island tourism. South East European Journal of Economics and Business, 5(2), 43-53. doi:10.2478/v10033-0100014-3.

Nepal, S. K. (2000). Tourism in protected areas: the Nepalese Himalaya. Annals of Tourism Research, 27(3), 661-681.

Ng, S. I., Chia, K. W., Ho, J. A., \& Ramachandran, S. (2017). Seeking tourism sustainability-A case study of Tioman Island, Malaysia. Tourism Management, 58, 101-107.

Ostrom, E. (2015). Governing the commons. Cambridge university press.

Ostrom, E. (2009). A general framework for analyzing sustainability of social-ecological systems. Science, 325(5939), 419-422. doi:10.1126/science.1172133.

Ostrom, E., Burger, J., Field, C. B., Norgaard, R. B., \& Policansky, D. (1999). Revisiting the commons: Local lessons, global challenges. Science, 284(5412), 278-282.

Ostrom, E. (1990). Governing the commons: The evolution of institutions for collective action. Cambridge University press.

Palmer, T., \& Riera, A. (2003). Tourism and environmental taxes with special reference to the "Balearic ecotax". Tourism Management, 24(6), 665-674. doi:10.1016/S0261-5177(03)00046-3.

Parliament of the Republic of Fiji. (2014) Fiji's system of government. Retrieved April $6^{\text {th }}, 2017$, from http://www.parliament.gov.fj/Our-Democracy/Fiji-s-System-Govwernment.aspx.

Pavia, N., Floricic, T., \& Cerovic, M. (2015). Sustainable sensitivity of tourists and sustainable initiatives in tourism destination. Tourism in South East Europe, 3, 245.

Pearce, D., \& Turner, R. K. (1990). Economics of natural resources and the environment. London: Harvester Wheatsheaf Press. 
Petrosillo, I., Costanza, R., Aretano, R., Zaccarelli, N., \& Zurlini, G. (2013). The use of subjective indicators to assess how natural and social capital support residents' quality of life in a small volcanic island. Ecological Indicators, 24, 609-620.

Piga, C. A. (2003). Pigouvian taxation in tourism. Environmental and Resource Economics, 26(3), 343-359.

Pigou, A. C. (1920). The economics of welfare. London: McMillan.

Pirotta, E., \& Lusseau, D. (2015). Managing the wildlife tourism commons. Ecological Applications, 25(3), 729-741.

Prakash, A., \& Potoski, M. (2012). Voluntary environmental programs: A comparative perspective. Journal of Policy Analysis and Management, 31(1), 123-138.

Prell, C., Hubacek, K., \& Reed, M. (2009). Stakeholder analysis and social network analysis in natural resource management. Society \& Natural Resources, 22(6), 501. doi:10.1080/08941920802199202 .

Ramdas, M., \& Mohamed, B. (2014). Impacts of tourism on environmental attributes, environmental literacy and willingness to pay: A conceptual and theoretical review. Procedia-Social and Behavioral Sciences, 144, 378-391.

Reed, M. S., Graves, A., Dandy, N., Posthumus, H., Hubacek, K., Morris, J., .. Stringer, L. C. (2009). Who's in and why? A typology of stakeholder analysis methods for natural resource management. Journal of Environmental Management, 90(5), 1933-1949. doi:10.1016/j.jenvman.2009.01.001.

Rivera, J. (2002). Assessing a voluntary environmental initiative in the developing world: The Costa Rican certification for sustainable tourism. Policy Sciences, 35(4), 333-360.

Rodríguez, I., Williams, A. M., \& Hall, C. M. (2014). Tourism innovation policy: Implementation and outcomes. Annals of Tourism Research, 49, 76-93.

Rowley, T. J. (1997). Moving beyond dyadic ties: A network theory of stakeholder influences. Academy of Management Review, 22(4), 887-910. 
Ruckelshaus, M., Doney, S. C., Galindo, H. M., Barry, J. P., Chan, F., Duffy, J. E., ... \& Knowlton, N. (2013). Securing ocean benefits for society in the face of climate change. Marine Policy, 40, 154-159.

Saarinen, J. (2006). Traditions of sustainability in tourism studies. Annals of Tourism Research, 33(4), 1121-1140.

Sattler, C., \& Matzdorf, B. (2013). PES in a nutshell: From definitions and origins to PES in practiceApproaches, design process and innovative aspects. Ecosystem Services, 6, 2-11. doi:10.1016/j.ecoser.2013.09.009.

Sautter, E. T., \& Leisen, B. (1999). Managing stakeholders a tourism planning model. Annals of Tourism Research, 26(2), 312-328.

Schmidtz, D. (2003). Tragedy of the commons. The International Encyclopedia of Ethics.

Shakeela, A., Breakey, N., \& Ruhanen, L. (2012). Tourism education's roles in sustainable tourism development: A case study of SIDS introduction. Journal of Hospitality \& Tourism Education, 24(1), 35-43. doi:10.1080/10963758.2012.10696660.

Shareef, R., \& McAleer, M. (2005). Modelling international tourism demand and volatility in small island tourism economies. International Journal of Tourism Research, 7(6), 313-333.

Sharpley, R., \& Ussi, M. (2014). Tourism and governance in small island developing states (SIDS): The case of Zanzibar. International Journal of Tourism Research, 16(1), 87-96.

Sher, K. L., Bagul, A. H. B. P., \& Din, S. A. M. (2015). The influence of community attachment and community involvement towards resident's support on sustainable tourism development by mediating perceived benefits and perceived costs. American-Eurasian Journal of Agriculture and Environmental Science, 15, 133-138. doi: 10.5829/idosi.aejaes.2015.15.s.21.

Segerson, K., \& Miceli, T. J. (1998). Voluntary environmental agreements: Good or bad news for environmental protection?. Journal of Environmental Economics and Management, 36(2), 109130.

Sims, K. R. (2010). Conservation and development: Evidence from Thai protected areas. Journal of Environmental Economics and Management, 60(2), 94-114.

Smith, A. (1759). The theory of moral sentiments. Oxford: Clarendon Press. 
Spenceley, A. (2010). Tourism product development: Interventions and best practices in sub-Saharan Africa: Part 1: Synthesis. Report to the World Bank. Washington, DC: World Bank.

Sterner, T. (2003). Policy instruments for environmental and natural resource management. Resources for the Future.

Sustainable Prosperity. (2015). Environmental taxes in Canada. Retrieved March $24^{\text {th }}, 2016$, from http://institute.smartprosperity.ca/sites/default/files/publications/files/SP_IS-Enviro-Tax-InCanada_FINAL.pdf.

The Fijian Government. (n.d). Who's who. Retrieved April 6 ${ }^{\text {th }}, 2017$, from http://www.fiji.gov.fj/Government-Directory/Government-Who-s-Who.aspx.

Thur, S. M. (2010). User fees as sustainable financing mechanisms for marine protected areas: An application to the Bonaire National Marine Park. Marine Policy, 34(1), 63-69.

United Nations Environment Program. (2003). Making tourism more sustainable: A guide for policy makers. Retrieved May $1^{\text {st }}, 2016$, from http://www.unep.fr/shared/publications /pdf/DTIx0592xPA-TourismPolicyEN.pdf.

United Nations Environmental Scientific Cultural Organization. (2017). Small island developing states. Retrieved April 1 ${ }^{\text {st }}, 2017$, from http://www.unesco.org/new/en/natural-sciences/priorityareas/sids/.

United Nations World Tourism Organization. (2015). Making tourism more sustainable - A guide for policy makers. Retrieved April $1^{\text {st }}$, 2016, from: http://sdt.unwto.org/content/about-us-5.

Uyarra, M. C., Gill, J. A., \& Côté, I. M. (2010). Charging for nature: Marine park fees and management from a user perspective. AMBIO, 39(7), 515-523. doi:10.1007/s13280-010-0078-4.

Van Sickle, K., \& Eagles, P. F. (1998). Budgets, pricing policies and user fees in Canadian parks' tourism. Tourism Management, 19(3), 225-235. doi:10.1016/S0261-5177(98)00017-X.

Vehkamaki, S. (2005). Sustainable use of renewable natural resources - From principles to practices. University of Helsinki Department of Forest Ecology Publications, 34.

Wagner Mainardes, E., Alves, H., \& Raposo, M. (2011). Stakeholder theory: issues to resolve. Management Decision, 49(2), 226-252. 
Waligo, V. M., Clarke, J., \& Hawkins, R. (2013). Implementing sustainable tourism: A multi-stakeholder involvement management framework. Tourism Management, 36, 342-353.

Walker, P. A. (2009). From 'tragedy' to commons: How Hardin's mistake might save the world. Journal of Natural Resources Policy Research, 1(3), 283-286. doi:10.1080/19390450903040520.

Wang, D., \& Ap, J. (2013). Factors affecting tourism policy implementation: A conceptual framework and a case study in China. Tourism Management, 36, 221-233. doi:10.1016/j.tourman.2012.11.021

Wang, P. W., \& Jia, J. B. (2012). Tourists' willingness to pay for biodiversity conservation and environment protection, Dalai Lake protected area: Implications for entrance fee and sustainable management. Ocean and Coastal Management, 62, 24-33.

Wells, E. C., Zarger, R. K., Whiteford, L. M., Mihelcic, J. R., Koenig, E. S., \& Cairns, M. R. (2016). The impacts of tourism development on perceptions and practices of sustainable wastewater management on the Placencia Peninsula, Belize. Journal of Cleaner Production, 111, 430-441.

Williams, T., \& Calvert, J. (1860). Fiji and the Fijians. D. Appleton.

Wilkinson, C., \& Salvat, B. (2012). Coastal resource degradation in the tropics: Does the tragedy of the commons apply for coral reefs, mangrove forests and seagrass beds. Marine Pollution Bulletin, 64(6), 1096-1105.

Winfield, M. (2016). Policy instruments in Canadian environmental policy. Canadian environmental policy and politics: prospects for leadership and innovation, 3, 46-63.

Williston, B. (2012). Environmental Ethics for Canadians. Oxford University Press.

World Atlas. (n.d). Fiji Geography. Retrieved April $7^{\text {th }}, 2017$, from http://www.worldatlas.com/geography/fijigeography.htm.

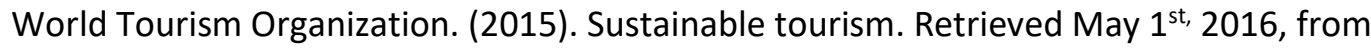
http://sdt.unwto.org/content/about-us-5.

World Tourism Organization. (2016). UNWTO Annual Report 2015. UNWTO, Madrid.

World Wildlife Fund. (2015). South Pacific: Fiji. Retrieved April $7^{\text {th }}, 2017$, from http://www.wwfpacific.org/about/fiji/. 
Yang, J., Ryan, C., \& Zhang, L. (2014). Sustaining culture and seeking a just destination: Governments, power and tension-a life-cycle approach to analysing tourism development in an ethnicinhabited scenic area in Xinjiang, China. Journal of Sustainable Tourism, 22(8), 1151-1174.

Yasamis, F. D. (2011). Economic instruments of environmental management. Proceedings of the International Academy of Ecology and Environmental Sciences, 1(2), 97. doi:http://dx.doi.org/10.0000/issn-2220-8860-piaees-2011-v1-0010. 